\title{
Calibration of Beta-Particle Radiation Instrumentation and Sources
}

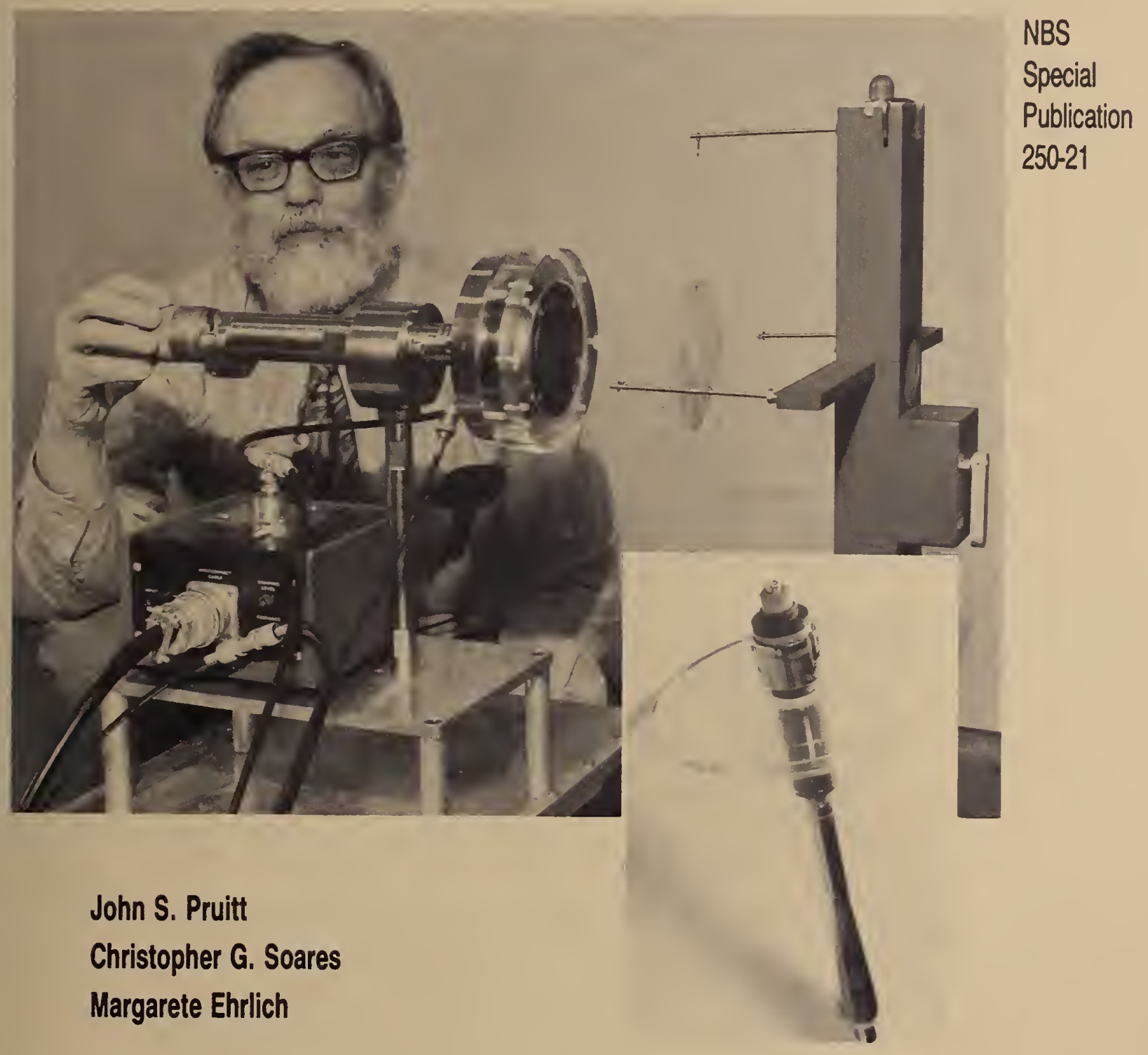

U.S. Department of Commerce

National Bureau of Standards 


\section{NBS MEASUREMENT SERVICES: CALIBRATION OF BETA-PARTICLE RADIATION INSTRUMENTATION AND SOURCES}

John S. Pruitt

Christopher G. Soares

Margarete Ehrlich

Center for Radiation Research

National Measurement Laboratory

National Bureau of Standards

Gaithersburg, MD 20899

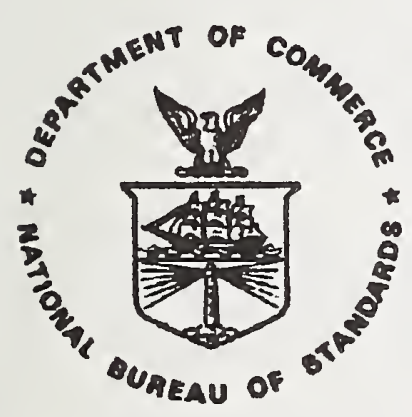

U.S. DEPARTMENT OF COMMERCE, C. William Verity, Secretary NATIONAL BUREAU OF STANDARDS, Ernest Ambler, Director

Issued April 1988 
Library of Congress Catalog Card Number: 88-600514

National Bureau of Standards Special Publication 250-21

Natl. Bur. Stand. (U.S.), Spec. Publ. 250-21, 75 pages (Apr. 1988)

CODEN: XNBSAV

U.S. GOVERNMENT PRINTING OFFICE

WASHINGTON: 1988

For sale by the Superintendent of Documents, U.S. Government Printing Office, Washington, DC 20402-9325 


\section{PREFACE}

The calibration and related measurement services of the National Bureau of Standards are intended to assist the makers and users of precision measuring instruments in achieving the highest possible levels of accuracy, quality, and productivity. NBS offers over 300 different calibration, special test, and measurement assurance services. These services allow customers to directly link their measurement systems to measurement systems and standards maintained by NBS. These services are offered to the public and private organizations alike. They are described in NBS Special Publication (SP) 250, NBS Calibration Services Users Guide.

The Users Guide is being supplemented by a number of special publications (designated as the "SP 250 Series") that provide a detailed description of the important features of specific NBS calibration services. These documents provide a description of the: (1) specifications for the service; (2) design philosophy and theory; (3) NBS measurement system; (4) NBS operational procedures; (5) assessment of measurement uncertainty including $r$ andom and systematic errors and an error budget; and (6) internal quality control procedures used by NBS. These documents will present more detail than can be given in an NBS calibration report, or than is generally allowed in articles in scientific journals. In the past NBS has published such information in a variety of ways. This series will help make this type of information more readily available to the user.

This document (SP 250-21), NBS Measurements Services: Calibration of Beta-Particle Radiation Instrument ation and Sources, by J. S. Pruitt, C. G. Soares, and M. Ehrlich, is the twenty first to be published in this new series of special publications. It describes the NBS calibration facility for beta-particle instruments and sources used in radiation-protection dosimetry for the measurement of absorbed dose to water. Inquiries concerning the technical content of this document or the specifications for these services should be directed to the authors or one of the technical contacts cited in SP 250.

The Center for Radiation Research (CRR) is in the process of publishing 21 documents in this SP 250 series, covering all of the calibration services offered by CRR. A complete listing of these documents can be found inside the back cover.

NBS would welcome suggestions on how publications such as these might be made more useful. Suggestions are also welcome concerning the need for new calibration services, special tests, and measurement assurance programs.

Joe D. Simmons

Acting Chief

Measurement Services
Chris E. Kuyatt

Director

Center for Radiation Research 
In a project funded jointly by the National Bureau of Standards (NBS) and the Nuclear Regulatory Commission (NRC), NBS has developed a calibration facility for beta-particle instruments and sources used in radiationprotection dosimetry. Central to this facility are beta-particle and nearly monoenergetic electron beams characterized in terms of absorbed-dose rates to water and in terms of pulse-height distributions of beta-particle and electron spectra.

This documentation utilizes material previously published or otherwise disseminated by members of the staff of the Ionizing Radiation Division of the Center for Radiation Research (CRR) of the National Bureau of Standards (NBS). After a description of the facility and the procedures, results are given of (1) studies that led to the determination of absorbed-dose rates to water for the NBS beta-particle and nearly monoenergetic electron beams, and to the uncertainties entering into these determinations; (2) studies of the influence of source configuration on beta-particle and nearly monoenergetic electron spectra; and (3) an estimate of the overall uncertainties associated with the proposed calibration service. Included also are the results of some calibrations similar to those that will be performed under the calibration service employing the beta-particle sources, and of samples of studies demonstrating the benefits of using the nearly monoenergetic electron beams in special instrument studies and in a future extension of the calibration service. 


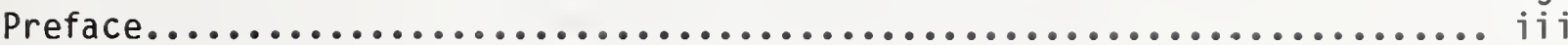

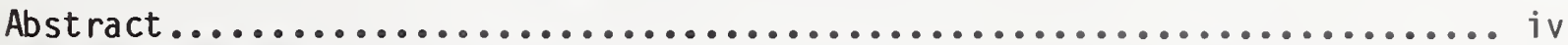

List of Tables............................................ vi

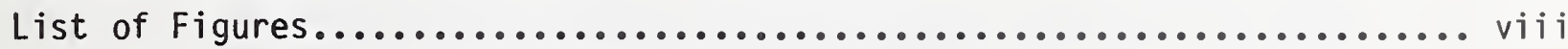

1. History and Description of Service........................... 1

1.1 Quantity for Reporting Calibration Results................... 1

1.2 Sources and Instruments Accepted for Calibration.............. 1

1.3 Procedures for Calibration and Internal Quality Control........ 1

2. The Facility for Beta-Particle Source and Instrument Calibration..... 2

2.1 Rationale for Facility Choice and for Preliminary Studies......? ?

2.2 Facility Design....................................... 2

2.3 The Beta-Particle Sources.............................. 3

2.4 The Extrapolation Ionization Chamber...................... 3

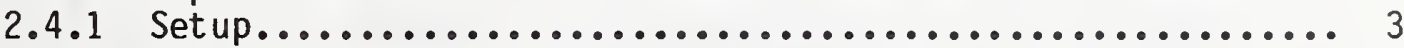

2.4 .2 Chamber Construction............................ 7

2.4 .3 Principle of Use.............................. 7

2.4.3.1 Measurement of Ionization Current as a Function of Electrode-Plate Separation .............. 7

2.4.3.2 Correcting the Measured Ionization Current...... 9

2.4.3.3 Computation of Absorbed-Dose Rate to Water...... 14

2.4.3.4 Comparison of Magnitude of Corrections for

the Three Types of NBS Sources............... 15

2.5 The Parallel-Plate Transfer Ionization Chamber............... 15

2.5.1 Description................................... 15

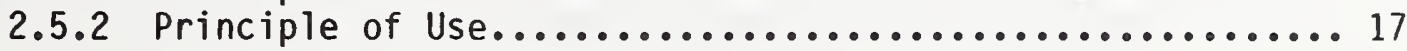

3. The Nearly Monoenergetic Electron Facility...................... 17

3.1 Int roduction........................................ 17

3.2 Facility Design....................................... 17

3.3 The Electron Accelerators.............................. 18

3.3.1 Beam Handling.................................. 18

3.3 .2 Beam-Exit Window............................... 18

3.3.3 Frequent Remote Beam Viewing....................... 18

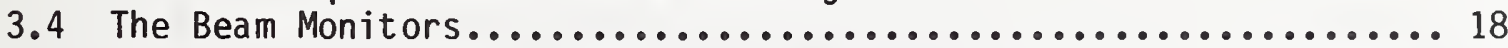

3.5 Use of Extrapolation Chamber to Measure Absorbed Dose to Water.. 20

3.5.1 Requirements of Limitation in Beam Intensity...........20

3.5.2 Dose (Rate) Measurements and Study of Radiation-

Protection Instruments...........................

4. Characterization of NBS Beta-Particle Beams...................... 20

4.1 Determination of Absorbed-Dose Rates to Water; International

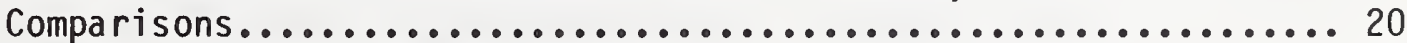

4.2 Influence of Measurement Geometry on Source Calibration......... 21

4.2.1 Dependence of Dose Rate on Off-Axis Shift of Detector.... 22

4.2.2 Dependence of Dose Rate on Precision of Source-to-

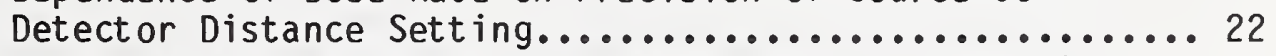

4.3 Spectral Characterization by Means of Measurements as a Function of Depth in Plastic.................................... 


\section{TABLE OF CONTENTS (Cont inued)}

4.4 Spectral Characterization by Means of Pulse-Height Distributionso

4.5 Uncertainty in the Calibration of Beta-Particle Sources and

Transfer Ionization Chambers Submitted to NBS.................. 31

5. Characterization of Nearly Monoenergetic Electron Beams............ 33

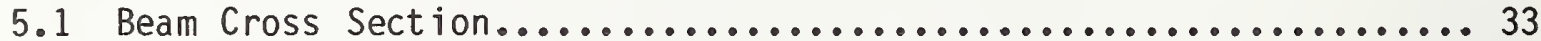

5.2 Determination of Range of Absorbed-Dose Rates to Water Available

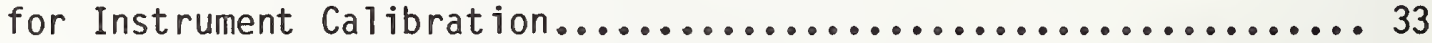

5.3 Determination of Spectral Composition of the Electron Beam...... 37

6. Examples of Practical Studies Performed with the Beta-Particle Beams.. 41

6.1 Compatibility of Different ${ }^{90} \mathrm{~S} r+90 \mathrm{Y}$ Sources with Existing

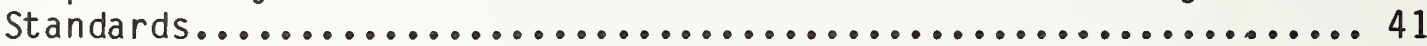

6.2 Comparison of $204 \mathrm{Tl}$ and $90 \mathrm{Sr}+90 \mathrm{Y}$ Source Calibrations at NBS

and at a DOE Laboratory.............................. 47

7. Examples of Studies Performed with the Nearly Monoenergetic Electron

Beams.......................................... 47

7.1 Predicting Beta-Particle Response of Instruments from

Response to Nearly Monoenerget ic Electrons.................. 47

7.2 A Study of Rate Dependence of the Response of Radiation-

Protection Survey Meters.............................. 47

7.3 Role of Nearly Monoenergetic Electron Sources in the Development

of a New Generation of Survey Meters...................... 48

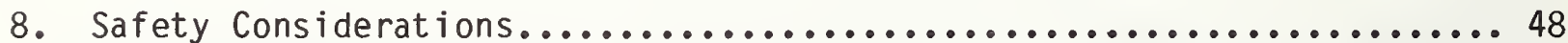

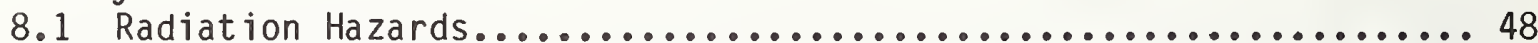

8.2 Electrical Hazards...................................... 49

8.3 The Nearly Monoenerget ic Electron Facility................... 49

9. References............................................. 50

10. Appendices............................................. 52

Appendix 1. Sample of Calibration Report Form................... 52

Appendix 2. Report of a Trip to a DOE Laboratory by J. S. Pruitt..... 54

Appendix 3. Measurement Assurance Study by Means of PTW Transfer

Ionization Chamber, Model 2047..................... 58

Appendix 4. Predicting Beta-Particle Response of Instruments from

their Response to Nearly Monoenergetic Electrons......... 60

Appendix 5. Role of Nearly Monoenergetic Electron Sources in the

Development of a New Generation of Survey Meters........6 63

11. List of Pertinent Tables and Reports on File in the Office of the

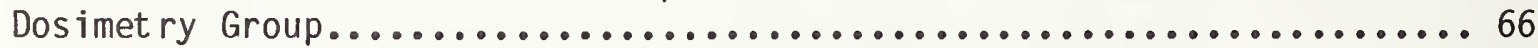

11.1 Pertaining to the Corrections Leading from Ionization Measure-

ments with The Extrapolation Ionization Chamber to Absorbed

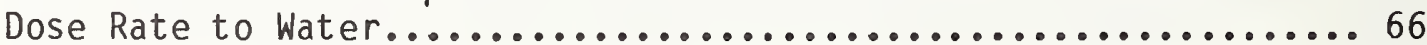

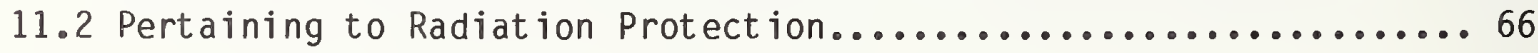


Table 1. Characteristics of Amersham-Buchler Beta-Particle Sources..... 4

Table 2. Typical Examples for Correction Factors to Measured

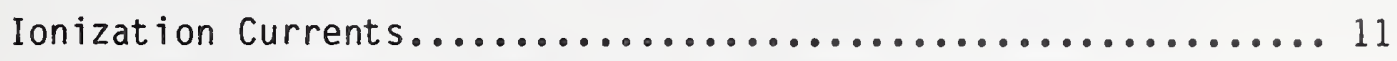

Table 3. Values of Parameters $\alpha$ and $\beta$ for Air Density Correction Factor 14

Table 4. Comparison of Absorbed-Dose Rates to Water, at the Surface, Obtained by NBS and PTB; and Absorbed-Dose Rates to water at Depth of Interest in Radiation Protection for Three of the

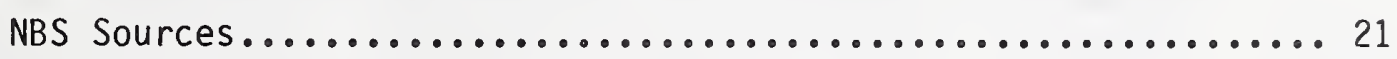

Table 5. Uncertainties in the Determination of Absorbed-Dose Rate to Water from Measurements with the Extrapolation Ionization

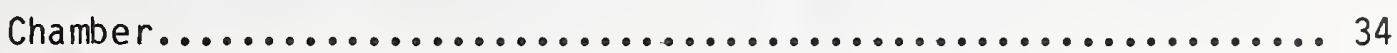

Table 6. Uncertainty in the Calibration of Beta-Particle Sources and Transfer Ionization Chambers Submitted to NBS.............. 35

Table 7. Examples of Pertinent Electron Beam Parameters Obtained Prior to Improvement in the Monitor System........................

Table 8. Comparison of Different Types of ${ }^{90} \mathrm{Sr}+90 \mathrm{Y}$ Sources........... 42 
Figure 1. Theoretical Beta-Particle Spectra for the Radionuclides

Employed......................................... 5

Figure 2. Beta-Particle Calibration Facility...................... 6

Figure 3. Extrapolation Ionization Chamber: Cross Section through the

Front Portion; Schematic Representation.................. 8

Figure 4. Current Measurements in the Extrapolation Ionization Chamber as a Function of Nominal Electrode-Plate Separation........... 10

Figure 5. Design of PTW Parallel-Plate Transfer Ionization Chamber....... 16

Figure 6. Monoenerget ic Electron Beam-Handling Arrangement............. 19

Figure 7. Degree of Non-Uniformity of Dose Rate along a Horizontal line through the Reference Point, Perpendicular to the Beam Axis..... 23

Figure 8. Dependence of Dose Rate on Source-to-Detector Distance........23

Figure 9. Ionization Current as a Function of Depth in PTP.............25

Figure 10. Attenuation Curve in Polystyrene for the $2-m C i \quad 90 S r+90 y$ Source.. 26

Figure 11. top: Spectrum of $14 / \mathrm{Pm}$ Source, Used with Flattening Filter

bottom: Spectrum of $204 \mathrm{Tl}$ Source, Used with Flattening Filter,

Showing Influence of Lead Collimator with Circular

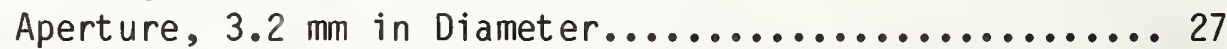

Figure 12. Spectrum of ${ }^{90} \mathrm{~S} r+90 \mathrm{Y}$ Sources, Showing Influence of Flattening

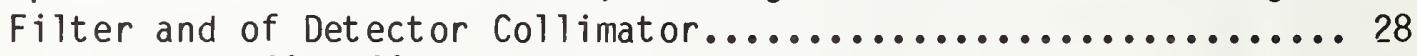

Figure 13. Spectrum of ${ }^{90} \mathrm{Sr}+90 \mathrm{Y}$ Sources Used without Flattening Filter,

Showing Influence of Source-to-Detector Distance............. 29

Figure 14. Energy Calibration Spectrum of $20 / \mathrm{Bi}$ Obtained with the $5-\mathrm{mm}$

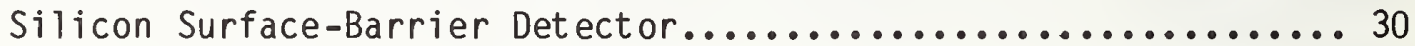

Figure 15. Effect of Added Polystyrene Absorbers on ${ }^{90} \mathrm{~S} r+{ }^{90} \gamma$ Spectrum..... 32

Figure 16. Degree of Uniformity of Cross Section of Scanned Electron

Beam over the Range of Energies and Distances of Interest...... 36

Figure 17. Degradation of Nominal 200-keV, 300-keV, and 400-keV Electrons

in Different Thicknesses of Polyimide Added to the 0.025-mm

Polyimide Exit Window...............................

Figure 18. Degradation of Nominal 1.5-MeV and 2.5-MeV Electrons in

Different Thicknesses of Aluminum Added to the 0.09-mm

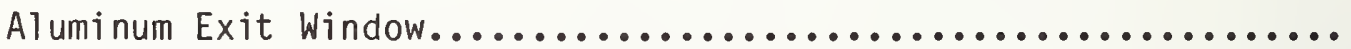

Figure 19. Degradation in Air of Nominal 200-keV to 2.5-MeV Electrons in

Different Thicknesses of Intervening Air Layers............. 40

Figure 20. Ionization-versus-Depth Curves for Three Different Types of

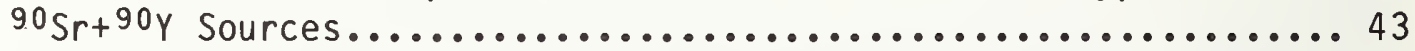

Figure 21. Comparison of Spectrum of the Buchler-Amersham and the NVLAP

Testing Laboratory's ${ }^{90} \mathrm{Sr}+90 \mathrm{Y}$ Sources, on Semi-Logarithmic

Scale...........................................

Figure 22. Comparison of Spectrum of the Amersham Experimental and the

NVLAP Testing Laboratory's $90 \mathrm{~S} r+90 \mathrm{Y}$ Sources, on Semi-

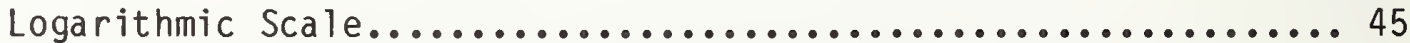

Figure 23. Comparison of Spectrum of Amersham Experiilental ${ }^{90 S r+90 Y}$

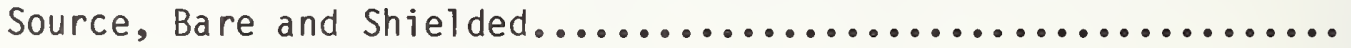




\section{History and Description of Service}

Between 1982 and 1985, the National Bureau of Standards (NBS), with partial support from the U.S. Nuclear Regulatory Commission, developed a facility suited to establish a service for calibrating certain user-owned encapsulated beta-particle sources and certain laboratory-standard transfer instruments for application in radiation protection. This work was undertaken in response to the need of the radiation-protection community for better calibrations of beta-particle survey instruments and dosimeters.

\subsection{Quantity for Reporting Calibration Results}

The physical quantity of interest in radiation protection is the absorbed dose (rate) 1 to tissue, from which the effective dose equivalent (rate) and the pertinent practical dose-equivalent (rate) quantity (or quantities) may be derived. For the application in radiation protection, absorbed dose (rate) to tissue may be set equal to absorbed dose (rate) to water. Therefore, sourcecalibration results will be reported by NBS in terms of absorbed-dose rate to water at a fixed source-to-detector distance, and instrument-calibration results will be reported as calibration factors, the quotients of absorbed dose (rate) to water and the corresponding instrument reading ("scale indication").

\subsection{Sources and Instruments Accepted for Calibration}

The following beta-particle sources and instruments are accepted:

(1) Encapsulated sources of $90 \mathrm{Sr}+90 \mathrm{Y}, 204 \mathrm{Tl}$, and $147 \mathrm{Pm}$, with activities leading to absorbed-dose rates to water ranging from a few tenths of one $\mu \mathrm{Gy} / \mathrm{s}$ to a few $\mathrm{mGy} / \mathrm{s}$, for calibration in terms of absorbed-dose rate to water, using the NBS extrapolation ionization chamber; and

(2) thin-window parallel-plate ionization chambers suited for use as transfer instruments for the calibration of beta-particle sources in terms of absorbed-dose rate to water. (See also sec. 2.5.)

Acceptance testing, handling, packing, and shipping of all materials and reporting of results are in accordance with NBS policy. For details of the NBS calibration service for beta-particle instrumentation and sources, see Chapter VI, Ionizing Radiation Measurements, test numbers 47035C - 47036C, of NBS Special Publication 250, The NBS Calibration Service Users Guide 1989-1991, which is in preparation at the time of writing (February 1988).

\subsection{Procedures for Calibration and Internal Quality Control}

Calibrations are performed at fixed source-to-detector distances. If a beam-flattening filter is to be used with the submitted source (see sec. 2.3), it is to be supplied with the source. The calibration uncertainty for

1 Throughout this Document, when a statement is made that can refer either to a particular radiation quantity or to its rate, the name of the quantity is followed by the word "rate," in parentheses. 
$90 \mathrm{Sr}+90 \mathrm{Y}$ and $204 \mathrm{Tl}$ sources is reported as 3 percent, that for $149 \mathrm{Pm}$ sources as 5 percent, and that for thin-window parallel-plate ionization chambers as 3 percent when calibrated with the ${ }^{90} \mathrm{Sr}+90 \mathrm{Y}$ and $204 \mathrm{Tl}$ sources and 5 percent when calibrated with the ${ }^{147} \mathrm{Pm}$ source (see sec.4.5). Consistency of calibration results is ensured through internal quality-control procedures comprising (a) the calibration in terms of absorbed-dose rate to water of an NBS beta-particle source of known activity along with the submitted unknown source incorporating the same radionuclide, or (b) the calibration of the NBS thin-window parallel-plate ionization chamber along with the chamber submitted, for calibration in at least one of the calibration beams. Calibration data on the submitted source or instrument are considered acceptable if the data obtained on the same day for the NBS source or instrument agree to within the statistical uncertainty (type A uncertainty) stated in table 5 of section 4.5. A sample report form is shown in appendix 1.

\section{The Facility for Beta-Particle Source and Instrument Calibration}

\subsection{Rationale for Facility Choice and for Preliminary Studies}

One of the reasons why protection measurements for beta particles are considerably more difficult than for photons is the beta particles' vastly greater interaction in the media intervening between the source and the point of measurement (the "reference point"), and the resulting greater change in beta-particle spectrum with a change in the measurement configuration - and consequently in most instances also in detector-response characteristics. As a consequence, calibrations of radiation-measurement instruments in betaparticle beams can be considered strictly valid only for the particular configuration in which they were performed, and are applicable to field measurements in similar configurations only. Conversely, knowledge of the degree to which changes in measurement configuration may produce changes in beam characteristics and therefore in calibration results is of considerable importance. Therefore, prior to establishing a calibration service, the influence on spectral characteristics of beam-flattening filters and other absorbing materials in the beta-particle beams, and the influence of changes in source-to-detector distance, had to be investigated. Changes in absorbeddose rates with elevation above sea level were given special attention.

Because of the strong influence of spectral characteristics on instrument response, NBS also did preliminary measurements of the response functions of several measuring instruments in nearly monoenergetic electron beams over a wide range of energies. The purpose of these measurements was to determine how well the response in any beta-particle field may be deduced from an instrument's response function obtained with monoenergetic electrons if the beta-particle spectrum is known at the reference point.

\subsection{Facility Design}

The NBS facility for carrying out beta-particle measurements for radiation-protection purposes consists of:

(1) a set of wel1-characterized beta-particle sources covering a wide energy range; 
(2) an extrapolation ionization chamber suited for the determination of absorbed-dose rates to water at distances from the beta-particle sources appropriate for the study of radiation-protection instruments;

(3) a rugged (although thin-walled) parallel-plate ionization chamber calibrated in the beta-particle beams, and suited for use as a transfer instrument, i.e., for establishing traceability to NBS of the results of beta-particle measurements performed by a secondarystandards laboratory; and

(4) an electrical interlock system causing the source sinutter to close automatically when the safety perimeter (established by infrared beams) is penetrated.

The rest of section 2 deals with a more detailed description of these systems, and with their use.

\subsection{The Beta-Particle Sources}

NBS purchased the complete Amersham-Buchler beta-particle calibration setup, initially standardized by the Physikalisch-Technische Bundesanstalt (PTB). The setup consists of four encapsulated beta-particle sources, a source holder on a stand equipped with a shutter, separate beam-flattening filters for each type of source, and associated electrical circuitry for shutter operation and timing. The beam-flattening filters are plastic discs, thicker in the center than on the periphery for ${ }^{90} \mathrm{Sr}+90 \mathrm{Y}$ and $204 \mathrm{Tl}$, and with a central circular opening for $147 \mathrm{Pm}$. When installed perpendicular to the beams and concentric with the beam axis at a pre-set distance from the sources, they filter the beams selectively so as to achieve beam cross sections of relatively constant absorbed-dose rates over an area sufficient for instrument calibration. (See also sec. 2.4.1 and 4.2.1.) Information on the properties of the beta-emitting radionuclides employed and on source structure and nominal activity is given in table 1. Figure 1 shows the approximate theoretical beta-particle spectra of the three radionuclides $[1,2]^{2}$, covering a range of average energies from 0.06 to $0.8 \mathrm{MeV}$.

\subsection{The Extrapolation Ionization Chamber}

\subsubsection{Setup}

Figure 2 is a picture of the arrangement for producing the beta-particle fields and for determining absorbed-dose rates to water in these fields by means of measurements with an extrapolation-ionization chamber. The betaparticle sources fit into the shuttered source holder. Different beamflattening filters are employed with the different radionuclide sources. The extrapolation ionization chamber on the left was designed by the PTB and built for NBS by Pychlau Technical Works (PTW). The body of the chamber is made of polymethyl methacrylate (PMMA). Its diameter is $140 \mathrm{~mm}$ - which makes it large

2 Numbers in brackets indicate the literature references at the end of this Document . 
Table 1. Characteristics of Amersham-Buchler Beta-Particle Sources

(a) Source Structure and Activity

\begin{tabular}{|c|c|c|c|c|}
\hline Radionuclide & Half Life & Structure & $\begin{array}{c}\text { Source } \\
\text { Encapsulation }\end{array}$ & $\begin{array}{l}\text { Nominal Activity } \\
\mathrm{MBq}(\mathrm{mC} i) \text {; date }\end{array}$ \\
\hline${ }^{90} S r+90 \gamma$ & $28.5 y$ & $\begin{array}{l}{ }^{90} \mathrm{Sr} \text { carbonate } \\
\text { pressed into } \\
\text { Ag foil }\end{array}$ & $\begin{array}{l}50 \mathrm{mg} / \mathrm{cm}^{2} \mathrm{Ag} \\
+0.1 \mathrm{~mm}\left(77 \mathrm{mg} / \mathrm{cm}^{2}\right) \\
\text { steel }\end{array}$ & $\begin{array}{l}1850(50) ; \\
\quad \text { May 24, } 1982\end{array}$ \\
\hline $90 S r+90 Y$ & $28.5 y$ & $\begin{array}{l}{ }^{90} \mathrm{Sr} \text { carbonate } \\
\text { pressed into } \\
\text { Ag foil }\end{array}$ & $\begin{array}{l}50 \mathrm{mg} / \mathrm{cm}^{2} \mathrm{Ag} \\
+0.1 \mathrm{~mm}\left(77 \mathrm{mg} / \mathrm{cm}^{2}\right) \\
\text { steel }\end{array}$ & $\begin{array}{l}74(2) ; \\
\quad \text { Dec 16, } 1982\end{array}$ \\
\hline $204 \mathrm{TI}$ & $3.78 y$ & $\begin{array}{l}204 \mathrm{Tl} \text { pressed }^{\mathrm{b}} \\
\text { into } \mathrm{Ag} \mathrm{foil}\end{array}$ & $20 \mathrm{mg} / \mathrm{cm}^{2} \mathrm{Ag}$ & $\begin{array}{l}18.5(0.5) ; \\
\quad \operatorname{Dec} 16,1982\end{array}$ \\
\hline $147 \mathrm{Pm}$ & $2.62 y$ & $\begin{array}{l}147 \mathrm{Pm}_{\text {pressed }}{ }^{\mathrm{b}} \\
\text { into } \mathrm{Ag} \text { foil }\end{array}$ & $5 \mathrm{mg} / \mathrm{cm}^{2} \mathrm{Ag}$ & $\begin{array}{l}518(14) ; \\
\quad \operatorname{Dec} 16,1982\end{array}$ \\
\hline
\end{tabular}

(b) Beta-Particle Energies and Ranges

\begin{tabular}{|c|c|c|c|c|c|}
\hline \multirow[t]{3}{*}{ Radionuclide } & \multirow{3}{*}{$\begin{array}{l}\text { Avg. and Max. } \\
\text { Beta-Particle } \\
\text { Energies }(\mathrm{MeV})^{\mathrm{C}}\end{array}$} & \multicolumn{4}{|c|}{ Range in } \\
\hline & & \multicolumn{2}{|c|}{$a i r^{d}$} & \multicolumn{2}{|c|}{ polystyrene } \\
\hline & & $\mathrm{cm}$ & $\mathrm{mg} / \mathrm{cm}^{2}$ & $\mathrm{~cm}$ & $\mathrm{mg} / \mathrm{cm}^{2}$ \\
\hline${ }^{90} \mathrm{Sr}^{\mathrm{e}}$ & $\begin{array}{l}\bar{E}=0.196 \\
E_{\text {max }}=0.546\end{array}$ & $\begin{array}{r}41 \\
187\end{array}$ & $\begin{array}{r}49 \\
225\end{array}$ & 0.19 & 204 \\
\hline $90 \gamma$ & $\begin{array}{l}\bar{E}=0.935 \\
E_{\max }=2.284\end{array}$ & $\begin{array}{r}375 \\
1037\end{array}$ & $\begin{array}{r}452 \\
1249\end{array}$ & 1.10 & 1167 \\
\hline $204 \mathrm{Tl}$ & $\begin{array}{l}\bar{E}=0.244 \\
E_{\max }=0.763\end{array}$ & $\begin{array}{r}58 \\
291\end{array}$ & $\begin{array}{r}70 \\
351\end{array}$ & 0.30 & 319 \\
\hline${ }^{147} \mathrm{Pm}$ & $\begin{array}{l}\overline{\mathrm{E}}=0.062 \\
E_{\max }=0.225\end{array}$ & $\begin{array}{l}5.9 \\
51\end{array}$ & $\begin{array}{r}7.2 \\
61\end{array}$ & 0.052 & 55 \\
\hline
\end{tabular}

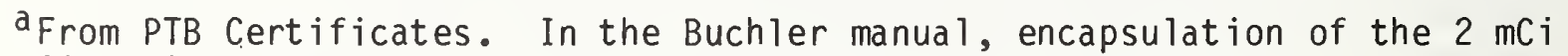
${ }^{90} \mathrm{Sr}+90 \mathrm{Y}$ source is 1 isted as $50 \mathrm{mg} / \mathrm{cm}^{2} \mathrm{Ag}$ plus $1 \mathrm{mg} / \mathrm{cm}^{2} \mathrm{Au}$.

${ }^{b}$ During the rolling stage.

${ }^{\mathrm{C}}$ Average and maximum energies are for the unmodified spectra.

$\mathrm{d}_{\mathrm{Air}}$ at reference conditions $\left(22^{\circ} \mathrm{C}\right.$ and $\left.101.325 \mathrm{kPa}\right)$.

epractically none of the beta particles from ${ }^{90} \mathrm{Sr}$ penetrate the combined filtration of (1) the source encapsulation, (2) the air between source and detector, and (3) the beam-flattening filter. 

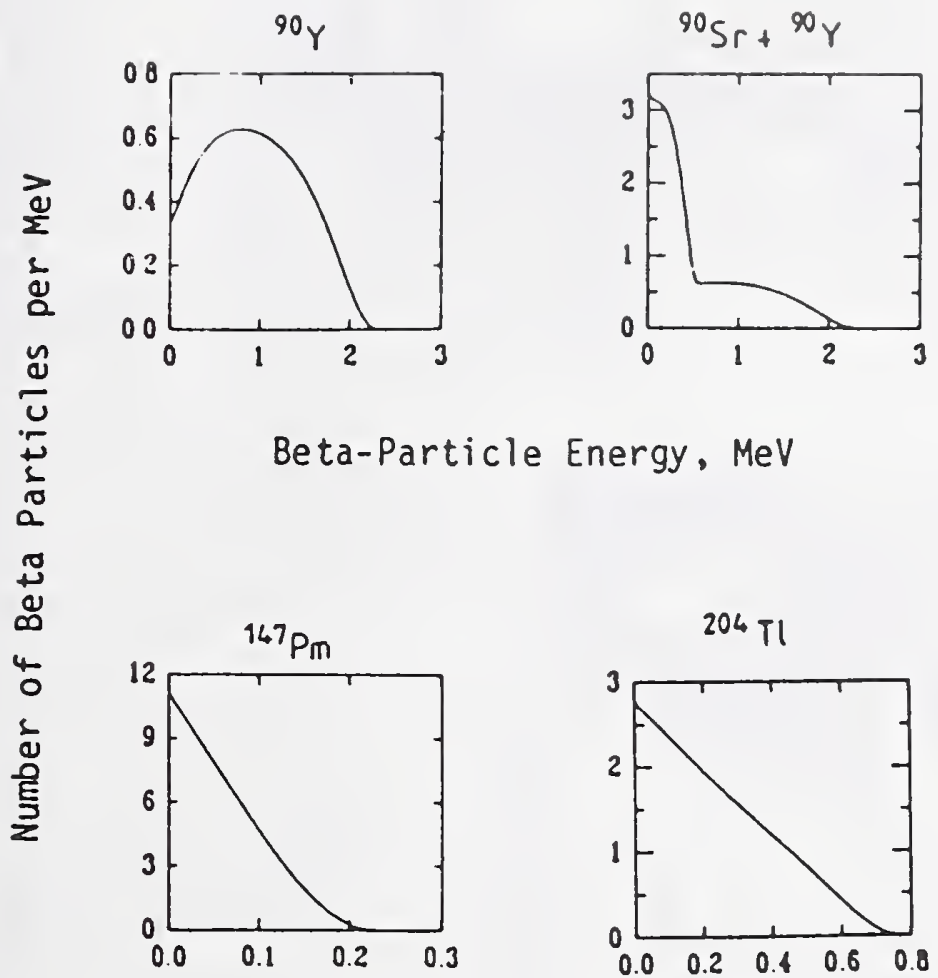

Beta-Particle Energy, MeV

Figure 1. Theoretical Beta-Particle Spectra for the Radionuclides Employed [2]. Plotted is the number of beta particles per MeV for one transition from the original state, against beta-particle energy in MeV. 


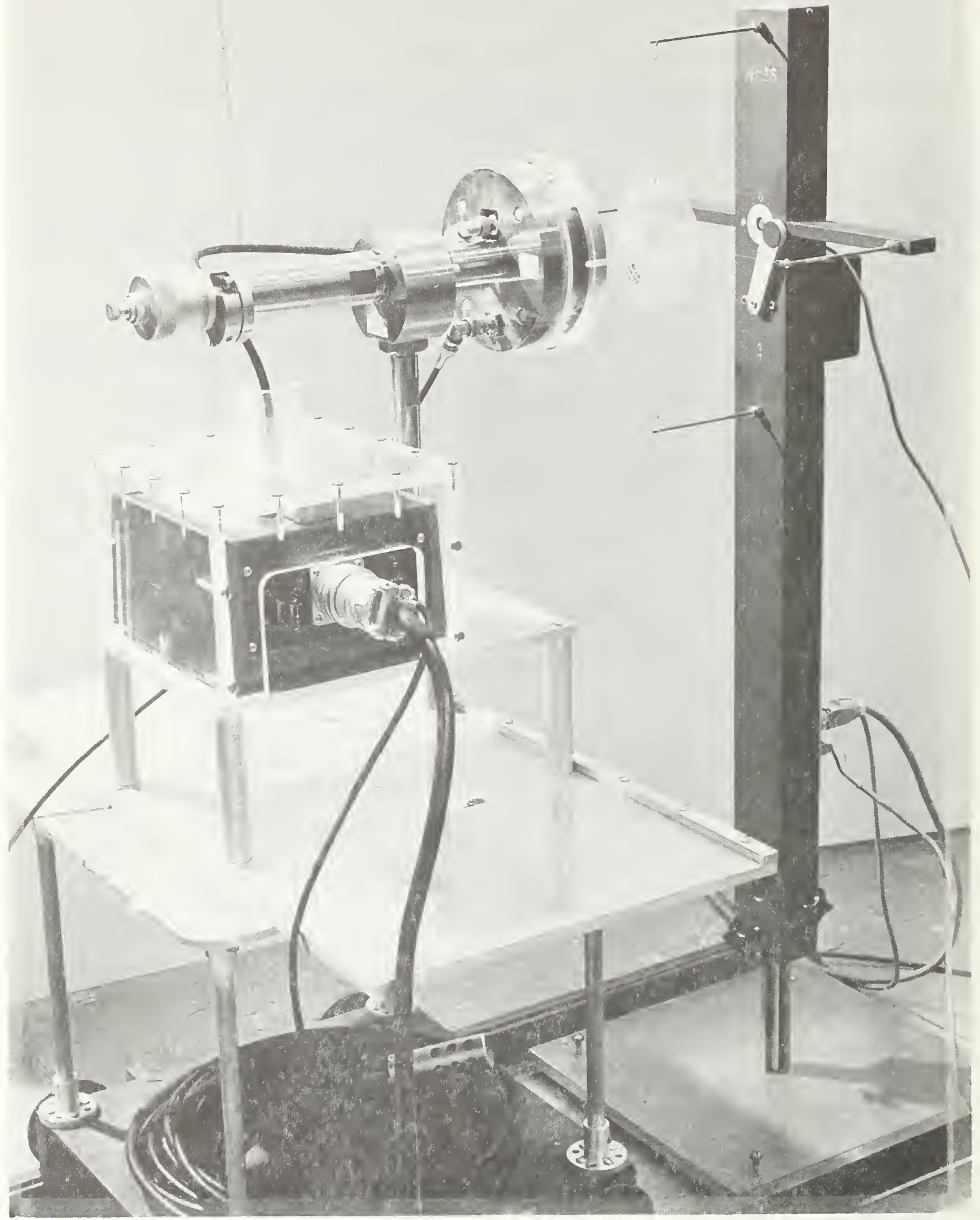

Figure 2. Beta-Particle Calibration Facility. The source-support stand is shown at the right, the extrapolation ionization chamber at the left, and a beam flattening filter supported by wires in-between. The pictured flattening filter is for the $14 / \mathrm{Pm}$ source, and is designed for use at the pictured source-to chamber distance of $20 \mathrm{~cm}$. The source shutter is shown in the open position. The chamber is mounted on a stand that can be moved from side to side across a table, which in turn is mounted on a cart, with wheels running on the tracks shown at the bottom. 
enough to simulate a phantom of infinite size. The plate separation of the ionization chamber is variable and can be accurately determined by means of a micrometer measurement (see screw on end of chamber at left). The thin entrance window for the beta particles is constructed of polyethylene terephthalate (PTP). The source shutter is electrically interlocked, with infrared beams and photocells defining a safety perimeter as long as the shutter is open.

The chamber is mounted on a stand that can be moved from side to side across the table, for investigating beam uniformity in the calibration plane (which is the plane perpendicular to the beam axis at the reference distance). The reference distances (distances from source to reference points) have been chosen to be $20 \mathrm{~cm}$ for $147 \mathrm{Pm}$, and $30 \mathrm{~cm}$ for both $90 \mathrm{Sr}+90 \mathrm{y}$ and $204 \mathrm{Tt}$. Variations in dose rate with reference distance can be studied by moving the chamber cart along the tracks.

\subsubsection{Chamber Construction}

Figure 3 shows a schematic cross-section through the front end of the extrapolation chamber, which was originally designed by Boehm [3]. The highvoltage electrode through which incident beta rays enter the chamber is a $2.6 \mathrm{mg} / \mathrm{cm}^{2}$ graphite-coated PTP foil. The collecting electrode and the guard electrode are both graphite coatings on the acrylic piston. The plate separation, $d$, is changed by moving the piston with the aid of a micrometer screw (not shown).

Ionization-chamber volume is taken to be the product of the area of the collecting electrode, $A=(\pi / 4)$ (effective diameter) ${ }^{2}$, and the plate separation (air gap), $d$, of the collecting electrodes. The effective diameter and consequently the area $A$ can be measured accurately with a traveling microscope. Accurate determination of $d$ is usually more difficult but can be readily accomplished by extrapolation measurements.

\subsubsection{Principle of Use}

The following is a guide to the use of the extrapolation chamber for determining absorbed-dose rate to water at the points of interest in the betaparticle beams. Covered are the steps leading from the initial ionization measurements to the fully corrected absorbed-dose rates, including a detailed discussion of the required corrections. While background references are given only in special cases (e.g., for the recombination and diffusion corrections, for scatter corrections and for the correction for measurements at high altitudes), the various tables and reports giving the relationships used in the derivation of the other corrections and the values of the pertinent constants entering in these relationships are on file in the office of the Dosimetry Group. (See sec. 11.1 for a list of documents.)

\subsubsection{Measurement of Ionization Current as a Function of Electrode-Plate Separation}

The ionization current is obtained from a measurement with an electrometer of the charge accumulated on a calibrated capacitor after irradiation of the extrapolation ionization chamber over a measured period of time. 


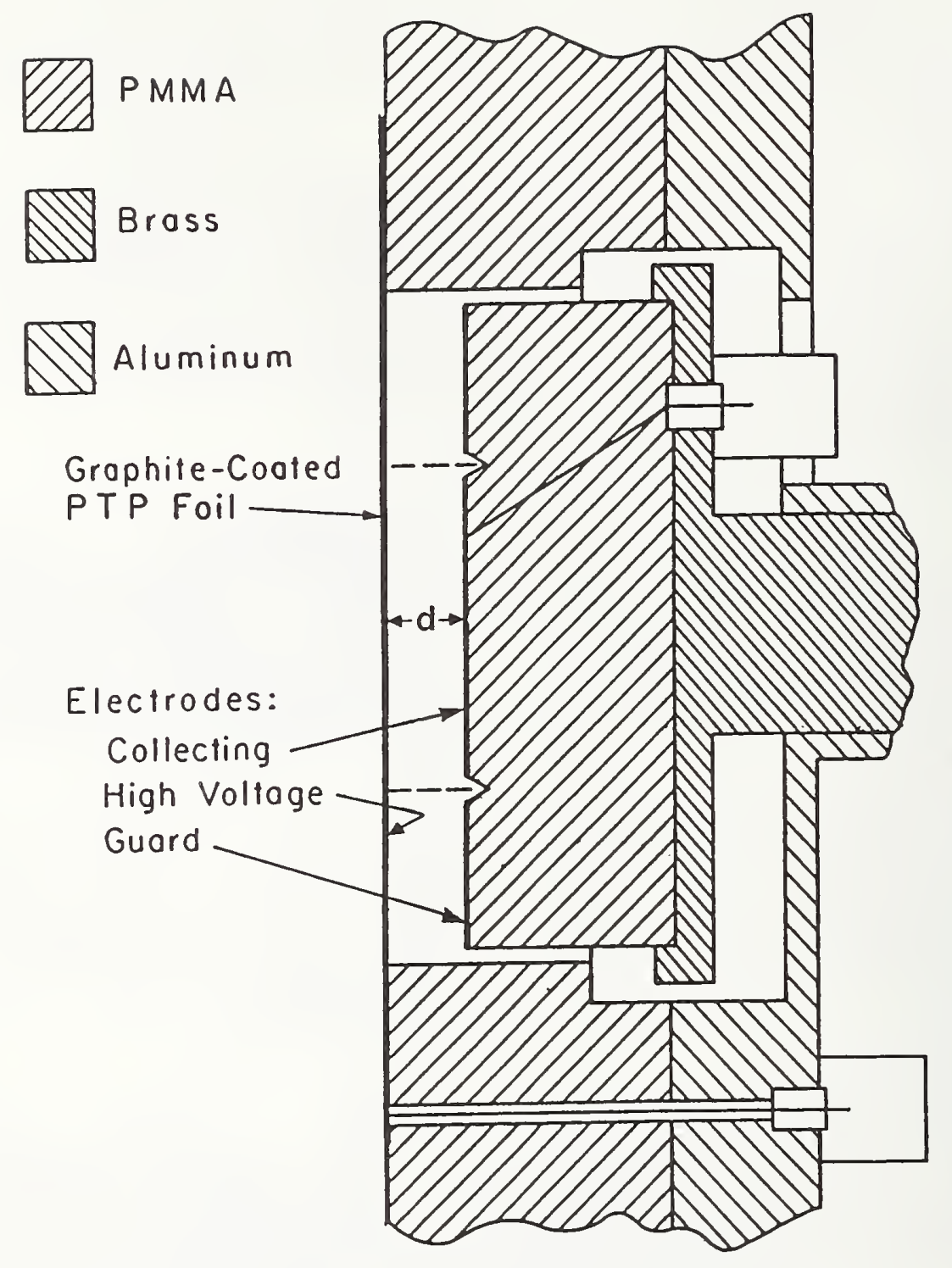

Fig. 3. Extrapolation Ionization Chamber: Cross Section through the Front Portion; Schematic Representation.

The collecting and guard electrodes (graphite coating on PMMA) are separated by a $0.2-\mathrm{mm}$ wide circular groove (shown of exaggerated size). The distance between the midpoints of the two grooves (distance between the indicated dashed lines) defines the effective diameter of the collecting volume. In this particular instrument, the diameter is $30 \mathrm{~mm}$. The entrance window is a $2.6 \mathrm{mg} / \mathrm{cm}^{2}$ PTP foil. For the measurements, the plate separation, d, (also referred to as air gap or chamber depth) is usually varied between about 0.5 and $2.5 \mathrm{~mm}$. During any experiment the voltage gradient across the chamber is kept constant, at a value between 10 and $40 \mathrm{~V} / \mathrm{mm}$. 
Figure 4 shows the results of current measurements as a function of plate separation with the three types of sources, after application of certain corrections. These corrections are introduced in eq. (1) below, and are subsequent ly discussed in detail. The corrected currents vary linearly with plate separation to a good approximation. Linearity is important since the slopes of the curves are used in the computation of absorbed-dose rate, as seen in eq. (2), section 2.4.3.3. The average of the absolute values of the deviations from the lines drawn, as determined from least-squares computations, are $0.03 \mathrm{fA}$ for the $147 \mathrm{Pm}$ points and $0.02 \mathrm{fA}$ for the $204 \mathrm{Tl}$ and $90 \mathrm{Sr}+90 \mathrm{Y}$ points, and are too small to be shown in the figure.

\subsubsection{Correcting the Measured Ionization Current}

The corrected ionization current, $I_{C}$, is given by

$$
I_{C}=I \prod_{i} C_{i} \prod_{j} k_{j},
$$

where I is the measured ionization current, the quantities $c_{j}$ are correction factors relating to the use of the particular type of ionization chamber with a particular beta-particle spectrum, and the correction factors $k_{j}$ relate to environmental conditions and source properties, and are independent of the type of ionization chamber employed. Sample values of the correction factors for the three types of sources are given in table 2. Following is a discussion of these correction factors:

(a) $\mathrm{C}_{\text {foil }}$ is required if the measurement is not carried out with a foil of the desired thickness. For radiation-protection applications, one is interested in absorbed-dose rates behind $7 \mathrm{mg} / \mathrm{cm}^{2}$ of tissue-equivalent material - a thickness considerably larger than that of the entrance window which one obtains by taping additional PTP foil to the front face for the measurements. A foil attenuation correction is required only for comparisons with results of others who extrapolate to zero wall thickness (see, e.g., sec. 4.1). It is large for the relatively low-energy beta-particle spectrum of ${ }^{147} \mathrm{Pm}$ because the calibration distance is close to the range of a large fraction of these beta particles. For $90 \mathrm{Sr}+90 \mathrm{y}$, the correction is much smaller in magnitude and of opposite sign, indicating buildup rather than attenuation. The correction factors were calculated from measurements of current as a function of foil thickness as $c_{f o i l}=I_{0} / I_{x}$, where $I_{0}$ is the ionization current in the absence of a foil (extrapolated) and $I_{x}$ the current at a foil thickness $x$ (including the thickness of the chamber window).

(b) $c_{\text {div }}$, the beam-divergence correction, is made necessary by the relatively short source-detector distance. During extrapolation measurements the entrance foil remains at a fixed distance $D_{0}$ from the source, and the collecting electrode is at a distance $D_{0}+d$ (see fig. 3 ). If it is assumed that the beam intensity obeys the inverse square law over the short distance $D_{0}+d$, it is readily shown that the correction for beam divergence is given by $c_{d i v}=1+d \gamma_{D}$, where $d$ is the plate separation in millimeters and $\gamma_{D}=1 / D_{0}$ $=0.005 / \mathrm{mm}$ for ${ }^{147} \mathrm{Pm}$ and $0.0033 / \mathrm{mm}$ for both $204 \mathrm{Tl}$ and $90 \mathrm{Sr}+90 \mathrm{Y}$ (Data Book $873 / 36)$. 


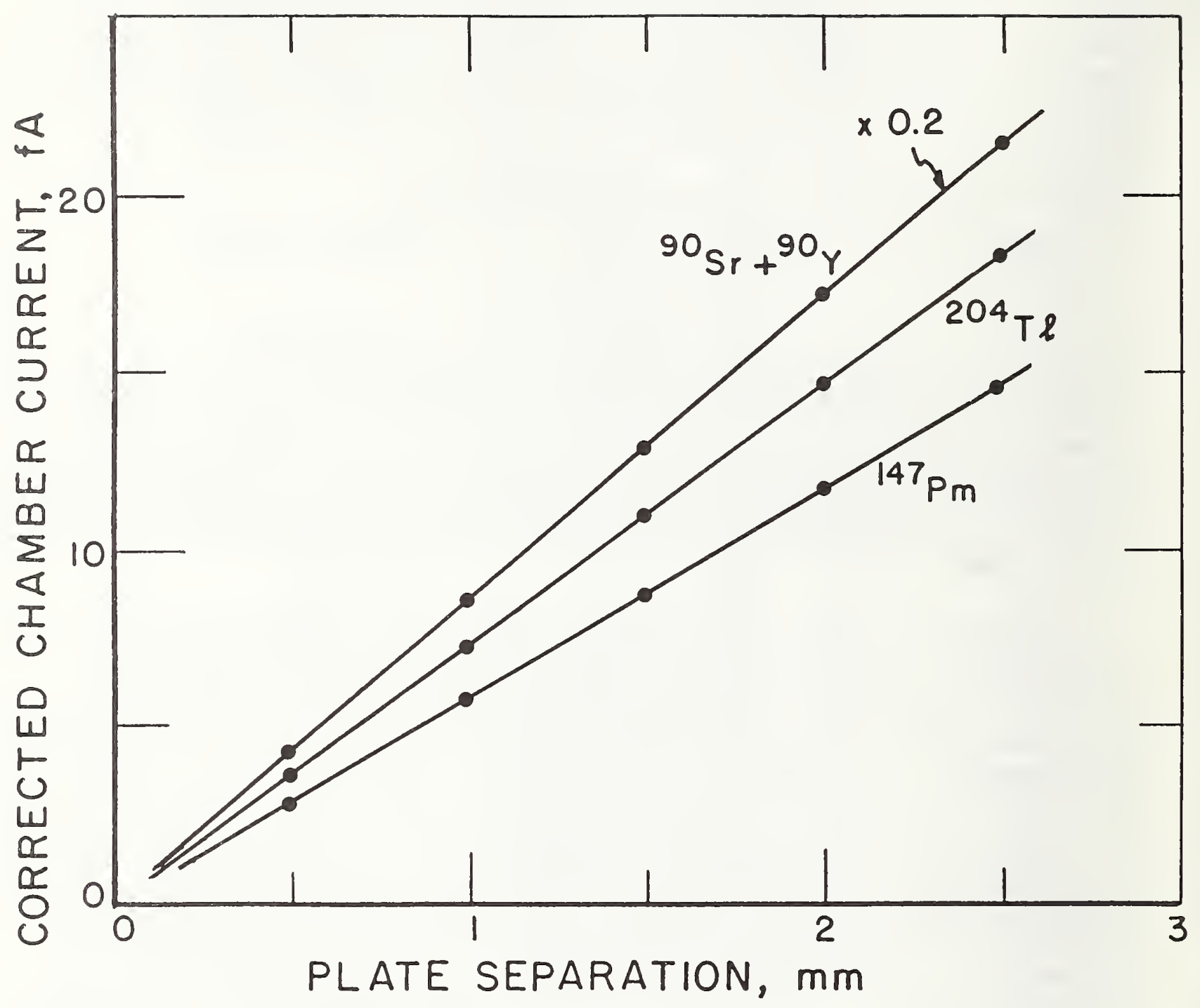

Fig. 4. Current Measurements in the Extrapolation Ionization Chamber as a Function of Nominal Electrode-Plate Separation (Micrometer Reading of Chamber Depth). The curves shown are referred to as extrapolation curves since they may be used to determine ionization currents for close-to-zero chamber depths (air gaps). The extrapolation curves go through the origin only when the micrometer readings coincide with the true chamber depths. If they do not, true chamber depths may be read off the graph after the origin is shifted to the intersection of the curves with the "plate separation" axis. 
Table 2. Typical Examples for Correction Factors to Measured Ionization Currents (from Data Books 863 and 868)

\begin{tabular}{l|l|l|l|l|l}
\hline Symbol & Correction to Reference Conditions & \multicolumn{2}{|c|}{ Value of Correction Factor for } \\
& $247 \mathrm{Pm}$ & $204 \mathrm{Tl}$ & $90 \mathrm{Sr}+90 \mathrm{Y}$ \\
\hline
\end{tabular}

A. Chamber Correction Factors

\begin{tabular}{|c|c|c|c|c|}
\hline${ }^{c_{\text {foil }}}$ & entrance foil attenuation ${ }^{a}$ & 1.76 & 1.000 & 0.982 \\
\hline$c_{\text {div }}$ & beam divergence ${ }^{b}$ & 1.013 & 1.008 & 1.008 \\
\hline catten & chamber air attenuation ${ }^{b}$ & 1.023 & 1.000 & 1.000 \\
\hline & density of air in chamber volume & 1.014 & 1.013 & 1.007 \\
\hline$c_{\text {back }}$ & chamber back scatter & 1.010 & 1.009 & 1.006 \\
\hline side & chamber side scatter ${ }^{b}$ & 1.005 & 1.002 & 0.992 \\
\hline recom & ion recombination and diffusion $b, c$ & 1.001 & 1.001 & 1.001 \\
\hline$c_{\text {phot }}$ & phot on contribution ${ }^{a}$ & 0.989 & 1.000 & 0.999 \\
\hline
\end{tabular}

B. Environmental Correction Factors

\begin{tabular}{l|l|l|l|l}
\hline$k_{\text {dec }}$ & source decay & 1.213 & 1.145 & 1.059 \\
$k_{\text {mass }}$ & $\begin{array}{l}\text { altitude variations } \\
\text { close to sea level } \\
\text { at } \sim 1500 \mathrm{~m} \text { above sea level }\end{array}$ & 0.941 & 0.998 & 1.001 \\
$k_{\text {hum }}$ & humidity changes & 1.05 & 1.002 & 0.984 \\
\hline
\end{tabular}

${ }^{a_{F}}$ actor to correct from a depth of $2.6 \mathrm{mg} / \mathrm{cm}^{2}$ of PTP, the chamber foil thickness, to zero depth.

${ }^{b}$ Corrections computed for plate separations of $2.5 \mathrm{~mm}$.

${ }^{\mathrm{C}}$ Corrections computed for applied potentials of $100 \mathrm{~V}$.

${ }^{d}$ Correction factor required when a source that had been calibrated at sea level is to be used at the indicated high altitude. 
(c) catten, the correction for attenuation in the chamber air gap, was determined by measuring chamber current as a function of distance $y$ between source and chamber using a fixed air gap $d=0.5 \mathrm{~mm}$. It was found that, after multiplying the current I by the square of the distance $y$, in order to compensate for beam divergence, the product $\mathrm{Iy}^{2}$ could be represented as a linear function of the distance $y$. It is then readily shown that the correction for air attenuation in the chamber is given by $c_{\text {atten }}=1+d \gamma_{A}$, where $d$ is in millimeters and $\gamma_{A}$ is $0.009 / \mathrm{mm}$ for $147 \mathrm{Pm}$, and zero for $204 \mathrm{Tl}$ and $90 \mathrm{Sr}+90 \mathrm{Y}$ (Data Book 873/36).

(d) $c_{t, p}$, the correction for air density changes inside the chamber, arises because of temperature and pressure variations of the ambient air, since the chamber is of a type that is open to the atmosphere. It corrects to the reference temperature and pressure using the ideal-gas law. The correction factor is given by $\rho / \rho_{0} \equiv c_{t, p}=[101.325(t+273.15)] / 295.15 p$, where $\rho / \rho_{0}$ is the ratio of the air density during the measurement of the ionization current to the density of dry air at the reference temperature and pressure. $t$ is the temperature in degrees Celsius, and the pressure $p$ is in kilopascals. ${ }^{3}$

(e) $c_{\text {back }}$, the backscatter correction, takes into account the difference between backscatter from water and backscatter from PMMA, the collecting electrode material. The correction factor can be evaluated from published backscatter probabilities [4] as $c_{b a c k}=1+\gamma_{B}$, where $\gamma_{B}$ is 0.010 for $147 \mathrm{Pm}$, 0.009 for $204 \mathrm{Tl}$, and 0.006 for ${ }^{90} \mathrm{Sr}+90 \mathrm{Y}$.

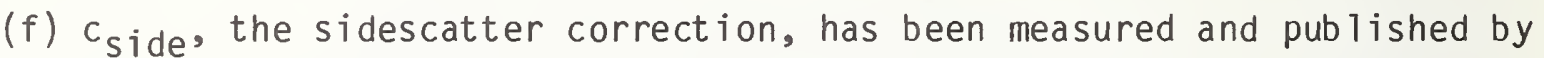
the PTB for this particular type of chamber, using the reference distances specified by the source manufacturer. [5] The correction is small (necessary onty when an accuracy of better than 1 percent is required). Therefore, it was decided to use the published value for the correction factor, given by $c_{\text {side }}=1+d \gamma_{S}$, where $\gamma_{S}$ is tabulated below for the three types of sources and for selected plate separations, d:

\begin{tabular}{l|c|c} 
Source & $d(\mathrm{~mm})$ & $\gamma_{S}\left(\mathrm{~mm}^{-1}\right)$ \\
\hline $147 \mathrm{Pm}$ & $0.5-2.5$ & 0.0019 \\
$204 \mathrm{T1}$ & 0.5 & -0.0016 \\
& 1.0 & -0.0016 \\
& 1.5 & -0.0012 \\
& 2.0 & -0.0003 \\
${ }^{90}{ }^{2} \mathrm{~S}+{ }^{90} \mathrm{\gamma}$ & $0.5-2.5$ & +0.0006 \\
& & -0.0032
\end{tabular}

${ }^{3} 101.325 \mathrm{kPa}=1013.25 \mathrm{mbar}=760 \mathrm{mmHg}=$ one standard atmosphere. 
(g) Crecom, the correction for ion recombination and diffusion in the air inside the chamber, is usually quite small for protection-level measurements. It only becomes appreciable for large ion currents and/or small voltages. It was calculated by means of published relationships [6] as $c_{\text {recom }}=\left(R_{v} R_{j} R_{d f}\right)^{-1}$ where the volume recombination $R_{v}=1-\left[5.05 \times 10^{13} \mathrm{Id}^{3} /\left(\mathrm{AV}^{2}\right)\right]$, the initial recombination $R_{j}=1-[4.4 \mathrm{~d} / \mathrm{V}]$, and the diffusion $R_{d f}=1-\left[\left(17.24 \times 10^{-5}\right)\right.$ $(t+273.15) / V]$. In these expressions, $I$ is the current in amperes, $d$ the plate separation in meters, A the area of the collecting plates in square meters (or the beam cross section at the reference point, in square meters, if it is smaller than the plate area), $V$ the potential in volts, and $t$ the temperature in degrees Celsius.

(h) cphot, the correction for contributions to the ionization current due to photons from material intervening between the source and the chamber air volume (chamber window plus added filtration, if any, of total thickness $x$ ), may be obtained from an ionization current-versus-depth curve in the particular material as $c_{\text {phot }}=1-I\left(x_{\text {phot }}\right) / I(x)$, where $I\left(x_{\text {phot }}\right)$ is the corrected ionization current measured at a depth $x_{\text {phot }}$ which is equal to or slightly greater than the maximum range of the beta particles, and $I(x)$ is the current measured at the depth $x$ of interest. Values of $x$ phot for which $I\left(x_{\text {phot }}\right)$ were measured in PTP or polystyrene for the three types of sources are shown below (Data Book 873/39):

\begin{tabular}{l|rl} 
Source & $x_{\text {phot }}\left(\mathrm{mg} / \mathrm{cm}^{2}\right)$ \\
\hline${ }^{147} \mathrm{Pm}$ & 46 & (Measured in PTP) \\
$204 \mathrm{Tl}$ & $320 \quad$ (Measured in polystyrene) \\
${ }^{90} \mathrm{Sr}+90 \mathrm{Y}$ & $1370 \quad$ (Measured in polystyrene)
\end{tabular}

(i) $k_{\text {dec }}$, the correction for source decay, depends both on the time interval $\Delta t$ and on the half life of the radionuclide. It is given by $k_{\text {dec }}=\exp (\lambda \Delta t)$, where $\Delta t$ is taken in the sense measurement date minus reference date (in days), and the decay constant $\lambda$ in reciprocal days is given by $7.234 \times 10^{-4}$ for $147 \mathrm{Pm}, 5.022 \times 10^{-4}$ for $204 \mathrm{Tl}$, and $6.659 \times 10^{-5}$ for $90 \mathrm{Sr}+90 \mathrm{Y}$.

(j) $k_{\text {mass }}$ is a correction for a variation in the total mass of air between source and phantom, caused by variations in air temperature and barometric pressure. While the correction is largest at high altitudes (say 1500 to $2000 \mathrm{~m}$ above sea level), it may also be appreciable at sea level under certain weather conditions. The total mass correction was studied in an environmental chamber in which the air pressure could be varied at will. [8] It was found that the effect was largest for ${ }^{147} \mathrm{Pm}$ and much smaller for both ${ }^{204} \mathrm{Tl}$ and ${ }^{90} \mathrm{Sr}+{ }^{90} \mathrm{Y}$. The correction factor is given by $k_{\text {mass }}=\left(1+\alpha h+\beta h^{2}\right)^{-1}$, where $h=1-\left(\rho / \rho_{0}\right), \rho / \rho_{0}$ being equal to $\left(c_{t, p}\right)^{-1}$, the temperature/pressure 
correction factor (see correction (d)), and $\alpha$ and $\beta$ are constants. Table 3 shows empirical values for $\alpha$ and $\beta$ for all three types of sources, with the beams attenuated by selected thicknesses of PTP. These corrections were checked by actual measurements on a ${ }^{147} \mathrm{Pm}$ source at an elevation of $\sim 1500 \mathrm{~m}$ above sea level (see Appendix 2). The absorbed-dose rate measured at this altitude and then corrected to the altitude of the PTB was found to agree to within 3 percent with the dose rate that had been measured for this source at the PTB, which is located near sea level. (See publication [8] for a fuller discussion.)

Table 3. Values of Parameters $\alpha$ and $\beta$ for Air Density Correction Factor

\begin{tabular}{c|c|c|c}
$\begin{array}{c}\text { Source with } \\
\text { flattening fi]ter }\end{array}$ & $\begin{array}{c}\text { Depth in PTP } \\
\left(\mathrm{mg} / \mathrm{cm}^{2}\right)\end{array}$ & $\alpha$ & $\beta$ \\
\hline $14 / \mathrm{Pm}$ & 2.6 & 4.5 & 12.7 \\
& 6.3 & 3.5 & 19.8 \\
& 10.1 & 0.69 & 31.2 \\
$204 \mathrm{Tl}$ & 2.6 & 0.165 & -0.50 \\
& 6.3 & 0.131 & -0.33 \\
& 46.2 & 0.143 & 0.48 \\
& 2.6 & -0.085 & -0.027 \\
& 6.3 & -0.054 & -0.18 \\
& 46.2 & 0.040 & -0.28 \\
\hline
\end{tabular}

(k) k hum, the correction for relative humidity, arises from the fact that the air mass correction is a function of air density and air density depends to a small extent on the relative humidity of the air. The correction is usually quite small and is required only for $147 \mathrm{Pm}$, for which it is given approximately by $k_{\text {hum }}=\left[\exp \left(4.40 \times 10^{-4} \mathrm{H}\right)\right] / 1.020$, where $H$ is the relative humidity, in percent (Buchler Source Manual).

\subsubsection{Computation of Absorbed-Dose Rate to Water}

The absorbed-dose rate to water on the reference date - in grays per second - is calculated from the slope $\Delta I_{C} / \Delta d$ of the extrapolation curve by Bragg-Gray cavity theory [7] as

$$
\dot{D}=(W / e) S_{a i r}^{\text {water }}\left(\Delta I_{c} / \Delta d\right)\left[1 /\left(\rho_{0} A\right)\right] \text {, }
$$


where W/e - energy required to produce an ion pair in air, in joules per coulomb;

$S_{\text {air }}^{\text {water }}$ - ratio, average mass stopping power of water to that of dry air, dimensionless;

$\rho_{0}$ - density of dry air at reference ambient conditions $\left(22^{\circ} \mathrm{C}\right.$ and $101.325 \mathrm{kPa})$, in kilograms per cubic meter;

A - area of collecting electrode, in square meters;

$\Delta I_{C} / \Delta d-$ slope of extrapolation curve, in amperes per meter.

The slope $\Delta I_{c} / \Delta d$ is determined from several independent current measurements carried out on several days. Reproducibility of the results was found to be independent of whether they were obtained from measurements done on any given day or on several days.

\subsubsection{Comparison of Magnitude of Corrections for the Three Types of NBS Sources}

Table 2 shows that the corrections for ${ }^{90} \mathrm{Sr}+90 \mathrm{Y}$ are mostly insignificant. At sea level, only two of them are larger than one percent, and of these, the correction for source decay can be calculated easily and accurately, and that for entrance foil attenuation is usually not required. For ${ }^{24} \mathrm{Pm}$, the situation is worse. Eight of the eleven corrections are greater than or equal to one percent, and of these eight, two are larger than ten percent. By far the largest correction for $147 \mathrm{Pm}$ is the one for entrance-foil attenuation, which however is usually not required. (See sec. 2.4.3.2.) It may be obtained with a high degree of accuracy since the dependence of current on absorber depth seems to be well represented by an exponential function. As could be expected, the magnitude of most of the corrections for $204 \mathrm{Tl}$ were found to be somewhat larger than for ${ }^{90} \mathrm{Sr}+90 \mathrm{Y}$, but considerably smaller than for $147 \mathrm{Pm}$.

\subsection{The Parallei-Plate Transfer Ionization Chamber}

\subsubsection{Description}

This is a rugged parallel-plate ionization chamber manufactured by PTW (PTW model 2047) for use in checking the $x$-ray exposure rate at a radiographic intensifying screen or image intensifier. It has a relatively large fixed volume (about $120 \mathrm{~cm}^{3}$ ) and thin PTP windows (nominal thickness: $0.05 \mathrm{~mm}$ ), making beta-particle measurements from roughly $300 \mu \mathrm{Gy} / \mathrm{h}$ to more than $30 \mathrm{mGy} / \mathrm{h}$ possible. Figure 5 shows a schematic drawing of the chamber. The solid aluminum body of this chamber makes it possible to ship it to other institutions in measurement-assurance studies designed to compare measurements of ionization currents at other institutions with those of NBS, in identical geometries. At the reference distance, the beta-particle beam has a sufficiently large cross section to strike the aluminum body of the chamber. But as long as measurement geometry is the same at NBS and the other institutions, the fact that electron scatter from the solid aluminum body contributes to the current measurements does not interfere with these studies. 

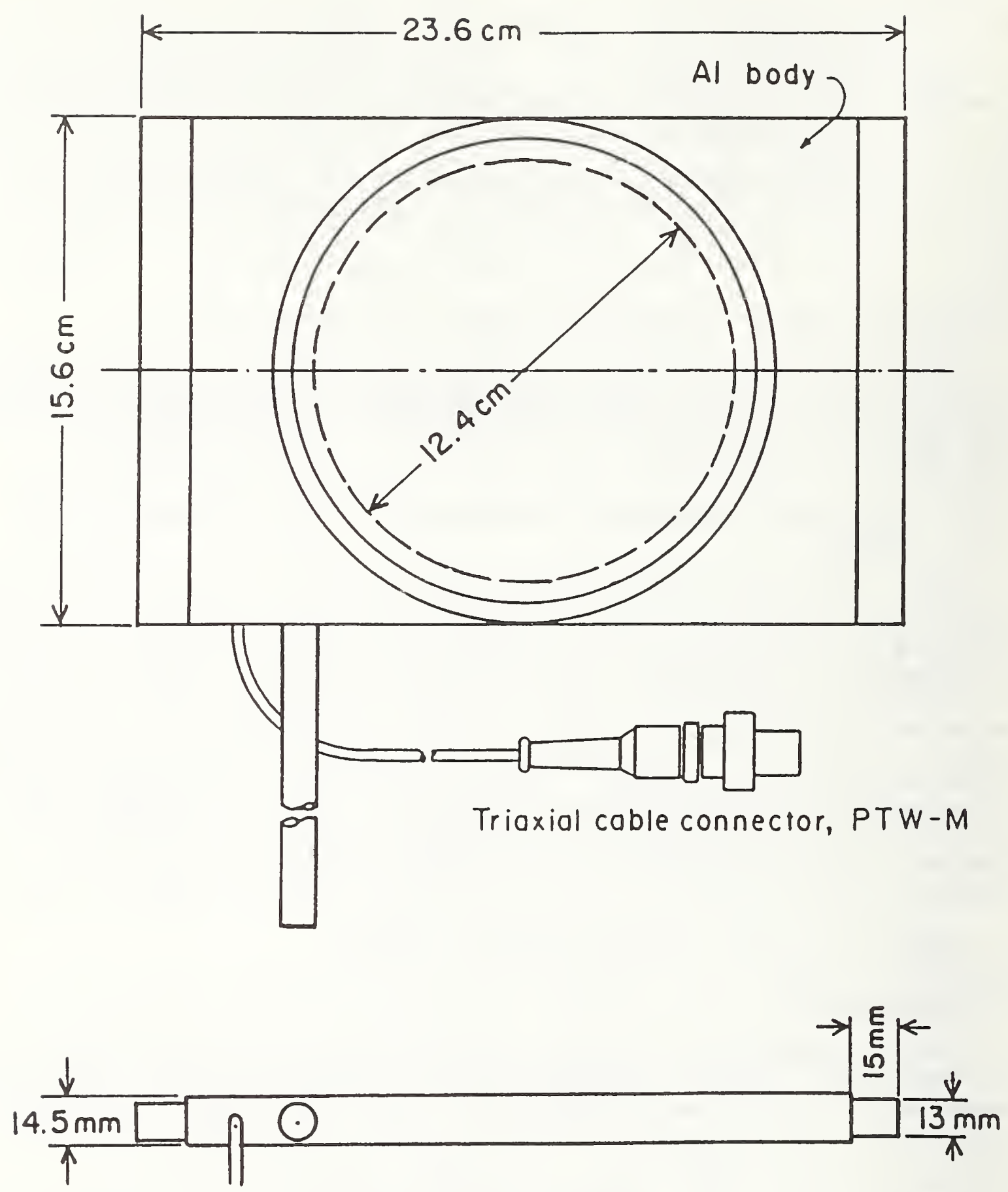

Fig. 5. Design of PTW Parallel-Plate Transfer Ionization Chamber. With a potential of $100 \mathrm{~V}$ across the chamber, absorbed-dose rates to water from roughly 0.3 to over $30 \mathrm{mGy} / \mathrm{h}$ ( 0.5 to over $50 \mathrm{mrad} / \mathrm{min})$ can be measured. During transport, the $0.05-\mathrm{mm}$ front and rear windows are covered with PMMA, about $1 \mathrm{~mm}$ in thickness. The diameter of the internal collecting electrode is $12.4 \mathrm{~cm}$. 


\subsubsection{Principle of Use}

For measurements, the front surface of the chamber is placed in the calibration plane, after removal of the extrapolation chamber. Ionization current is measured with an electrometer. The calibration factor of the transfer chamber is then given by the quotient of absorbed-dose rate determined at the reference point from extrapolation-chamber measurements, and ionization current corrected to reference values of temperature and pressure of the air inside the chamber.

\section{The Nearly Monoenerget ic Electron Facility}

\subsection{Introduction}

Studies of the response of instruments in beta-particle beams of different spectral characteristics aid in judging the relative merit of the instruments for certain field applications. But because of the strong influence of spectral characteristics on instrument response, it is important to have the capability of measuring instrument-response functions with essentially monoenergetic electron beams, from which the response in any beta-particle field may be deduced if the beta-particle spectrum is known at the reference point. Also, because the response of some survey instruments to beta particles is rate dependent (see, e.g., sec. 7.3), it is important to have means for performing rate-dependence studies on instruments over a wide range of absorbed-dose rates without a change in the spectrum - which is difficult to do in beta-particle beams. This is why NBS has adapted two of its electron accelerators to supplement - and in part replace - the function of the beta-particle sources for the study of the properties of beta-radiation protection instruments.

\subsection{Facility Design [9-11]}

The facility consists of:

(1) Two Electron Accelerators, Equipped with Beam Scanners. The NBS 500-keV cascaded-rectifier and 4-MeV Van de Graaff accelerators were adapted for use in the calibration of radiation-protection instruments with electrons in the range from 0.2 to $2.5 \mathrm{MeV}$ by (a) magnetic scanning of the electron beams in a two-dimensional raster pattern in order to produce suitably large beam cross sections; and (b) having the beams exit from the vacuum through thin, low-atomic number windows. In order to prevent unnecessary spectral degradation the air path is kept as short as possible.

(2) Beam Monitors. Because of spatial and intensity fluctuations of the electron beams, continuous beam monitoring is required as a part of the routine measurement procedure. Four fast plastic-scintillator-plusphotomultiplier detectors placed about the beam periphery are used for this purpose.

(3) An Extrapolation Ionization Chamber. A chamber of essentially identical design to that employed in the beta-particle dosimetry setup is used for the determination of absorbed-dose (rate) to water in the accelerator-produced electron beams. 
Operation of the facility is described in some detail in the subsequent parts of section 3. For general safety precautions in the operation of electron accelerators see the pertinent literature listed in section 11 , which is on file in the office of the Dosimetry Group.

\subsection{The Electron Accelerators}

The two electron accelerators have been owned, maintained, and operated by the Ionizing Radiation Division of the Center for Radiation Research for a considerable length of time. Therefore, discussions in this Document will be limited to special features added for their use in calibrations and other studies related to radiation-protection dosimetry.

\subsubsection{Beam Handling}

One of these features is concerned with beam handling. The beam handling arrangement is shown schematically in figure 6. Aligned and focused electron beams of energies from $200 \mathrm{keV}$ to $2.5 \mathrm{MeV}$ are passed through a set of deflection coils which cause the beam to be scanned in a two-dimensional raster pattern. The scan signal has a horizontal frequency of $416 \mathrm{~Hz}$ and a vertical frequency of $12.5 \mathrm{~Hz}$; the amplitudes in the two directions are independent ly variable.

\subsubsection{Beam-Exit Window}

Another feature concerns the choice of beam-exit windows. These windows must be thick enough to withstand atmospheric pressure over a $16-\mathrm{cm}^{2}$ area, yet thin enough not to degrade the electron beam energy appreciably. A thin foil (25 $\mathrm{mm}$ ) of commercially available polyimide is well suited for electron energies up to $500 \mathrm{keV}$. At higher energies, for which energy degradation does not pose a large problem, either the same type of foil or a $0.10-\mathrm{mm}$ aluminum foil is used.

\subsubsection{Frequent Remote Beam Viewing}

Because of the interference of fluctuations in beam location ("beam wandering") with the reproducible use of the beams for calibration purposes, the electron-beam position is checked frequently, especially at the lower energies. This is done by viewing the beam remotely on a light-emitting phosphor screen placed at the exit window. The unscanned beam is centered on the exit window and the scanning-signal amplitudes are adjusted to spread the scanned beam over the window area.

\subsection{The Beam Monitors}

At both accelerators, beam intensity is continuously monitored with four fast plastic-scintillator-plus-photomultiplier detectors fixed in off-axis locations $\left(60^{\circ}\right.$ off-axis and $20 \mathrm{~cm}$ from the exit window at the low-energy accelerator, and $30^{\circ}$ off-axis and $40 \mathrm{~cm}$ from the exit window at the Van de Graaff accelerator). In order to limit counting rates, the monitors are equipped with plastic collimators with circular apertures of various sizes, depending on the sensitivity desired, located near the front surface of the scintillator. The fast (10-ns) pulses from the detector allow counting rates up to $10^{5} / \mathrm{s}$ with no significant pile-up and with very low background 


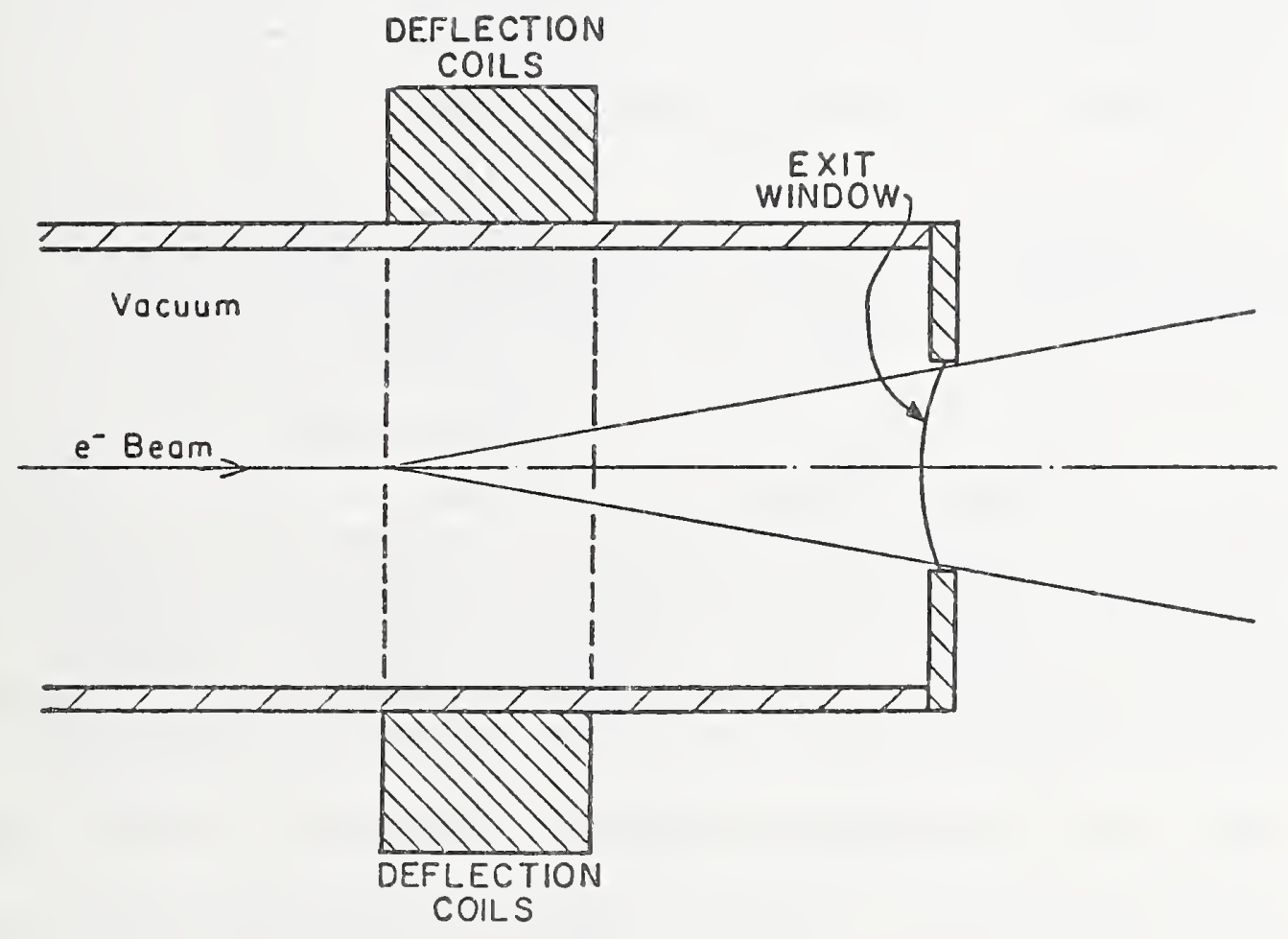

Figure 6. Monoenergetic Electron Beam-Handling Arrangement. 
rates (less than $2 / \mathrm{s}$ ). When only one monitor was used, the magnitude of beam wandering and fluctuations in beam intensity were large enough to limit dosimetry reproducibility to about 15 percent when the beam was turned off between individual measurements. Therefore, the four plastic-scintillatorplus-photomultiplier monitors, fixed in a circular array about the beam axis, were installed to replace the single monitor. Their signals are being fed back to additional beam-steering elements for dynamic control of beam location. With this monitoring control, measurement reproducibility is better than 5 percent.

\subsection{Use of Extrapolation Chamber to Measure Absorbed Dose to Water}

Because basic construction and principle of operation of the extrapolation ionization chamber has been discussed in some detail in section 2.4, this section is limited to features of operation special to the application in accelerat or beams.

\subsubsection{Requirements of Limitation in Beam Intensity}

The particular type of extrapolation-ionization chamber was designed mainly for operation with relatively low-activity radionuclide sources, as a rule producing ionization currents not exceeding a few nanoamperes. When beam intensities are such that about $1 \mu \mathrm{A}$ is exceeded, strong insulator leakage prevents the use of the chamber for at least one day. Around accelerators, it is difficult to avoid at all times beam intensities that produce large ionization currents in the chamber. When the accelerator beam is operated without a beam shutter, excessive chamber currents may occur during beam tuning. For this reason, the chamber is removed from the beam for the time of beam viewing and adjustment. Even with this precaution - and even when a shutter is available - excessive chamber currents cannot be entirely ruled out since current surges may occur during actual irradiations, i.e., with the shutter in the "open" position. For this reason, NBS has two essentially identical extrapolation ionization chambers - one of them for use solely in calibration work with radionuclide sources, and one for use in accelerator beams.

\subsubsection{Dose (Rate) Measurements and Study of Radiation-Protection Instruments}

Because of fluctuations in accelerator current, a ratio must be established between the ionization current in the extrapolation ionization chamber at the reference point and the indication of the monitor(s). Only if this ratio is constant to within an acceptable limit, can the extrapolation chamber be replaced by the instrument to be calibrated, and a calibration factor obtained for the instrument. Constancy of the ratio is checked before and aiter each instrument-calibration run. With the new monitor setup, it is possible to maintain the monitor reading sufficiently constant to yield the calibration factor with adequate reproducibility.

\section{Characterization of NBS Beta-Particle Beams}

4.1 Determination of Absorbed-Dose Rates to Water; International Comparisons

Absorbed-dose rates to air and water were determined for the four sources purchased from Buchler-Amersham at the reference distances from measurements of ionization currents in the extrapolation-ionization chamber. The methods 
used were those described in detail in section 2.4.3. The results are shown in table 4. Since the sources had been initially calibrated at the PTB, it was possible to compare the NBS calibrations with those obtained at the PTB in a similar geometry at the same reference distances. Table 4 shows a comparison for absorbed-dose rates to water. The results agree to 1 percent or better for the ${ }^{90} \mathrm{Sr}+90 \mathrm{Y}$ source and to 2 percent for $204 \mathrm{~T} 1$. A 4-percent disagreement for ${ }^{147} \mathrm{Pm}$ is not surprising, considering the size of the overa 11 uncertainty in the measurement of the ionization current (see table 5, sec. 4.5) and the relatively strong dependence of the measurement results on calibration geometry (see sec. 4.2 and 4.3 below).

\subsection{Influence of Measurement Geometry on Source Calibration}

In order to arrive at the uncertainty to be expected in NBS source calibrations, measurements were made with the NBS sources of the variation of dose rate with source-to-detector distance and with detector alignment. Following is a discussion of the results of these measurements made with the extrapolation ionization chamber as the detector.

Table 4. Comparison of Absorbed-Dose Rates to Water, at the Surface, Obtained by NBS and PTB; and Absorbed-Dose Rates to Water at Depth of Interest in Radiation Protection for Three of the NBS Sources.

\begin{tabular}{|c|c|c|c|c|c|c|}
\hline \multicolumn{2}{|c|}{ Source } & \multirow{3}{*}{$\begin{array}{l}\text { Source- } \\
\text { to-detect or } \\
\text { distance } \\
(\mathrm{cm})\end{array}$} & \multicolumn{4}{|c|}{ Absorbed Dose Rate ${ }^{a}$} \\
\hline \multirow[b]{2}{*}{ Type } & \multirow{2}{*}{$\begin{array}{l}\text { Nomina } 1 \\
\text { act i vity } \\
\quad(\mathrm{mC} i)\end{array}$} & & \multicolumn{3}{|c|}{ to water, at the surface } & \multirow{2}{*}{$\begin{array}{c}\text { to water } \\
\text { at a depth } \\
\text { of } 7 \mathrm{mg} / \mathrm{cm}^{2 b} \\
(\mu \mathrm{Gy} / \mathrm{s})\end{array}$} \\
\hline & & & $\begin{array}{c}\text { NBS } \\
(\mu \mathrm{Gy} / \mathrm{s})\end{array}$ & $\begin{array}{c}\text { РТВ } \\
(\mu G y / s)\end{array}$ & $\begin{array}{l}\text { Rat io } \\
\text { NBS / PTB }\end{array}$ & \\
\hline $147 \mathrm{Pm}$ & 14 & 20 & 0.267 & 0.257 & 1.04 & 0.06 \\
\hline $204 \mathrm{~T}$ & 0.5 & 30 & 0.341 & 0.333 & 1.02 & 0.33 \\
\hline${ }^{90} S r+90 Y$ & 2 & 30 & 1.93 & 1.90 & 1.01 & 2.01 \\
\hline$"$ & 50 & 11 & 513 & 506 & 1.01 & - \\
\hline$"$ & $"$ & 30 & 70.6 & 69.9 & 1.01 & - \\
\hline " & $"$ & 50 & 25.2 & 25.1 & 1.00 & - \\
\hline
\end{tabular}

aReferred to January 1,1983 and $20^{\circ} \mathrm{C}$ at 1 standard atmosphere $(101.325 \mathrm{kPa})$.

${ }^{b}$ From column 4 (NBS data). 


\subsubsection{Dependence of Dose Rate on Off-Axis Shift of Detector}

For this study, the detector was moved horizontally within the calibration plane so as to cover the entire beam cross section. Typical results are shown in figure 7 . Along the horizontal line passing through the reference point, the points of equal dose rate are seen to be distributed symmetrically about the beam center for ${ }^{90} \mathrm{Sr}+90 \mathrm{Y}$ and for ${ }^{204} \mathrm{Tl}$, the dose rates varying by less than \pm 0.5 percent and \pm 2 percent, respectively, for points not more than $10 \mathrm{~cm}$ from the reference point. The troughs in the center are to be expected because of the presence of the flattening filters.

For $147 \mathrm{Pm}$ the dose-rate distribution is asymmetric, the variation in dose rate amounting to about \pm 10 percent for points up to $10 \mathrm{~cm}$ removed from the central beam axis ( $\pm 6 \%$ for points removed by not more than $\sim 8 \mathrm{~cm}$ ). Measurements with the shutter removed demonstrated that this asymmetry is caused by the shutter. When the shutter is in the open position, it is located on the side of lower dose rate. Presumably the relatively low-energy beta particles of $147 \mathrm{Pm}$ are scattered at short distances at a wide enough angle to impinge on the open shutter, even though it is mounted close to the source, and this results in a strong deficit of electrons on that side. The higher energy electrons of the other sources are presumably not scattered sufficiently at short distances to be significantly attenuated by the open shutter.

\subsubsection{Dependence of Dose Rate on Precision of Source-to-Detector Distance Setting}

Source-to-detector distance was increased and decreased by up to about $3 \mathrm{~cm}$ from the reference distance selected for the calibration. Figure 8 shows that positioning of the detector is not too critical for any but the $14 \% \mathrm{Pm}$ source, for which a change in distance by $5 \mathrm{~mm}$ causes a change in dose rate by close to 10 percent. As a consequence, there also will be a significant dose-rate gradient over the depth of a transfer instrument calibrated in the $147 \mathrm{Pm}$ beta-particle beam if this depth extends over more than just a few millimeters.

In figure 8 , the dose rates have been multiplied by the square of the reference distance so that a horizontal line in this graph represents a dependence on the inverse-square of the distance. It can be seen that none of the sources shows such a dependence. For ${ }^{90} \mathrm{Sr}+90 \mathrm{Y}$ and $204 \mathrm{Tl}$, the deviations from the inverse-square dependence probably are caused by a combination of the angular spread of the scattered-electron buildup and the use of flattening filters. The strong variation exhibited by $147 \mathrm{Pm}$ is due to a large fraction of the $147 \mathrm{Pm}$ beta particles having ranges comparable to the reference distance. 


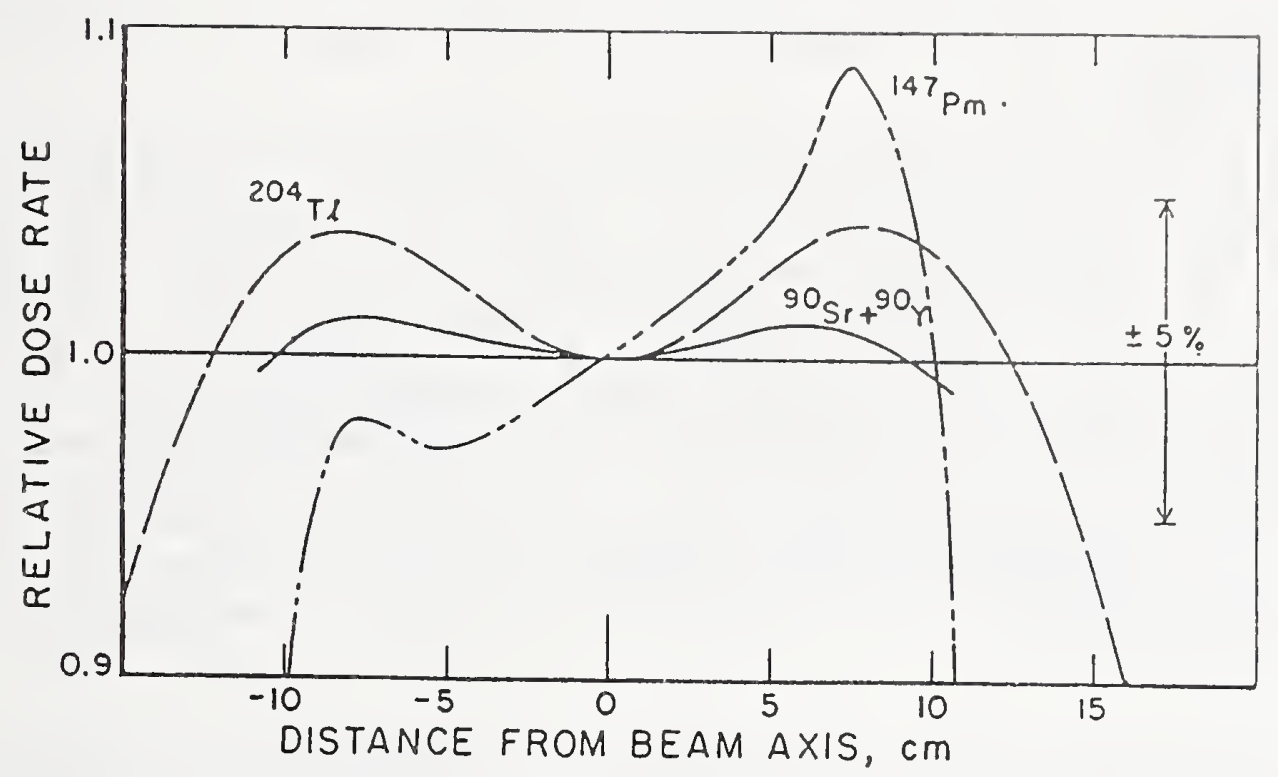

Fig. 7. Degree of Non-Uniformity of Dose Rate along a Horizontal Line through the Reference Point, Perpendicular to the Beam Axis. Reference distance: $30 \mathrm{~cm}$ for $90 \mathrm{Sr}+90 \mathrm{Y}$ and $204 \mathrm{Tl}, 20 \mathrm{~cm}$ for $147 \mathrm{Pm}$.

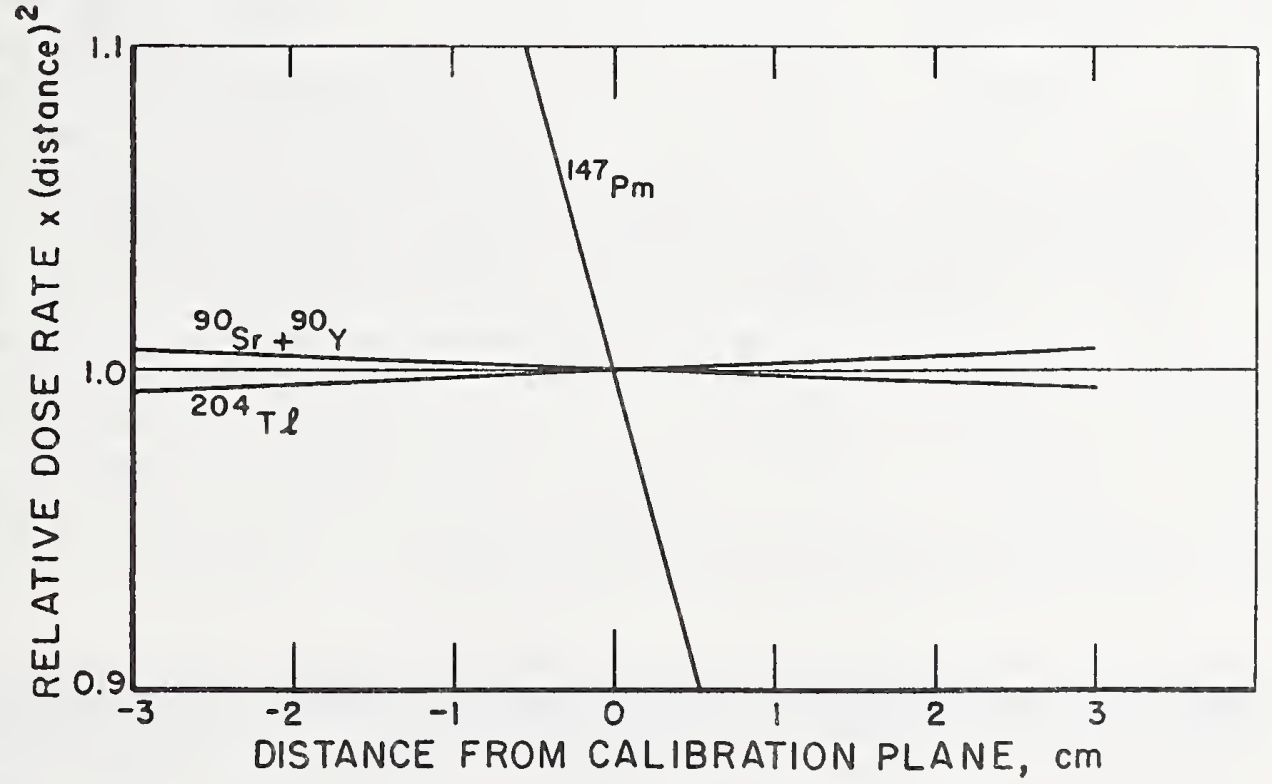

Figure 8. Dependence of Dose Rate on Source-to-Detector Distance. 

in Plastic

Measurements were made of ionization current in the extrapolation ionization chamber as a function of thickness of polyethylene terephthalate (PTP) added to the $2.6-\mathrm{mg} / \mathrm{cm}^{2}$ window of the chamber. The results are shown in figure 9 for all three types of beta-particle sources. For $147 \mathrm{Pm}$, the decrease in current with PTP thickness is roughly exponential from the onset, and absorption is essentially complete after an addition of $\sim 20 \mathrm{mg} / \mathrm{cm}^{2}$ of PTP. For larger thicknesses, the ionization current remains at $\sim 1$ percent of the maximum current, and probably is due to a combination of bremsstrahlung produced by the $147 \mathrm{Pm}$ beta particles in the PTP and 121-keV gamma rays from $147 \mathrm{Pm}$. For ${ }^{90} \mathrm{Sr}+{ }^{90} \mathrm{Y}$, there is an ionization buildup over the first $\sim 40 \mathrm{mg} / \mathrm{cm}^{2}$ of added PTP before attenuation starts to dominate, while for ${ }^{204} \mathrm{~T} 1$ the attenuation in PTP seems partially offset by buildup over the first $\sim 15 \mathrm{mg} / \mathrm{cm}^{2}$ of PTP.

Because PTP is not readily adaptable to measurements at larger thicknesses, attenuation curves for $90 \mathrm{~S} r+90 \mathrm{y}$ were also obtained with added polystyrene, covering a range of thicknesses from $\sim 100 \mathrm{mg} / \mathrm{cm}^{2}$ to beyond $2 \mathrm{~g} / \mathrm{cm}^{2}$. The results are shown in figure 10 , demonstrating that any bremsstrahlung background (ionization-current contribution by the source for polystyrene thicknesses beyond the beta-particle range) is less than 0.06 percent.

\subsection{Spectral Characterization by Means of Pulse-Height Distributions}

Because of the emphasis on the change in spectral characteristics with changes in certain experimental parameters rather than on spectral characteristics per se, these studies were confined to a comparison of pulse-height distributions, measured with a silicon surface-barrier detector and converted to an absolute energy scale, ignoring certain spectral distortions introduced by the detector. Figures 11 through 13 show these spectral distributions for the three types of sources. (No difference was found between the spectra of the two ${ }^{90} \mathrm{Sr}+90 \mathrm{Y}$ sources used in the same geometry.) The spectra were obtained with a $5-\mathrm{mm}$ deep silicon surface-barrier detector operated at room temperature, in air, under a cover of $0.013 \mathrm{~mm}$ of aluminized PTP for light protection. A low-scatter ${ }^{207} \mathrm{Bi}$ point source (NBS Standard Reference Material 4240) was used for the energy calibration (pulse-height-to-energy conversion). The pulse-height distribution obtained with this source using the surfacebarrier detector is shown in figure 14 . For a 11 but the $147 \mathrm{Pm}$ source, a lead collimator with either a $1.6-\mathrm{mm}$ or a $3.2-\mathrm{mm}$ diameter circular aperture was employed near the detector, since collimation was found to remove a considerable amount of scatter (see fig. 11 and 12, bottom). Following is a detailed discussion of the results for the ${ }^{90} \mathrm{Sr}+90 \mathrm{Y}$ sources:

(a) Influence of Flattening Filter on ${ }^{90} \mathrm{Sr}+90 \mathrm{Y}$ Pulse-Height Distribution. Figure 12 shows that the flattening filter causes a shift in the energy endpoint. This should be kept in mind when the $80-\mathrm{MBq}$ source (used with flattening filter) is replaced by the $2000-\mathrm{MBq}$ source (used without flattening filter) in the course of an instrument calibration. 


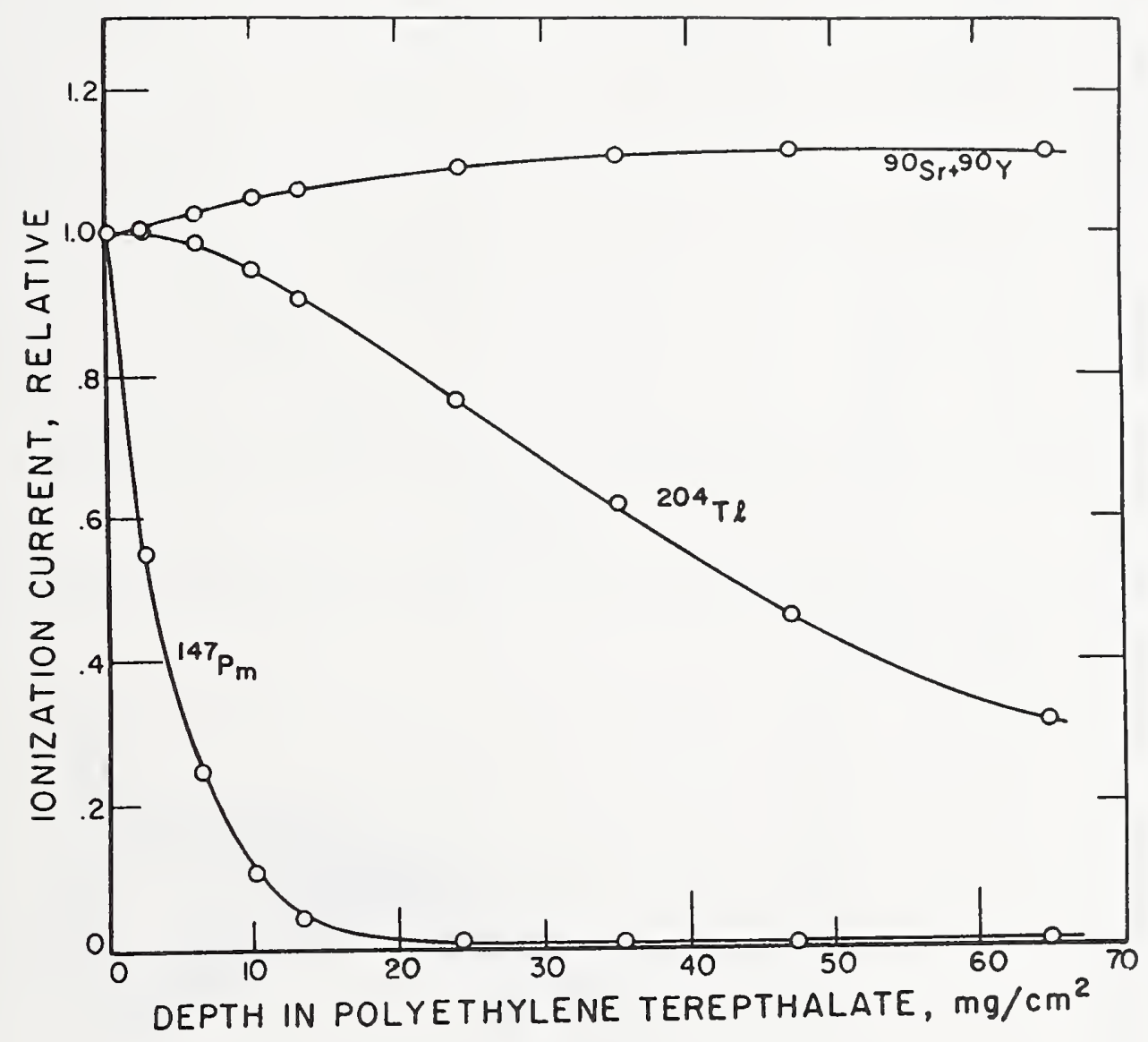

Figure 9. Ionization Current as a Function of Depth in PTP. 


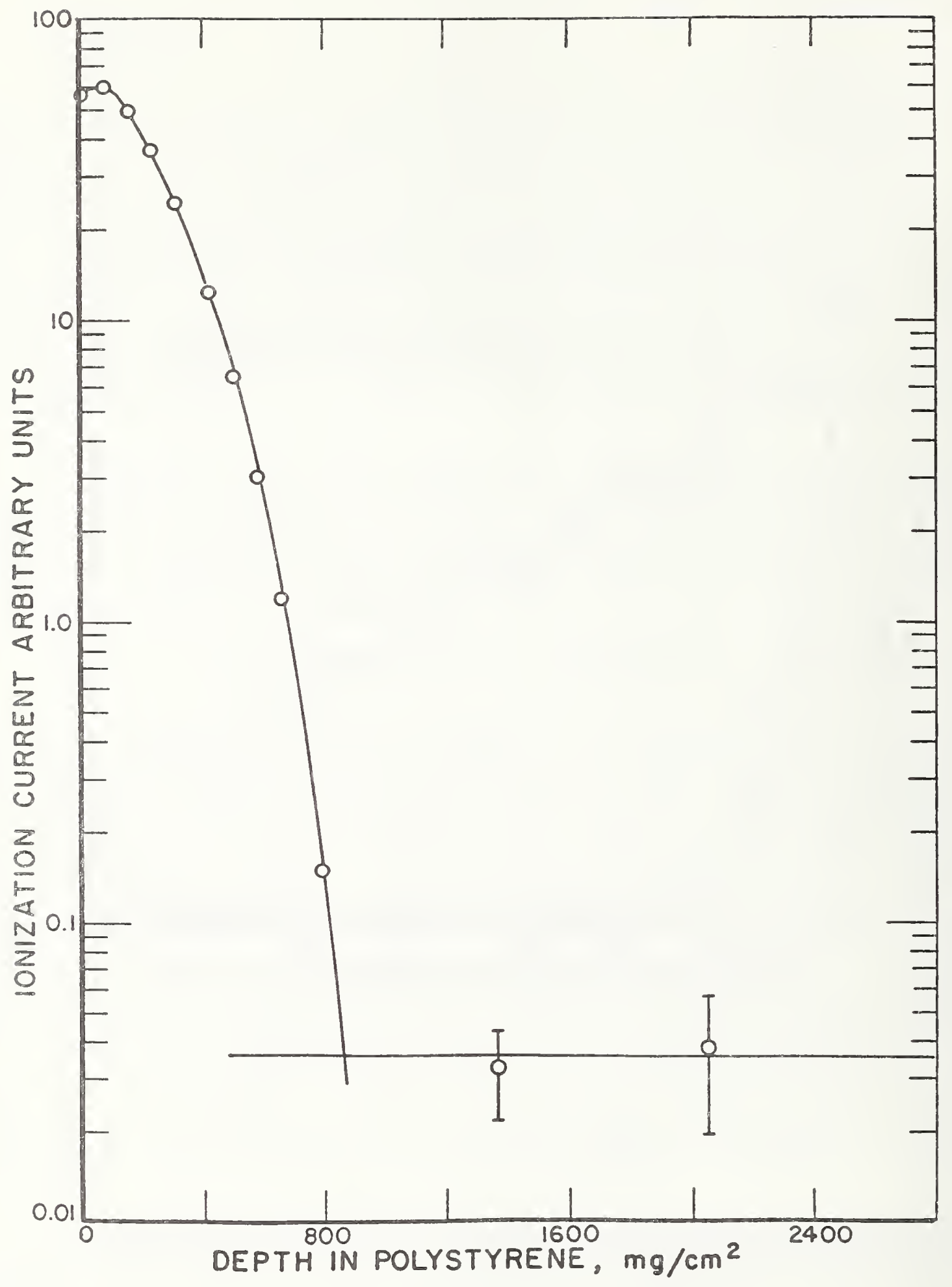

Figure 10. Attenuation Curve in Polystyrene for the 2-mCi $90 \mathrm{Sr}+90 \mathrm{Y}$ Source. 

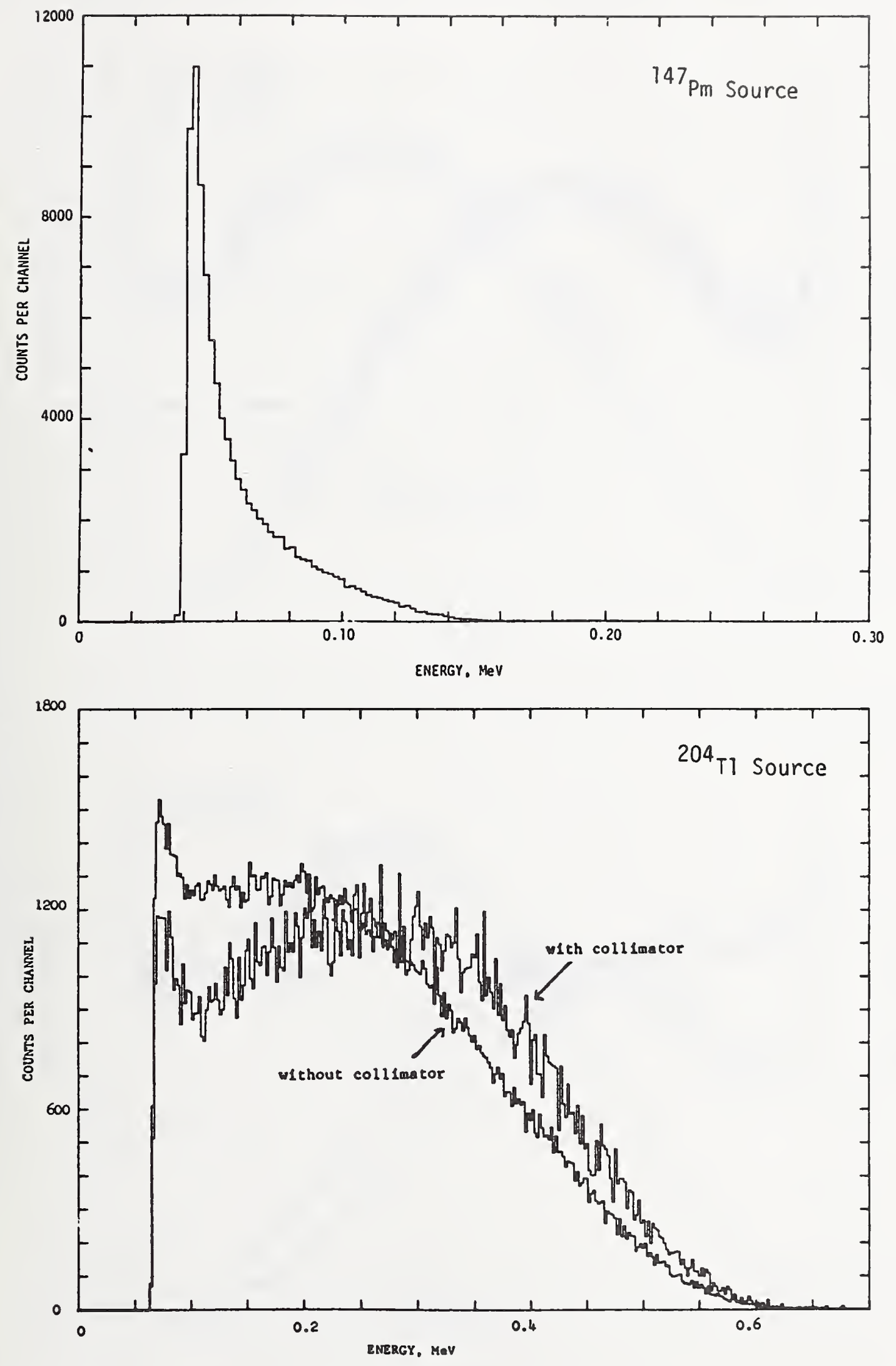

Figure 11. top: Spectrum of $147 \mathrm{Pm}$ Source, Used with Flattening Filter. Distance: $20 \mathrm{~cm}$. Detector uncollimated. bottom: Spectrum of $204 \mathrm{Tl}$ Source, Used with Flattening Filter, Showing Influence of Lead Collimator with Circular Aperture, $3.2 \mathrm{~mm}$ in Diameter. Distance: $30 \mathrm{~cm}$. 

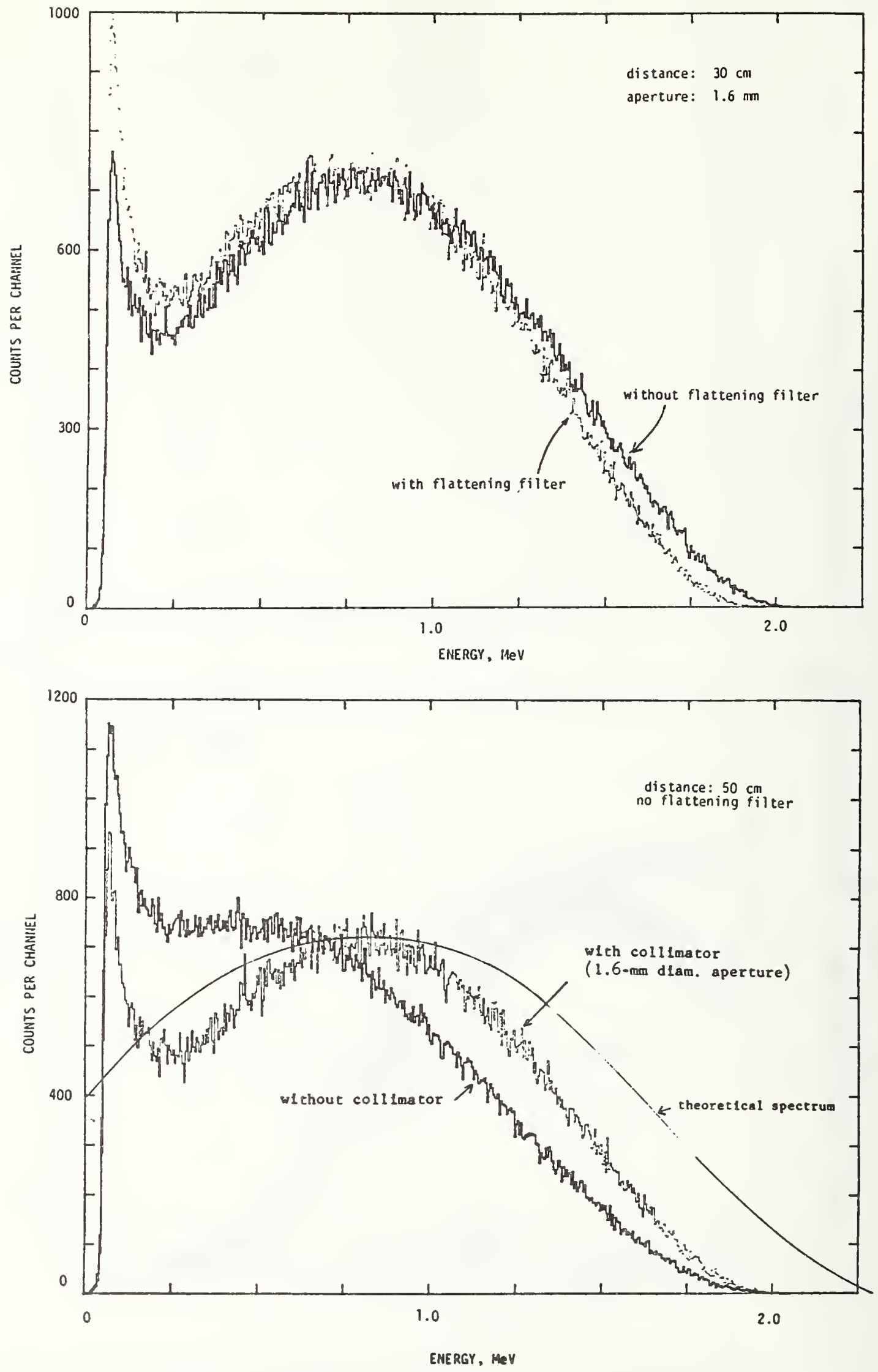

Figure 12. Spectrum of $90 \mathrm{Sr}+90 y$ Sources, Showing Influence of Flattening Filter and of Detector Collimator. The theoretical spectrum of $90 \mathrm{y}$ is shown for comparison. 

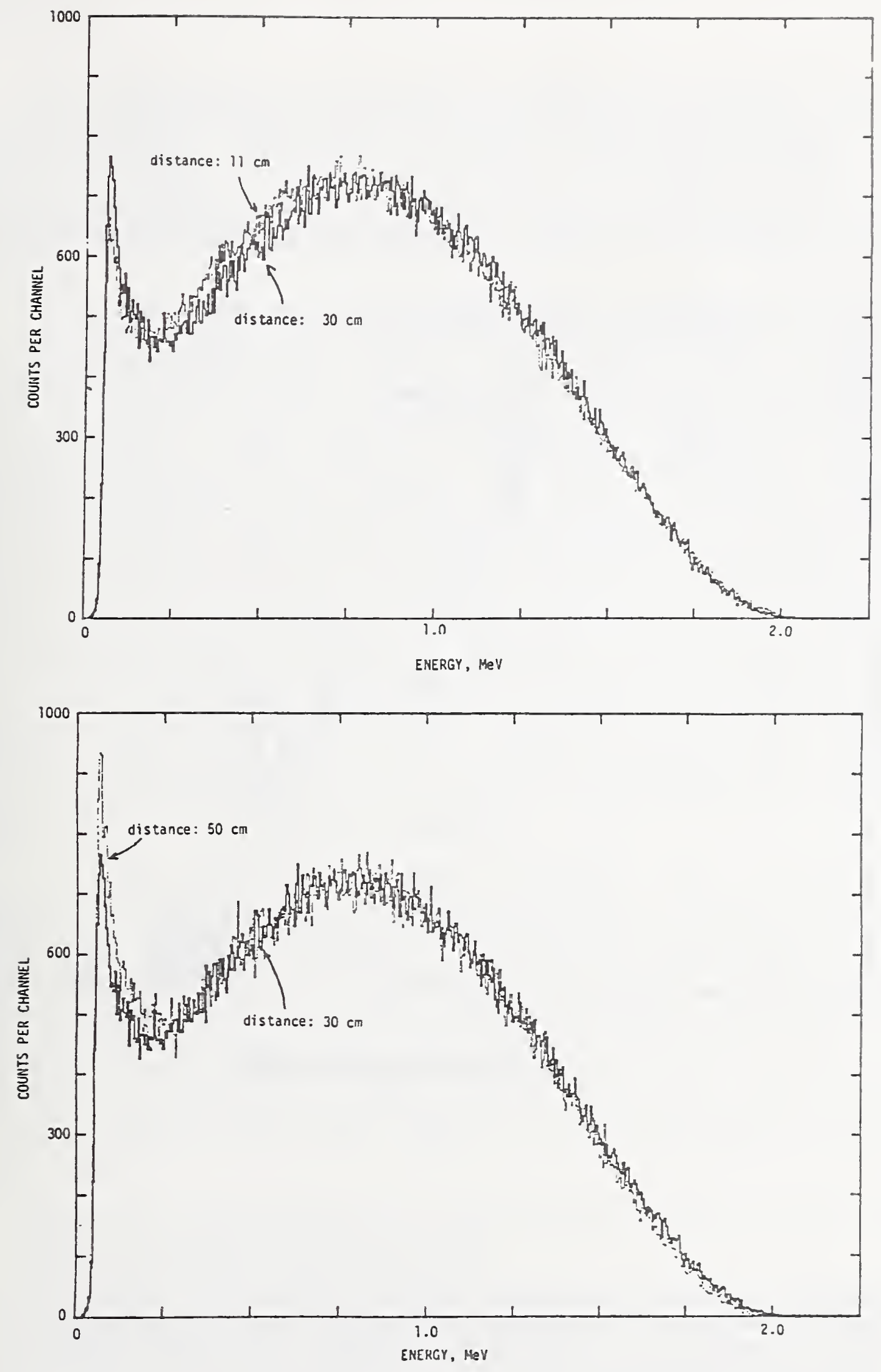

Figure 13. Spectrum of $90 \mathrm{Sr}+90 \mathrm{Y}$ Sources Used without Flattening Filter, Showing Influence of Source-to-Detector Distance. Detector collimator with circular aperture, $1.6-\mathrm{mm}$ in diameter. 


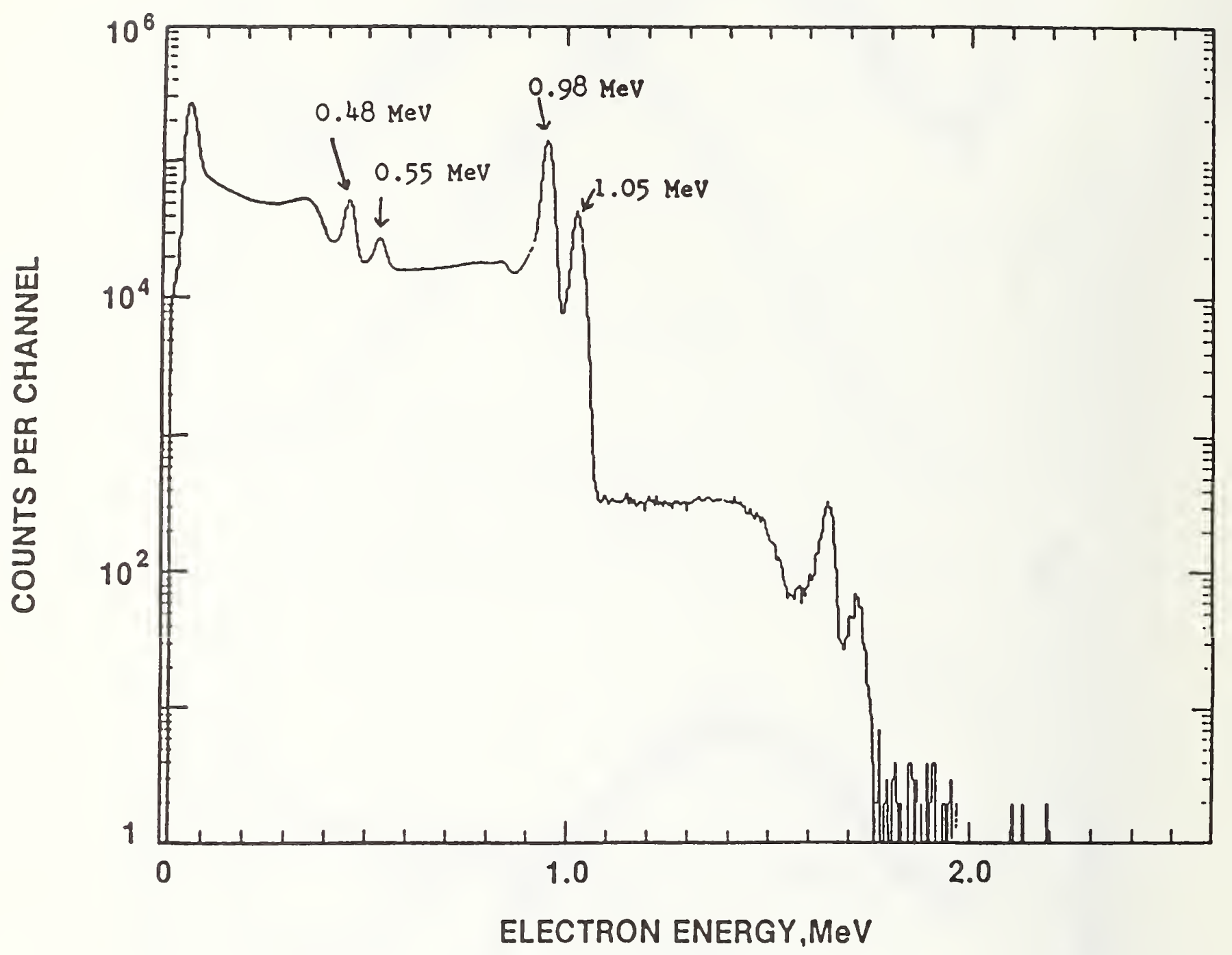

Figure 14. Energy Calibration Spectrum of ${ }^{207} \mathrm{Bi}$ Obtained with the 5-mm Silicon Surface-Barrier Detector. Assignment of pulse-height peaks to known conversion-electron energies below $1.1 \mathrm{MeV}$ [12] took into account energy losses in the source covering, in the detector covering, and in the $2.54 \mathrm{~cm}$ of air between source and detector. 
(b) Influence of source-to-detector distance for ${ }^{90} \mathrm{Sr}+90 \mathrm{Y}$. Figure 13 shows the spectral distributions at the three distances specified by the source manufacturer. The effect of distance is seen to be relatively small. Therefore, a change in distance, necessitated by considerations either of required absorbed-dose rate or of required size of uniform beam cross section, is not expected to introduce an appreciable change in instrument-calibration results.

(c) Comparison of the measured pulse-height distribution with theory. For this comparison, one must consider (1) that the theoretical spectrum shown in figure 12 was computed for a bare $90 y$ source; and (2) that the measured spectral distribution is for a ${ }^{90} \mathrm{Sr}+90 \mathrm{y}$ source encapsulated in $50 \mathrm{mg} / \mathrm{cm}^{2}$ of silver and $0.1 \mathrm{~mm}\left(77 \mathrm{mg} / \mathrm{cm}^{2}\right)$ of iron, at a distance of $50 \mathrm{~cm}\left(61 \mathrm{mg} / \mathrm{cm}^{2}\right)$ in air, with a layer of about $1 \mathrm{mg} / \mathrm{cm}^{2}$ of aluminized PTP over the detector, or a composite total of roughly $190 \mathrm{mg} / \mathrm{cm}^{2}$. But for the average and maximum beta-particle energies given in table 1, one arrives at respective approximate average and maximum ranges for the ${ }^{90} \mathrm{Sr}$ beta particles of 60 and $270 \mathrm{mg} / \mathrm{cm}^{2}$. This means that there are relatively few ${ }^{90} \mathrm{Sr}$ beta particles reaching the detector, making the measured pulse-height distribution mainly that of $90 \%$, slowed down by the intervening absorbers. Figure 12 (bottom) shows that the general shape of the pulse-height distribution obtained with the collimated detector compares relatively well with the theoretical 9oy spectrum. The peak is roughly at the same location. The high-energy endpoint of the pulse-height distribution is at a lower energy, which is qualitatively compatible with the energy loss in the intervening absorbers. The difference in shape in the low-energy region may be the result of a composite of the residual ${ }^{90} \mathrm{Sr}$ beta particles reaching the detector (see figure 2 for the theoretical ${ }^{90} \mathrm{Sr}+90 \mathrm{Y}$ spectrum) and of the distortions introduced by detector-edge and encapsulation effects, for which no corrections were made.

(d) Change in spectrum with depth of absorber. Figure 15 shows the change of the ${ }^{90} \mathrm{Sr}+90 \mathrm{y}$ spectrum with added thickness of polystyrene absorber, in a semi-logarithmic representation which enhances the visibility of the effect. The results are of interest since shallow and deep absorbed-dose rates to water (or plastic) of the type shown in figure 10 often are obtained from measurements with parallel-plate ionization chambers whose response depends on spectral composition. There is seen to be a radical change in the spectrum with increasing polystyrene thickness, the thickest shown $\left(0.58 \mathrm{~g} / \mathrm{cm}^{2}\right)$ corresponding to a reduction by a factor of ten in the measured ionization current. These results emphasize the need to know the response function of the $i$ onization chamber employed for such measurements, over a wide energy range.

\subsection{Uncertainty in the Calibration of Beta-Particle Sources and Transfer Ionization Chambers Submitted to NBS}

The method of uncertainty assessment used here follows the recommendation of the Comite International des Poids et Mesures (CIPM) [13]. The uncertainty estimates are of two kinds. Conventional statistical estimates of random uncertainties are given as standard deviations of the mean, designated "Type A," which can be considered to be objective estimates. All other uncertainty estimates, designated "Type B," are subjective estimates, based on the extensive experience of the calibration staff. The Type B uncertainties are estimated so as to have roughly the character of standard deviations. 


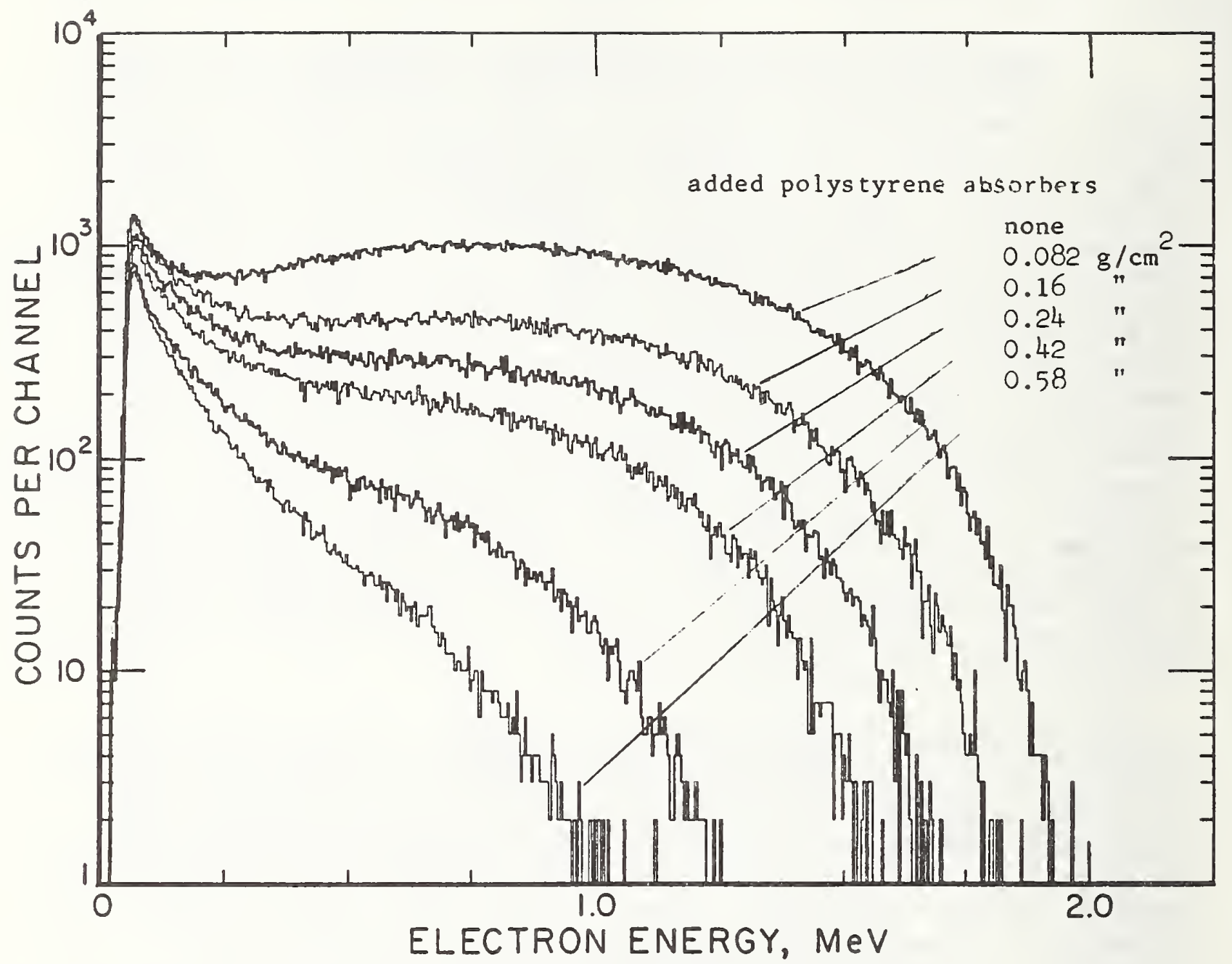

Figure 15. Effect of Added Polystyrene Absorbers on $90 \mathrm{Sr}+90 \mathrm{Y}$ Spectrum. Detector collimator with circular aperture, $1.6 \mathrm{~mm}$ in diameter. 
The estimates of each type are combined in quadrature, and then the two results are combined in quadrature to give a combined uncertainty. The combined uncertainty in turn is multiplied by two (or three), to give an overall uncertainty.

Table 5 gives a breakdown of the uncertainties in the determination of absorbed-dose rate to water at the $7 \mathrm{mg} / \mathrm{cm}^{2}$ depth of interest from the ionization current measured with the extrapolation chamber. The data in this table are based on the detailed presentation of measurement procedures in section 2.4.3. The uncertainty in the determination of absorbed-dose rate to water and the results presented in section 4.2 on the influence of measurement geometry on source calibration then are used in table 6 to arrive at combined uncertainties in the calibration of beta-particle sources and transfer ionization chambers submitted to NBS. The overall uncertainty is quoted as two times the combined uncertainty.

\section{Characterization of Nearly Monoenerget ic Electron Beams}

\subsection{Beam Cross Section}

The degree of uniformity of the electron-beam cross section was determined radiographically over a range of electron energies and distances from the exit window. Industrial x-ray film was used, in light-opaque paper envelopes for electron energies of $300 \mathrm{keV}$ and above, and bare in a darkened room for lower energies. Densitometric scans were obtained of the optical densities of the radiographs along two perpendicular diameters of the essentially circular images of the beam cross sections. Figure 16 shows plots of the Gaussian fits to representative data obtained for several electron energies from $200 \mathrm{keV}$ to $2.5 \mathrm{MeV}$ at several distances from the exit window. Plots of this type permit a choice of distance from the exit window suitable for covering an instrument of a given size with a beam of a cross section of a pre-determined degree of uniformity. A synopsis of typical results prior to the improvement in the monitoring system is given in the first three columns of table 7 where usable field size is shown over the covered energy range.

\subsection{Determination of Range of Absorbed-Dose Rates to Water Available for Instrument Calibration}

The method of using the extrapolation chamber in conjunction with a beam monitor for obtaining monitor indication per unit of absorbed-dose rate to water (the ratio R) was described in section 3. Because the beam properties were not sufficiently reproducible when the machine was turned off between measurements, it was not possible to measure definitive values for $R$ in the NBS setup prior to installation of the new beam-monitoring and control system. All that could be done was to establish an approximate range of the absorbeddose rates that were attainable with the initial monitor setup at each of the chosen accelerator potentials and exit window-to-detector distances. The results are shown in the last two columns of table 7 . The second-to-last column of the table represents the dose obtained in 10 seconds at a nominal monitor counting rate of 20 per second, which was the minimum rate that could be monitored with a sufficient degree of accuracy. The maximum dose rates 
Table 5. Uncertainties in the Determination of Absorbed-Dose Rate to Water from Measurements with the Extrapolation Ionization Chamber

\begin{tabular}{|c|c|c|c|c|c|c|}
\hline Parameter & Symbol & $14 / \mathrm{Pm}$ & Type $A^{a}$ & $\begin{array}{l}\text { ercent Unc } \\
90 S r+90 y\end{array}$ & $\left|\begin{array}{r}\text { Type } \\
\text { Tyin } \\
14 / \mathrm{Pm}\end{array}\right|$ & $\begin{array}{l}\text { nty } \\
\mathrm{B}^{\mathrm{D}} \\
204 \mathrm{Tl} \\
90 \mathrm{~S} r+90 \mathrm{Y}\end{array}$ \\
\hline $\begin{array}{l}\text { A. Corrected Ioniza } \\
\text { Ionization current measured } \\
\text { at a depth of } 7 \mathrm{mg} / \mathrm{cm}^{2} \text { in PTP } \\
\text { Correction for: } \\
\text { Entrance foil } \\
\text { thickness }{ }^{\mathrm{c}} \\
\text { attenuation } \\
\text { Beam Divergence } \\
\text { Chamber air attenuation } \\
\text { Chamber air not at reference } \\
\text { conditions } \\
\text { Chamber backscatter } \\
\text { Chamber sidescatter } \\
\text { lon recombination and diffusion } \\
\text { Source decay } \\
\text { External air mass } \\
\text { near sea level } \\
\text { at high altitudes } \\
\text { Relative humidity }\end{array}$ & $\begin{array}{l}\text { I } \\
c_{\text {foil }} \\
c_{\text {div }} \\
c_{\text {att en }} \\
c_{t, p} \\
c_{\text {back }} \\
c_{\text {side }} \\
c_{\text {recom }} \\
k_{\text {dec }} \\
k_{\text {mass }} \\
k_{\text {hum }}\end{array}$ & arrent & (Extra & apolation & $\begin{array}{l}0.1 \\
1.5 \\
1.0 \\
0.05 \\
0.5 \\
0.1 \\
0.3 \\
0.2 \\
0.3 \\
0.05 \\
1.0 \\
3.0 \\
0.1\end{array}$ & $\begin{array}{l}0.2 \\
0.1 \\
0.05 \\
0.05 \\
0.1 \\
0.3 \\
0.2 \\
0.3 \\
0.05 \\
0.5 \\
1.0 \\
0.05\end{array}$ \\
\hline $\begin{array}{c}\text { Corrected ionization current at a } \\
\text { depth of } 7 \mathrm{mg} / \mathrm{cm}^{2} \text { in PTP } \\
\text { near sea level } \\
\text { at high altitudes }\end{array}$ & $I_{c}$ & $\begin{array}{l}0.4 \\
0.4\end{array}$ & $\begin{array}{l}0.3 \\
0.3\end{array}$ & $\begin{array}{l}0.1 \\
0.1\end{array}$ & $\begin{array}{l}1.9 \\
3.4\end{array}$ & $\begin{array}{l}0.7 \\
1.1\end{array}$ \\
\hline
\end{tabular}

B. Absorbed-Dose Rate to Water at a Depth of $7 \mathrm{mg} / \mathrm{cm}^{2}$

Corrected ionization current per

unit air gap (slope) ${ }^{f}$

near sea level

at high altitudes

Air density

Area of collecting electrode

Energy expended per unit charge

in air

Stopping-power ratio

Absorbed-dose rate to water at a depth of $7 \mathrm{mg} / \mathrm{cm}^{2}$ in PTPE

near sea level

at high altitudes

\begin{tabular}{|l|l|l|l|l|l|}
\hline$\Delta I_{c} / \Delta d$ & & & & & \\
& 0.4 & 0.3 & 0.1 & 1.9 & 0.7 \\
& 0.4 & 0.3 & 0.1 & 3.4 & 1.1 \\
$\mathrm{~A}$ & & & & 0.05 & 0.05 \\
W/e & & & & 0.1 & 0.1 \\
water & & & & 0.5 & 0.5 \\
$\mathrm{~S}_{\text {air }}$ & & & & 1.0 & 1.0 \\
\hline & & & & & \\
$\dot{D}_{\mathrm{t}}$ & & & & & \\
& 0.4 & 0.3 & 0.1 & 2.2 & 1.3 \\
\hline
\end{tabular}

${ }^{a}$ Conventional statistical estimates (standard deviations of the means), obtained from repeated measurements.

${ }^{b}$ Subjective estimates (see text). A normal error distribution was assumed.

${ }^{\complement}$ For radiation-protect ion measurements, ionization current is usually measured at or near the depth of interest (i.e., with an entrance foil thickness of $7 \mathrm{mg} / \mathrm{cm}^{2}$ of tissue-equivalent material). $c_{f o j l}$ then refers only to the uncertainty in the thickness (area density) of the entrance foil used.

dhis additional uncertainty in $c_{\text {foil }}$ refers to the correction for attenuation in the entrance foil, which is required only for certain special procedures in which extrapolation to zero-entrance foil is necessary. It is not included in the total uncertainties given in this table. (See also sec. 2.4.3.2.)

esquare root of the sum of the squares of all uncertainties of one type.

fince, in some instances, the current ( $I_{f}$ ) is determined for not more than two plate separations (d), the uncertainty in the slope $(\Delta I / \Delta d)$ was set equal to that of the determination of $I_{c}$ at a given value of $d-a$ procedure which, as a rule, will result in an overestimate of the uncertainty. 
Table 6. Uncertainty in the Calibration of Beta-Particle Sources and Transfer Ionization Chambers Submitted to NBS

\section{A. Source Calibration}

\begin{tabular}{|c|c|c|c|c|c|c|}
\hline Parameter & \multicolumn{5}{|c|}{$\begin{array}{l}\text { Percent Uncertainty } \\
\text { Type } A^{a} \quad \text { Type } B^{b}\end{array}$} & $\begin{array}{l}\text { ty } \\
\text { pe } B^{b} \\
204 T 1 \\
90 S r+90 Y\end{array}$ \\
\hline $\begin{array}{l}\text { Positioning of extrapolation- } \\
\text { ionization chamber and sources } \\
\text { Absorbed dose rate to water at } \\
\text { depth } t=7 \mathrm{mg} / \mathrm{cm}^{2} \mathrm{c} \\
\text { near sea level } \\
\text { at high altitude }\end{array}$ & $\begin{array}{l}0.4 \\
0.4\end{array}$ & $\begin{array}{l}0.3 \\
0.3\end{array}$ & \multicolumn{2}{|c|}{$\begin{array}{l}0.1 \\
0.1\end{array}$} & $\begin{array}{l}1.0 \\
2.2 \\
3.6\end{array}$ & $\begin{array}{l}1.3 \\
1.6\end{array}$ \\
\hline Overall Uncertainties & $\begin{array}{l}1 \\
\text { near se } \\
\text { level }\end{array}$ & $\begin{array}{l}147 \mathrm{Pm} \\
\mathrm{at} \mathrm{ati}\end{array}$ & igh & $\begin{array}{r}204 \mathrm{~T} \\
\text { near } \\
\text { lev }\end{array}$ & $\begin{array}{l}\text { Tl and } \\
\text { r sea } \\
\text { vel }\end{array}$ & $\begin{array}{l}90 \mathrm{Sr}+90 \mathrm{Y} \\
\text { at high } \\
\text { altitude }\end{array}$ \\
\hline $\begin{array}{l}\text { Combined uncertainty, } \%^{d} \\
2 \text { times combined uncertainty, \% } \\
3 \text { times combined uncertainty, \% }\end{array}$ & $\begin{array}{l}2 \cdot 5 \\
5 \\
8\end{array}$ & $\begin{array}{r}3 \\
8 \\
11\end{array}$ & & $\begin{array}{l}1 \\
3 \\
4\end{array}$ & & $\begin{array}{l}1.6 \\
3 \\
5\end{array}$ \\
\hline
\end{tabular}

\section{B. Calibration of Transfer-Ionization Chamber}

\begin{tabular}{|c|c|c|c|c|c|}
\hline Parameter & \multicolumn{5}{|c|}{$\begin{array}{c}\text { Percent Uncertainty } \\
\text { Type } A^{a} \\
\text { Type } B^{b} \\
204 T 1\end{array}$} \\
\hline $\begin{array}{l}\text { Positioning of transfer } \\
\text { ionization chamber and sources } \\
\text { Measured ionization current } \\
\text { Correction of chamber air to } \\
\text { reference conditions } \\
\text { Absorbed dose rate to water at } \\
\text { a depth of } 7 \mathrm{mg} / \mathrm{cm}^{2} \mathrm{C} \\
\text { near sea level } \\
\text { at high altitude } \\
\text { Source Decay Correction }\end{array}$ & $\begin{array}{l}0.4 \\
0.4\end{array}$ & $\begin{array}{l}0.3 \\
0.3\end{array}$ & $\begin{array}{l}0.1 \\
0.1\end{array}$ & $\begin{array}{l}1.0 \\
0.1 \\
0.1\end{array}$ & $\begin{array}{l}0.2 \\
0.1 \\
0.1\end{array}$ \\
\hline
\end{tabular}

\begin{tabular}{|c|c|c|c|c|}
\hline Overall Uncertainties & $\begin{array}{l}14 \\
\text { near sea } \\
\text { level }\end{array}$ & $\begin{array}{l}7 \text { Pm } \\
\text { at high } \\
\text { altitude }\end{array}$ & $\begin{array}{l}204 \mathrm{Tl} \text { and } \\
\text { near sea } \\
\text { level }\end{array}$ & $\begin{array}{l}90 \mathrm{Sr}+90 \mathrm{y} \\
\text { at high } \\
\text { altitude }\end{array}$ \\
\hline $\begin{array}{l}\text { Combined uncertainty, } \% \text { d } \\
2 \text { times combined uncertainty, \%e } \\
3 \text { times combined uncertainty, \%e }\end{array}$ & $\begin{array}{l}2.5 \\
5 \\
8\end{array}$ & $\begin{array}{l}3.7 \\
8 \\
11\end{array}$ & $\begin{array}{l}1.4 \\
3 \\
4\end{array}$ & $\begin{array}{l}1.6 \\
3 \\
5\end{array}$ \\
\hline
\end{tabular}

${ }^{a}$ Conventional statistical estimates (standard deviations), obtained from repeated measurements.

${ }^{b}$ Subjective estimates (see text). A normal error distribution was assumed.

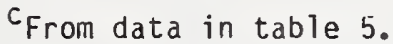

dTe square root of the sum of the squares of all the uncertainties.

e Rounded. 


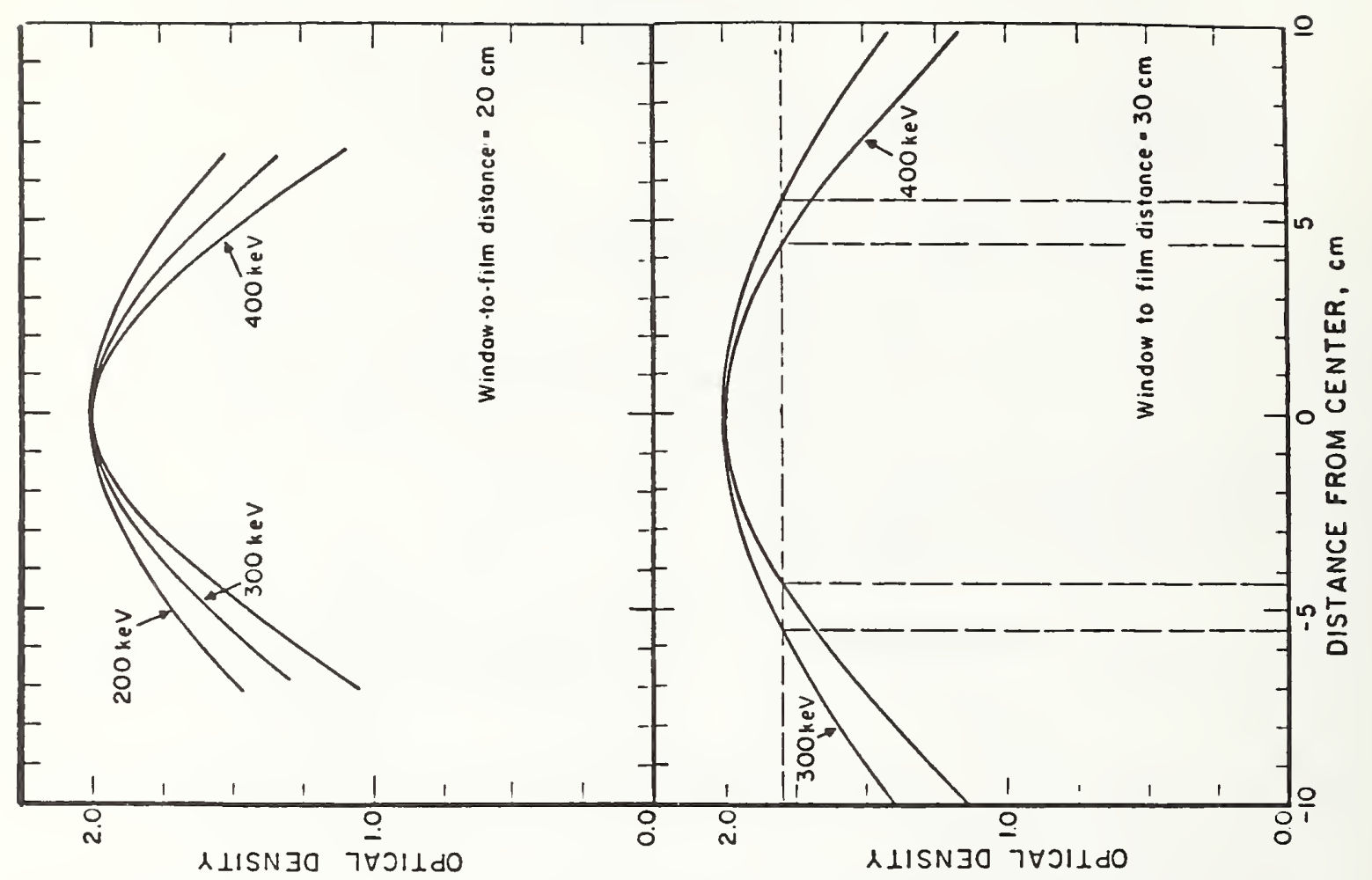

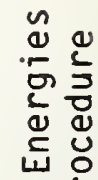

4 웅

뜬

잉

范

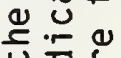

드을

仓를

틍 은

\&

๑过

동은엉

岁㟔

피든

రัه

둥ㅁㅇ

도음

등

s 0

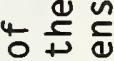

등

式里要

崩.

$\sim-\frac{u}{5}$

^ 융

$\therefore$ 든

告这

4 ○

$\stackrel{\otimes}{\Sigma}$

E. ज

4 능

돈

ए

등 을

ปั

कั n.

d 도

U.

$0+9$

0 눙

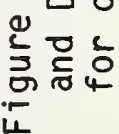


shown in the last column of the table correspond to a monitor counting rate of $10^{5}$ per second. At the time of writing (February 1988), representative values for $R$ and for minimum absorbed-dose levels are being obtained for the new monitor system. No assessment of uncertainties in possible future calibration procedures with the nearly monoenergetic electron beams is feasible before this work is completed.

\subsection{Determination of Spectral Composition of the Electron Beam}

The 5-mm deep silicon surface-barrier detector equipped with the 1.6-mm aperture lead collimator (see also section 4.4) was employed. Beam currents were limited so that count rates did not exceed $2000 \mathrm{~s}^{-1}$. Measurement procedures were similar to those employed for beta-particle spectrometry. Therefore, the same caveats expressed in section 4.4 about absolute spectral shapes apply here. The importance of making the exit windows (polyimide for the low energies, aluminum for the high energies) as thin as possible is brought out in figures 17 and 18 . Figure 19 shows the spectral distributions as a function of the distance between detector and exit window. At low electron energies, degradation in air is seen to be not negligible, but the spectra are still fairly narrow at distances at which the beam cross section is sufficiently large and uniform for the study of survey instruments. The most probable energies shown in these figures were used in column 4 of table 7 , relating these energies to accelerator potential, exit window-todetector distance, and usable field size.

Table 7. Examples of Pertinent Electron Beam Parameters Obtained Prior to Improvement in the Monitor System

\begin{tabular}{|c|c|c|c|c|c|}
\hline $\begin{array}{c}\text { Accelerator } \\
\text { Potential } \\
(k V)\end{array}$ & $\begin{array}{l}\text { Distance } \\
\text { From Window } \\
\qquad(\mathrm{cm})\end{array}$ & $\begin{array}{l}\text { Usable } \\
\text { Field Size } \\
\text { (cm) }\end{array}$ & $\begin{array}{c}\text { Most Probable } \\
\text { Electron Energy } \\
(\mathrm{keV})\end{array}$ & $\begin{array}{l}\text { Absorbed Dose } \\
\text { Minimum } \\
\text { Del i verable } \\
\text { in } 10 \mathrm{~s} \\
(\mu \mathrm{Gy})\end{array}$ & $\begin{array}{l}\text { to water } \\
\text { Maximum } \\
\text { Rate } \\
\text { (mGy } s^{-1} \text { ) }\end{array}$ \\
\hline 200 & 20 & 8.3 & 130 & 140 & 70 \\
\hline 300 & 30 & 11 & 220 & 30 & 15 \\
\hline 300 & 20 & 6.7 & 250 & 70 & 35 \\
\hline 400 & 30 & 8.7 & 340 & 90 & 45 \\
\hline 400 & 20 & 5.7 & 360 & 190 & 95 \\
\hline 1500 & 100 & 22 & 1280 & 13 & 7 \\
\hline 1500 & 50 & 8.9 & 1370 & 90 & 45 \\
\hline 2500 & 100 & 14 & 2230 & 60 & 30 \\
\hline 2500 & 50 & 5.7 & 2320 & 350 & 175 \\
\hline
\end{tabular}

${ }^{a}$ Defined as the diameter of the beam cross section over which flux density does not decrease by more than $10 \%$. 


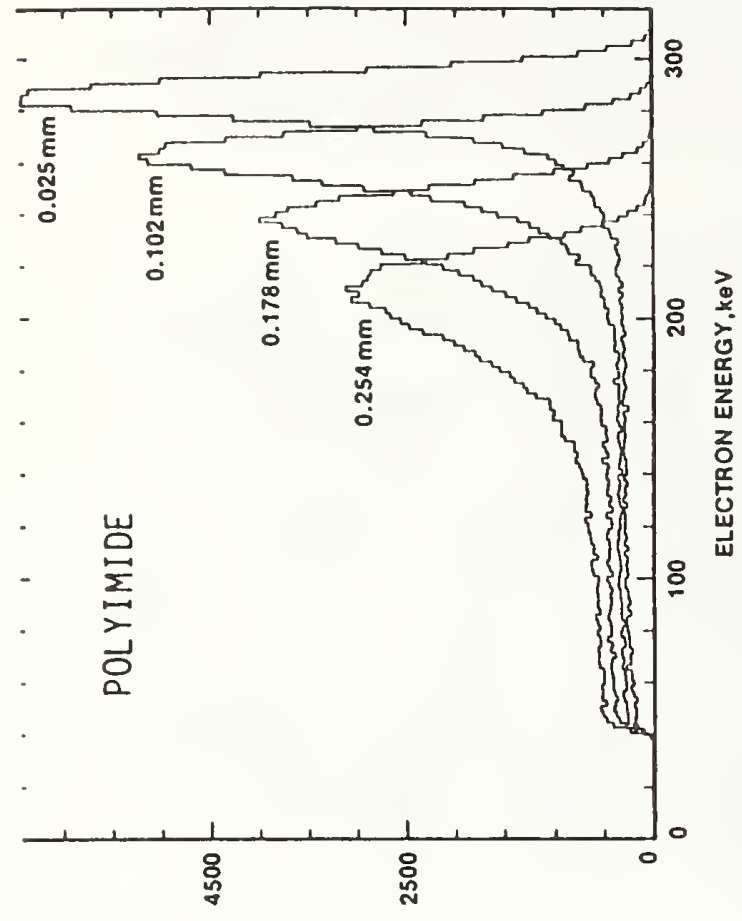

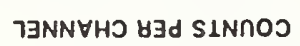

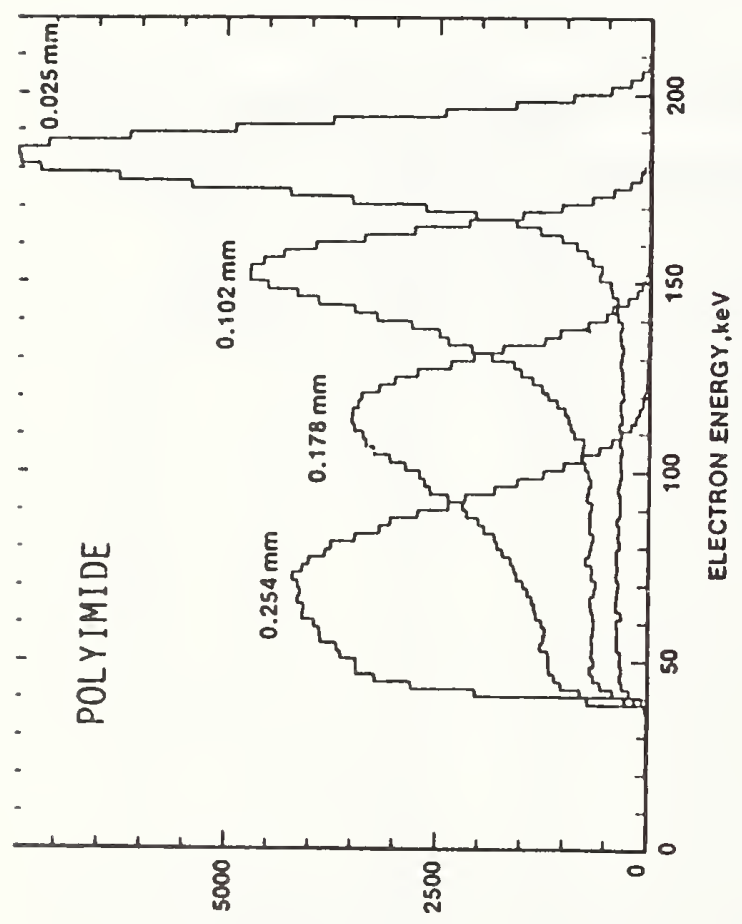

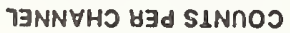

4

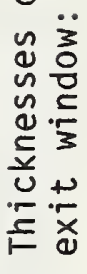

흔

(4)

40

○ بِ

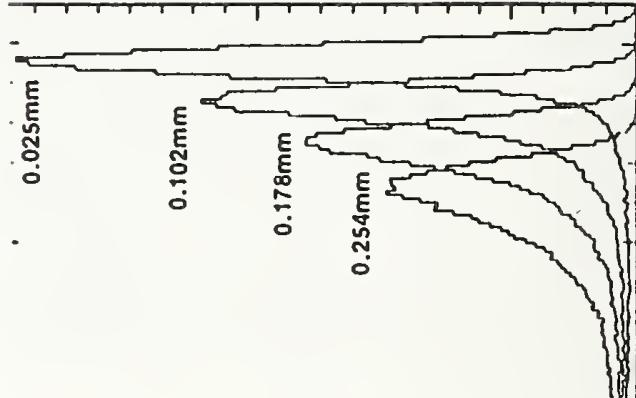

8

$=\stackrel{d}{0}$

동

بै.

II

유

ऐ)

辛

b.

80

:

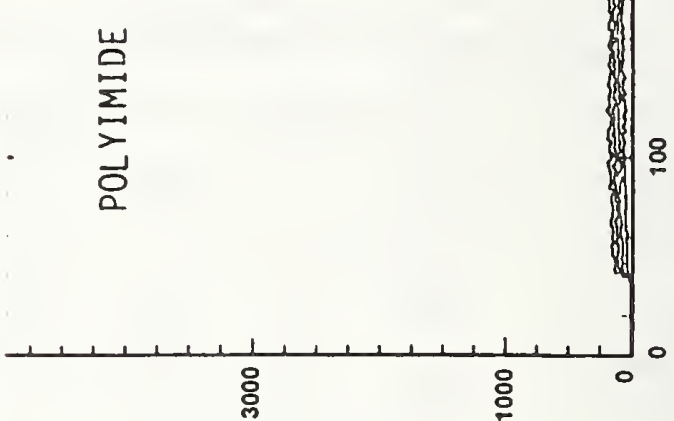

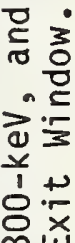

8

m

$>\frac{1}{0}>$

ब.

동ㅇ

응?

它

TヨNNVHO \&ヨd SINกOS

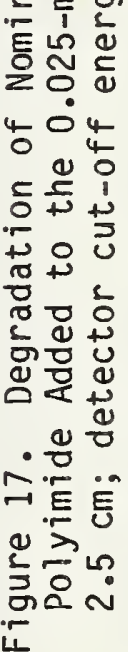



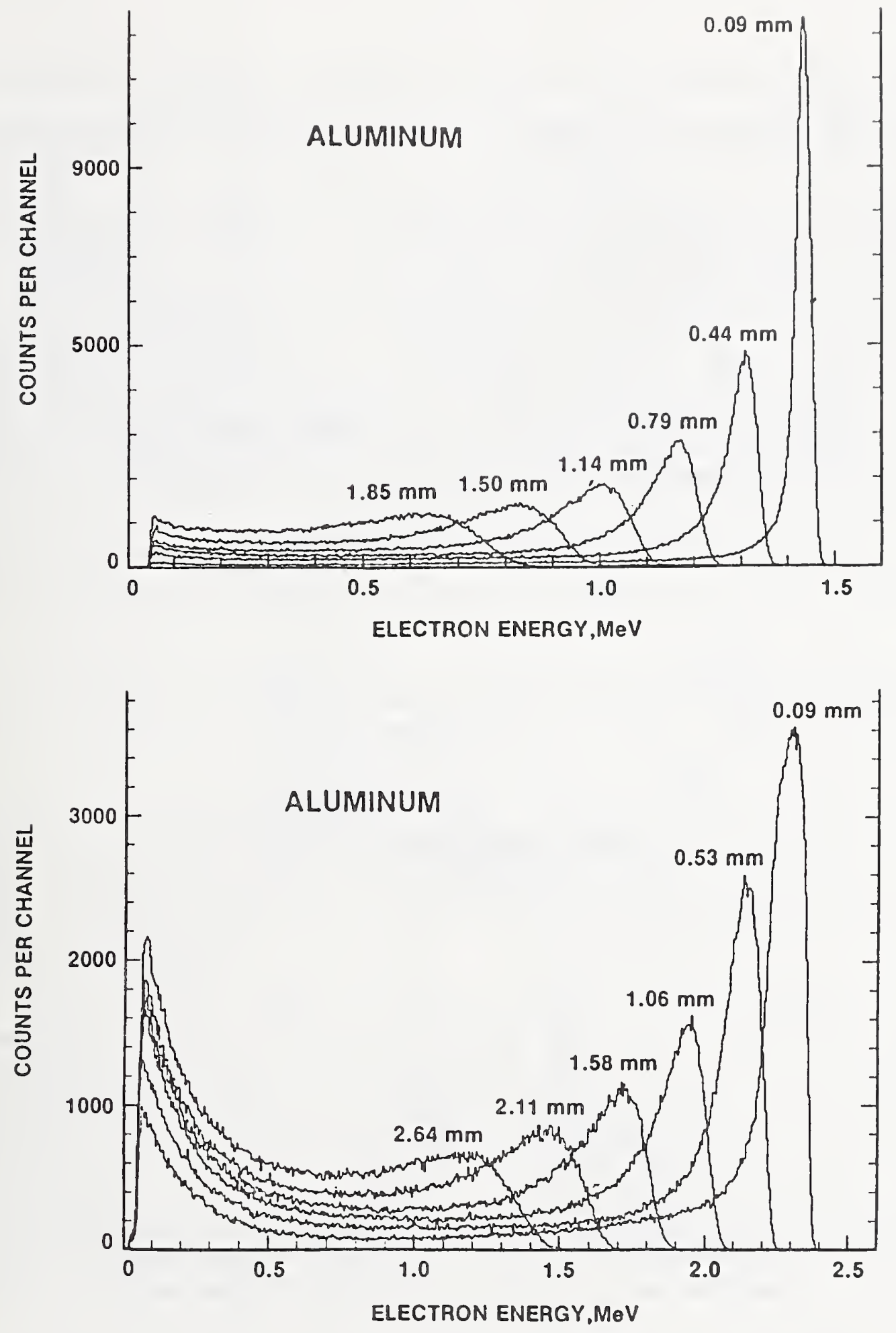

Figure 18. Degradation of Nominal 1.5-MeV and 2.5-MeV Electrons in Different Thicknesses of Aluminum Added to the 0.09-mm Aluminum Exit Window. Distance between detector and exit window: $2.0 \mathrm{~cm}$ for $1.5-\mathrm{MeV}$ electrons, $50 \mathrm{~cm}$ for 2.5-MeV electrons. 

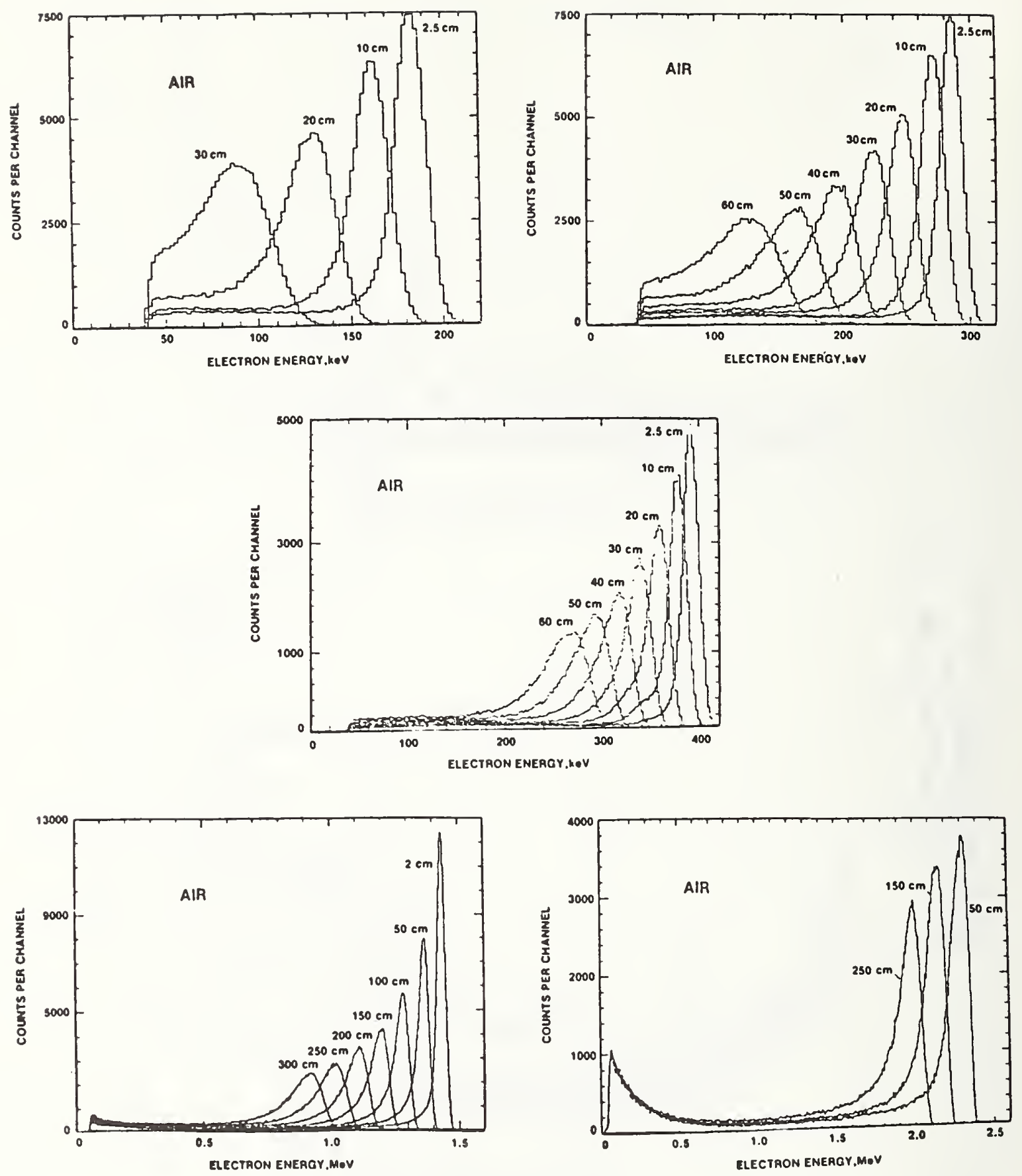

Figure 19. Degradation in Air of Nominal 200-keV to 2.5-MeV Electrons in Different Thicknesses of Intervening Air Layers. 
6. Examples of Practical Studies Performed with the Beta-Particle Beams

6.1 Compatibility of Different ${ }^{90} S r+90 Y$ Sources with Existing Standards

Since spectral characteristics of ${ }^{90} \mathrm{Sr}+90 \mathrm{Y}$ beta-particle sources may vary widely with source geometry, a certain degree of standardization of source construction is required if sources from different manufacturers are to be used successfully in programs for testing personnel-dosimeter performance. Three sets of criteria are described below, each designed to limit the spectral variations allowed for test purposes. The American National Standards Institute (ANSI N13.11, 1983) specifies a filtration thick enough $\left(\sim 100 \mathrm{mg} / \mathrm{cm}^{2}\right.$ ) to remove the ${ }^{90} \mathrm{Sr}$ component, but of a sufficient $7 \mathrm{y}$ low at omic number ( $<26)$ not to cause excessive bremsstrahlung production [14]. The International Organization for Standardization (ISO 6980) specifies a residual maximum energy ( $E_{\text {res }}$ ) of $>1.80 \mathrm{MeV}$ [15]. The Department of Energy (DOE/EH-0027) specifies the limits on absorption characteristics in PMMA of the beta-particle beam emitted by the source, requiring the ratio of absorbed-dose rates to PMMA at depths of $100 \mathrm{mg} / \mathrm{cm}^{2}$ and $7 \mathrm{mg} / \mathrm{cm}^{2}$ to be equal to $1.01 \pm 0.05$, and the corresponding ratio at $1000 \mathrm{mg} / \mathrm{cm}^{2}$ and $7 \mathrm{mg} / \mathrm{cm}^{2}$ to be less than $0.01[16]$.

The relatively high-activity ( $5 \mathrm{GBq}, 140 \mathrm{mCi})$ source used up to late 1985 by the National Voluntary Laboratory Accreditation Program (NVLAP) testing laboratory for dosimetry performance was built to ANSI specifications.

The source that is used in the Department of Energy Laboratory Accreditation Program (DOELAP) for testing dosimetry performance by DOE contract or laboratories was manufactured by Buchler-Amersham according to specifications given by members of the National Physical Laboratory in England, who also were instrumental in developing the standard for betadosimetry sources of the ISO. It is of the same type and geometry as the sources owned by NBS.

At the time this matter was studied (1984), it was considered of interest to compare the DOELAP source and the source then used for NVLAP testing, employing the different criteria. In this comparison, we also included an experimental source produced by Amersham to meet the ANSI specifications but designed to have less internal scattering than the NVLAP source. (As a consequence, its activity is too low for convenient use as a calibration source.) Table 8 shows the results of this comparison. Also shown is some pertinent information on source construction. Only the experimental Amersham source is seen to meet all three criteria. The DOELAP source does not meet the ANSI criterion since it contains silver. The NVLAP source does not meet the ISO criterion, because the residual energy is too small.

Further elucidation of these results is possible if one examines the response-versus-depth curves on which the DOE criterion is based (fig. 20) and the associated pulse-height distributions (figs. 21 through 23) which give equivalent information but can be obtained with less effort than attenuation curves. They show that the experimental Amersham source indeed has the most energetic spectrum and that the present NVLAP source is degraded most. They also reveal that (a) an operational criterion of the DOE or ISO type may be better suited for obtaining desirable source characteristics than a criterion of the ANSI type, which specifies material properties and dimensions; and 


\begin{tabular}{|c|c|c|c|c|c|c|c|}
\hline $\begin{array}{l}4 \\
0 \\
0 \\
0 \\
0 \\
0 \\
0\end{array}$ & 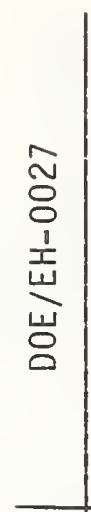 & 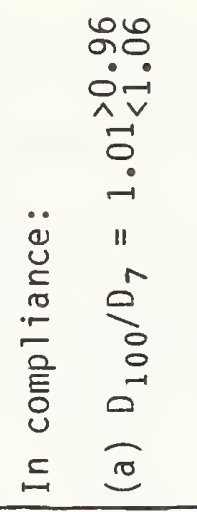 & $\begin{array}{l}\overrightarrow{0} \\
\dot{0} \\
\dot{r} \\
0 \\
\vdots \\
\vdots \\
0 \\
0 \\
\text { a }\end{array}$ & 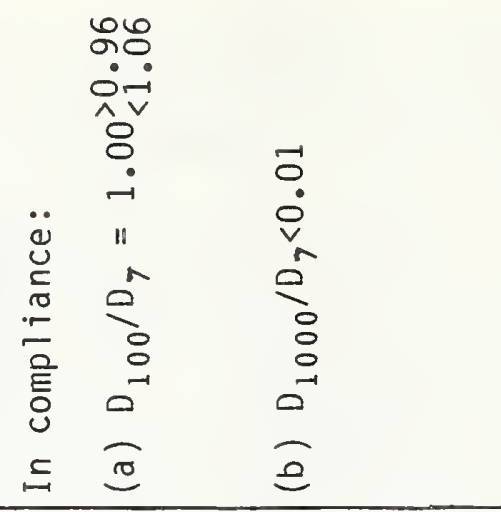 & & 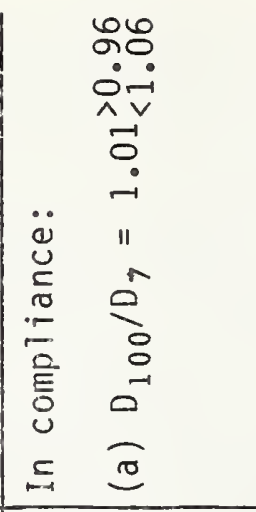 & $\begin{array}{l}0 \\
0 \\
0 \\
0\end{array}$ \\
\hline 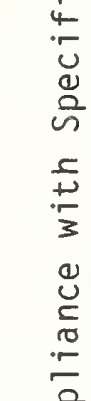 & $\begin{array}{l}\circ \\
0 \\
0 \\
0 \\
\text { O }\end{array}$ & 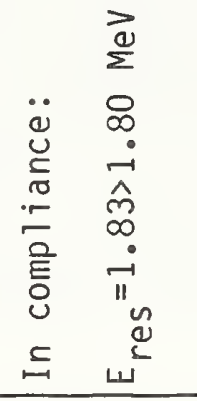 & & 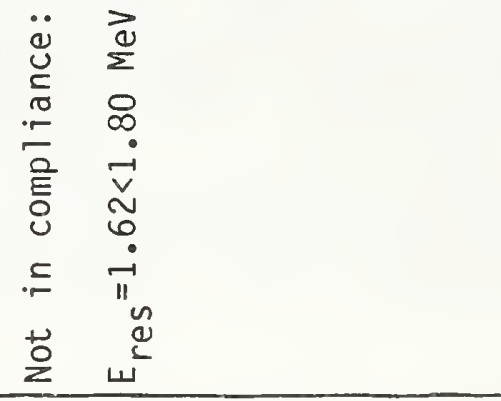 & & 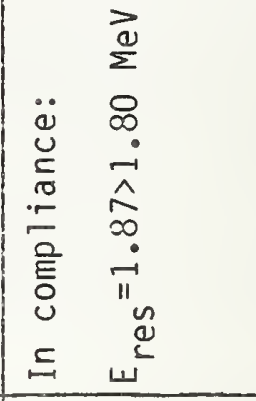 & \\
\hline 言 & 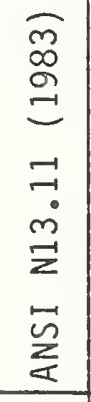 & 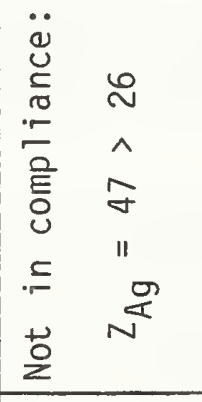 & & 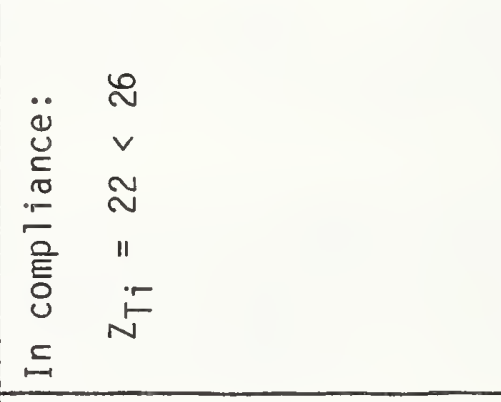 & & 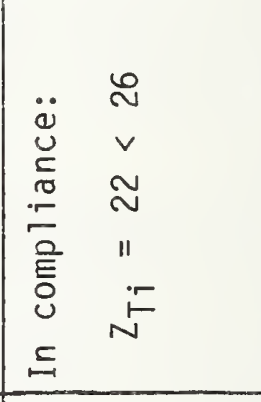 & \\
\hline 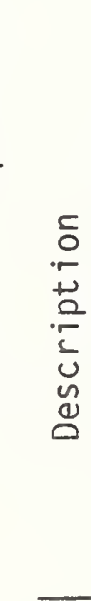 & & 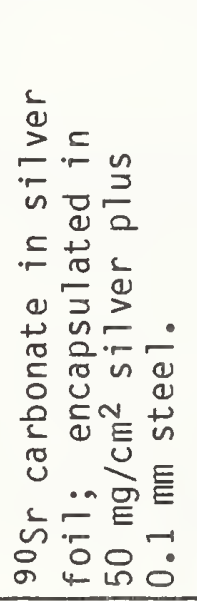 & 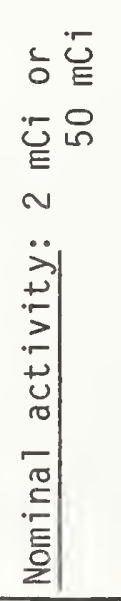 & 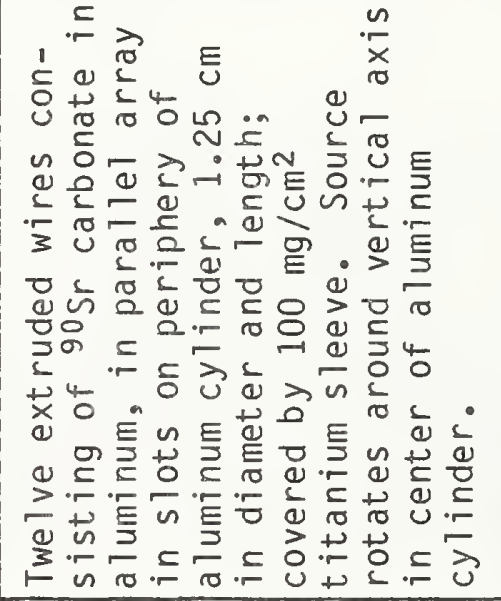 & 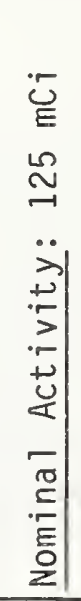 & 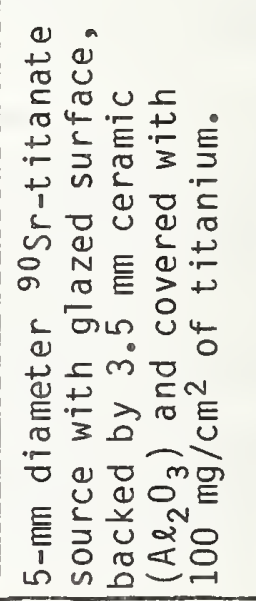 & 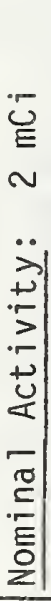 \\
\hline $\begin{array}{l}\mathscr{y} \\
\text { 今े }\end{array}$ & & 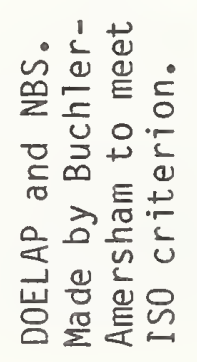 & & 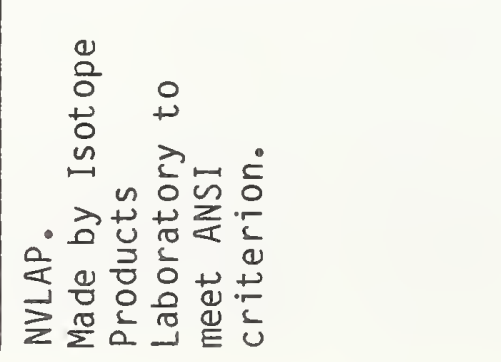 & & 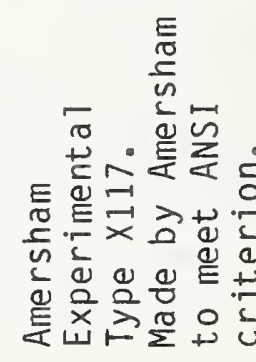 & \\
\hline
\end{tabular}




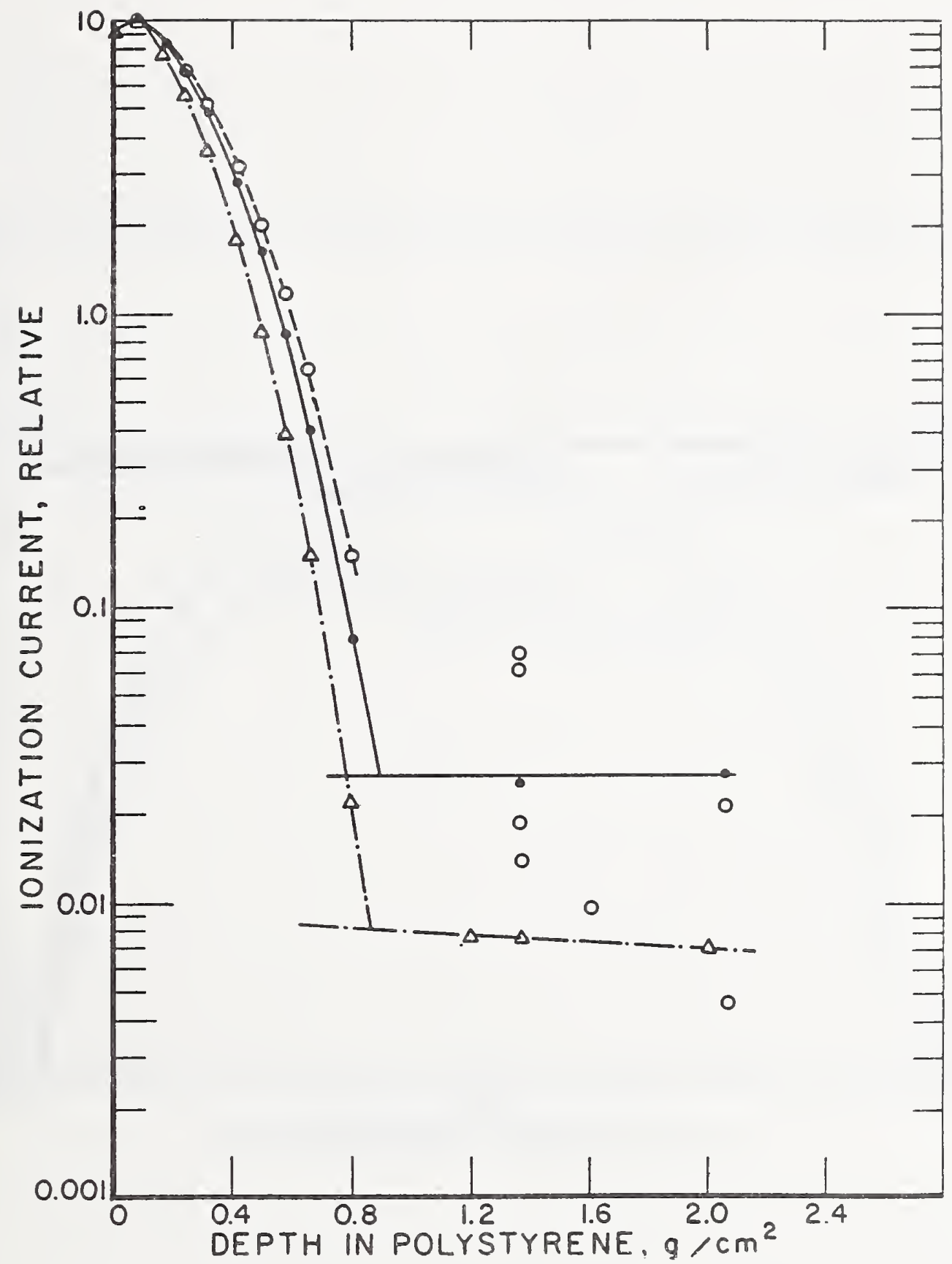

Figure 20. Ionization-versus-Depth Curves for Three Different types of $90 \mathrm{Sr}+90 \mathrm{y}$ Sources. Solid line: Buchler-Amersham source; dashed line: Amersham experimental source; dash-dotted line: special high-activity source used by the NVLAP Testing Laboratory unt $i 1$ 1985. The curves in PMMA are indistinguishable from those in polystyrene. No line could be drawn for the bremsstrahlung background of the Amersham experimental source because of the wide scatter of the associated data points (some of them off-scale, representing relative ionization currents $<0.001$ ). This behavior probably was due to the erratic high background noise introduced in the ionization chamber by a preceding irradiation in a high-intensity electron beam. 


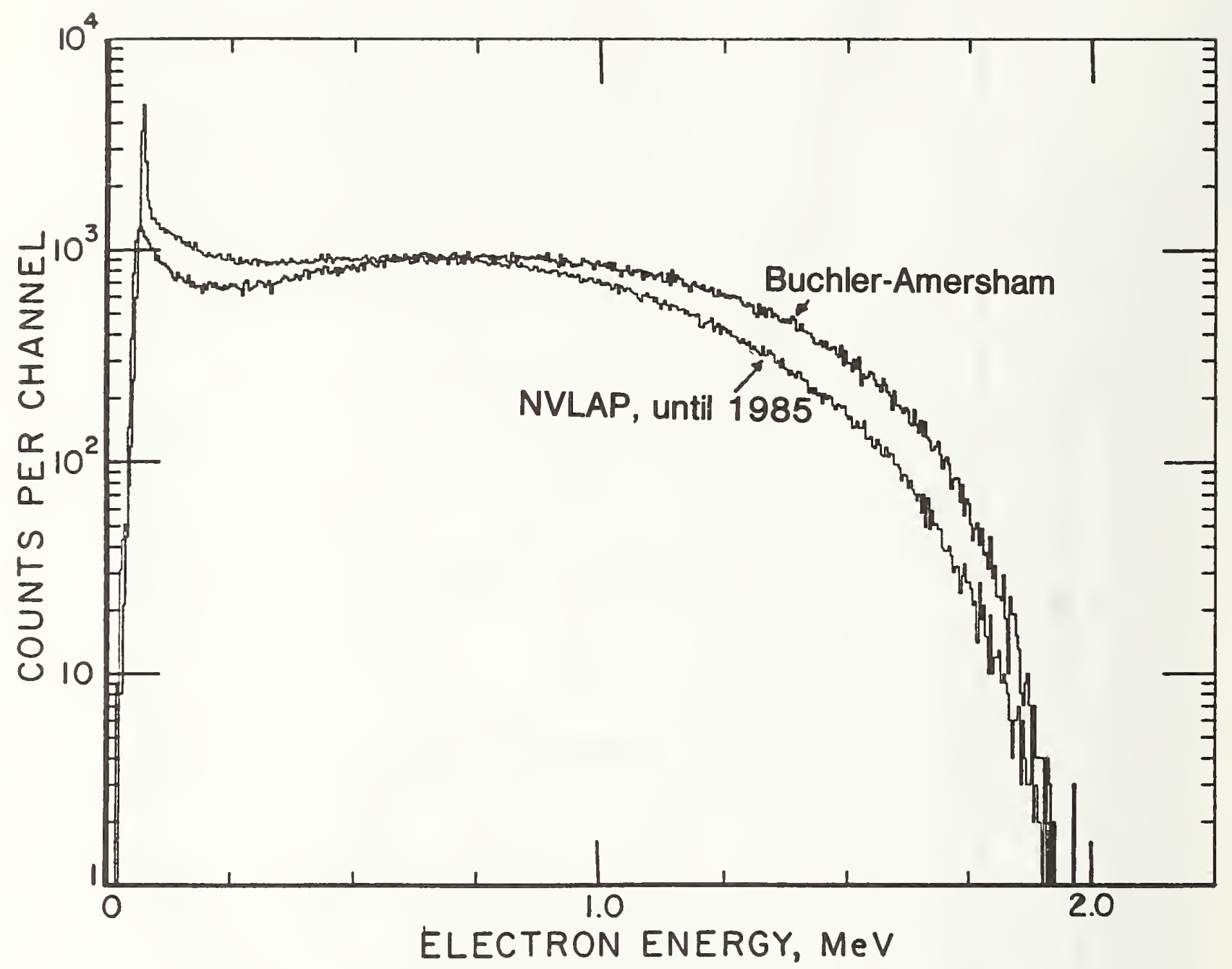

Figure 21. Comparison of Spectrum of the Buchler-Amersham and the NVLAP Testing Laboratory's $90 \mathrm{Sr}+90 \mathrm{Y}$ Sources, on Semi-Logarithmic Scale. The ordinates were adjusted for equal total number of counts. 


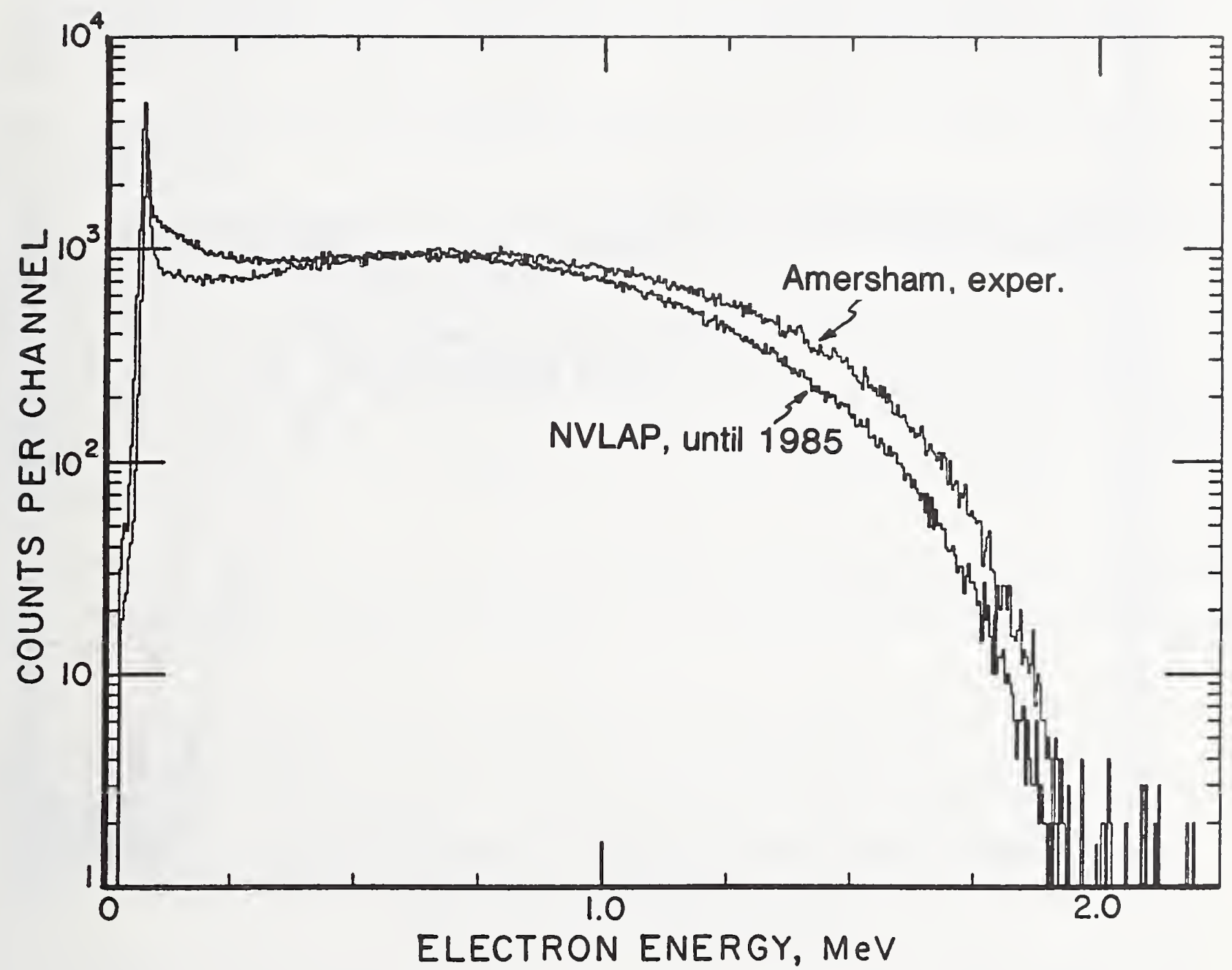

Figure 22. Comparison of Spectrum of the Amersham Experimental and the NVLAP Testing Labortory's ${ }^{90} \mathrm{Sr}+90 \mathrm{Y}$ Sources, on Semi-Logarithmic Scale. The ordinates were adjusted for equal total number of counts. 


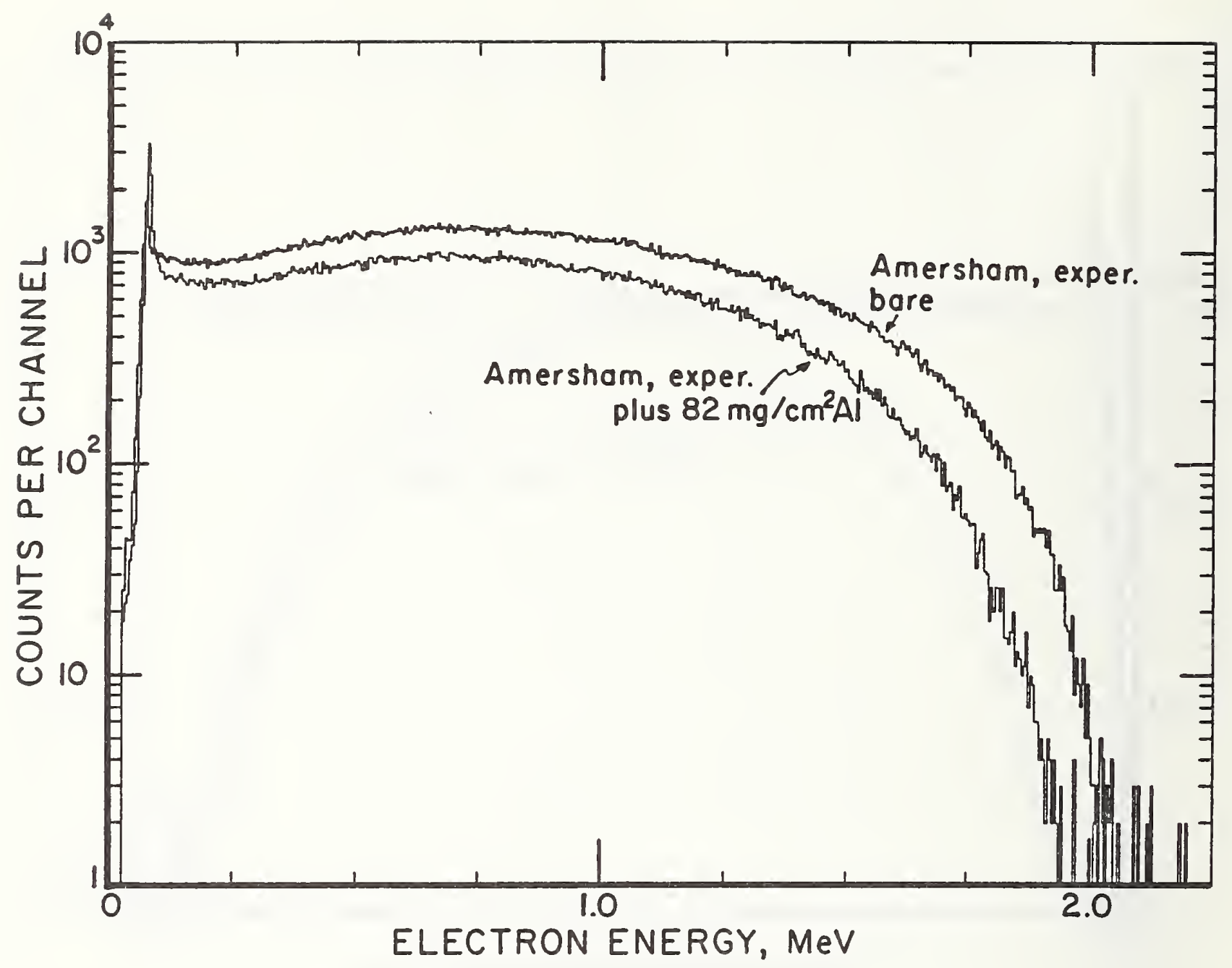

Figure 23. Comparison of Spectrum of Amersham Experimental ${ }^{90} \mathrm{Sr}+90 \mathrm{y}$ Source, Bare and Shielded. Adding $82 \mathrm{mg} / \mathrm{cm}^{2}$ of aluminum to the Amersham experimental source makes its spectrum similar to that of the Buchler-Amersham source (fig. 21). 
(b) that the DOE criterion is too loose, since it does not discriminate between the operationally very different NVLAP and Amersham experimental sources, while the ISO criterion does. The high background noise shown in figure 20 for the experimental Amersham source resulted from the use of the extrapolation chamber after it had been irradiated with an electron beam producing an absorbed-dose rate to water of the order of kilorads per second. This alerts one to the need for special care in the use of such a chamber.

\subsection{Comparison of $204 \mathrm{Tl}$ and ${ }^{90} \mathrm{Sr}+90 \mathrm{Y}$ Source Calibrations at NBS and at a DOE Laboratory}

This study was undertaken because the DOE requires traceability to NBS of a 11 measurement standards used in the DOELAP program for testing personneldosimetry performance. The calibrations of the transfer ionization chamber in the ${ }^{90} \mathrm{Sr}+90 \mathrm{Y}$ beams were found to agree to within 1 percent, while the calibration by the staff of the DOE laboratory in their $204 T 1$ beam proved higher by almost 8 percent than that by NBS in the NBS beam. Test Report DG 8555/86 covering these results is reproduced in Appendix 3. The study also confirmed that, in spite of its thin entrance window, the PTW ionization chamber number 2047 is sufficiently rugged to be used as a transfer instrument. (See also sec. 2.5).

7. Examples of Studies Performed with the Nearly Monoenergetic Electron Beams

7.1 Predicting Beta-Particle Response of Instruments from Response to Nearly Monoenergetic Electrons

This study was considered important since its results are intimately related to an assessment of the role of the nearly monoenergetic electron beams in a contemplated type-testing program for beta-particle survey instruments. In spite of the relatively poor reproducibility of the electron-beam dosimetry prior to improvements in beam stabilization and monitoring, the results were encouraging. They are covered in a recent publication [11], which is incorporated in this Document as Appendix 5.

\subsection{A Study of Rate Dependence of the Response of Radiation-Protection Survey Meters}

At the time of writing (February 1988), C. G. Soares is studying the response to nearly monoenergetic electrons of beta-particle survey meters over a wide range of electron currents [17]. The accelerator-produced electrons lend themselves well to this type of work because currents (and therefore absorbed-dose rates) can be readily changed without a change in irradiation geometry and thus in electron spectrum. This is not the case with betaparticle beams.

An example of an instrument being studied is the Eberline Ion Chamber Type Survey Meter R0-2A, SN 953, which is used in the field for photon and beta-particle surveys. In an earlier study [18], some rate dependence of its phot on response had been demonstrated. Soares finds that, in the range from about $5 \mathrm{mGy} / \mathrm{h}$ to $2 \mathrm{~Gy} / \mathrm{h}$ of absorbed-dose rate to water, the decrease in the response of the instrument with increasing dose rate is more than twice as 
large with $350-k e V$ electrons as with ${ }^{137}$ Cs gamma radiation. "Response" here is defined as scale reading (indication) of the instrument divided by absorbed-dose rate.

7.3 Role of Nearly Monoenergetic Electron Sources in the Development of a New Generation of Survey Meters

During the past several years, instrument designers have given thought to avoiding the difficulties in beta-particle surveys arising from the strong energy dependence of survey-meter response. Instruments are now under development that incorporate tissue-equivalent scintillation detectors and associated multi-channel analyzers for spectrometry, and microprocessors for data analysis. Monoenergetic electron beams over wide ranges of energy are required in the development of such instruments (a) for arriving at resolution and efficiency functions of the detector, needed for spectral unfolding of the pulse-height distributions, and (b) for obtaining instrument-response functions needed to develop suitable algorithms that lead to instrument indication in terms of absorbed-dose rate, independent of electron energy. We have assisted groups from both Los Alamos National Laboratory and from EG\&G Idaho, Inc., with such instrument developments. Excerpts of pertinent publications by members of these institutions $[19,20]$ are incorporated in this Document as Appendix 6.

\section{Safety Considerations}

It is likely that many of the procedures associated with the calibration service for which this facility was established will be carried out by junior personnel, who may start without previous experience in radiation work. The senior staff member in charge of the facility must take all steps necessary to ensure that each person working with this facility is thoroughly familiar with the pertinent radiation protection literature, and is aware of the potential hazards, the importance of the safety features built into the facility, the procedures to follow for safe operation, how to detect potentially dangerous malfunctioning of any part of the system, and what steps to take in case of an accident.

\subsection{Radiation Hazards}

All sources arriving at NBS, and periodically all sources kept at NBS, are examined by a member of the NBS Health Physics Group for radioactive surface contamination, including shipping and storage containers. This is considered to remove the hazard of ingestion of or other body contamination by radioactive materials. 
The radiation hazard is only moderate for sources with the activity level that will be calibrated in the facility in question, since even a direct exposure of the skin for a brief time would not be serious, with the possible exception of the eyes. However direct exposure will never be necessary, since protection from a beta-particle source is readily provided by materials such as a few millimeters of plastic, or by simply directing the source away from the body. Handling tools are provided for removing the source capsules from their storage containers and placing them on the irradiation stand, without exposure of any part of the operator's body to a significant fraction of the maximum permissible exposure. A survey meter is on hand for checking radiation levels' whenever there is any doubt about when a faulty procedure or faulty equipment has created a potential radiation hazard. This could be the case, for example, if the shutter failed to close at the electrical command.

Light beams are used to establish a safety perimeter around the measurement area, such that breaking a beam causes the shutter to close. Such a safety device could be defeated by simply crawling under the beam, so the cooperation of all personnel is required to make the device effective, and it becomes particularly important to instruct all personnel in the radiation hazards involved.

If a source is involved in an accident, e.g., if a source is dropped during transfer, the NBS Health Physics Group will be notified, and they will test the source and the area involved for radioactive contamination.

\subsection{Electrical Hazards}

The electrical hazards are of the same type as in other dosimetry laboratories, and require the same level of skill. Since the collecting voltage used on the beta-particle ionization chambers is never more than one hundred volts, this hazard is somewhat less than with other ionometric procedures. As in other dosimetry laboratories, it is essential to verify all power-supply settings before applying the voltage to the ionization chamber, and to avoid contact with the off-ground exposed part of an ionization chamber.

\subsection{The Nearly Monoenergetic Electron Facility}

This facility, described in section 3.2, can involve high-energy, highintensity beam operation, and may present greater radiation hazard than any mentioned above. The facility is not involved in the calibration service described here, but has been limited to research on and development of betaparticle calibration services. If in the future it becomes desirable to employ accelerator-produced electrons in routine calibrations, a manual of safe operation procedures will be drawn up and made available to all operators. 
9. References

[1] Mante1, J. The beta ray spectrum and the average beta energy of several isotopes of interest in medicine and biology. Int. J. Appl. Radiat. Is ot opes. 23, 407-413 (1972).

[2] Cross, W. G.; Ing, H.; Freedman, N. A short at las of beta-ray spectra. Phys. Med. Biol. 28, 1251-1260 (1983).

[3] Boehm, J. Standardization and calibration in beta dosimetry. Proceedings of the International Beta Dosimetry Symposium; 1983 February; Washington, D.C., U.S. Nuclear Regulatory Commission NUREG/CP-0050, 73-97, 1984 .

[4] Tabata, I.; Ito, R.; Okabe, S. An Empirical Equation for the Backscattering Coefficient of Electrons. Nucl. Inst. Meth. 94, 509 (1971).

[5] Boehm, J. The perturbation correction factor of ionization chambers in B-radiation fields. Phys. Med. Biol. 25, 65-75 (1980).

[6] Boehm, J. Saturation corrections for plane-parallel ionization chambers. Phys. Med. Biol. 21, 754-759 (1976).

[7] Burlin, T. E. Cavity chamber theory; Chapter 8, Radiation Dosimetry, Volume 1, Fundamentals; Second Edition; F. H. Attix and W. C. Roesch, editors. Academic Press; 1968.

[8] Pruitt, J. S. The effect of altitude on beta-ray source calibrations. Rad. Prot. Dosim. 11, 151-157 (1985).

[9] Soares, C. G; Dick, C. E.; Pruitt, J. S.; Sparrow, J. H. Development of monoenergetic electron beam sources for radiation instrument calibration. Nucl. Inst. Meth. Phys. Research; Section B: Beam Interactions with Materials and Atoms 10/11, 937-941 (1985).

[10] Ehrlich, M.; Pruitt, J. S.; Soares, C. G. et al. Standard beta-particle and monoenergetic electron sources for the calibration of beta-radiation protection instrumentation. NUREG/CR-4266, U.S. Nuclear Regulatory Commission, Washington, D.C. 20555; also as NBSIR 85-3169, U.S. Department of Commerce, Gaithersburg, MD. 20899; 1985.

[11] Soares, C. G. Predicting beta particle response of instruments from their response to monoenergetic electrons. Rad. Prot. Dosim. 14, 113-115 (1986).

[12] A handbook of radioactivity measurements procedures. National Council on Radiation Protection and Measurements. NCRP Report No. 58, 1978.

[13] See, e.g., Giacomo, P. Meeting of experts on the subject of expression of uncertainties, in News from the BIPM. Metrologia 17, 69-74 (1981). 
[14] American National Standard for dosimetry - personnel dosimetry performance - criteria for testing. Am. Nat. Standards Institute ANSI N13.11-1983.

[15] Reference beta radiations for calibrating dosimeters and dose-rate meters and for determining their response as a function of beta radiation energy. International Organization for Standardization. ISO 6980, 1984 .

[16] Standard for the performance testing of personnel dosimetry systems, DOE/EH-0027. Department of Energy; Washington, D.C., 1986.

[17] Soares, C. G. Unpublished data.

[18] Colle, R.; et al. Characterization of Survey Instruments; in Quality Assurance for Measurements of Ionizing Radiation, Eisenhower, E. H. editor; NUREG/CR-3775; U.S. Nuclear Regulatory Commission, Washington, D.C. 20555,1984 .

[19] Erkkila, B. H.; Brake, R. J.; and Waechter, D. A. Los Alamos Portable beta-ray spectrometer. Proceedings of the International Beta Dosimetry Symposium; 1983 February 15-18; Washington, D.C., U.S. Nuclear Regulatory Commission NUREG/CP-0050, 1984 .

[20] Martz, D. E.; Rich, B. L.; Johnson, L. 0.; David, S. H. III. Field tests of a portable tissue equivalent survey meter for monitoring mixed beta/gamma radiation fields. Idaho National Engineering Laboratory; NUREG/CR-4553; EGG-2448. EG\&G Idaho, Inc.; Idaho Falls, ID 83415; 1986. 
Appendix 1. Sample of Calibration Report Form (See sec.1.3)

DG $8751 / 87$

DB $873 / 170$

TFN 240032

1987 Sep 14
U. S. DEPARTMENT OF COMRERCE NATIONAL BUREAU OF STANDARDS GAITHERSBURG, MD 20899

Page 1 of 2

\section{REPORT OF TEST}

$0.5 \mathrm{mCi}{ }^{204} \mathrm{Tl}$ Beta-Particle Source

Amersham-Buchler Source \#-RS \#87-0068

Submitted by

Received:

1987 Jul 21

Calibrated: 1987 Aug 03

Beta-particle sources are calibrated in terms of the absorbed-dose rate to water. Absorbed-dose rate is determined from current measurements with an extrapolation ionization chamber that has a polymethylmethacrylate collecting electrode. The water absorbed-dose rate is given in SI units by:

$$
D=(W / e)\left(S_{w a t e r} / S_{a i r}\right)\left(\rho_{a 1 r} A\right)^{-1}\left(d_{i} \text { orr } / d s\right) \quad G y / s
$$

where $(\mathrm{W} / \mathrm{e})=33.7 \mathrm{~J} / \mathrm{C}$ is the mean energy expended per unit charge in ambient air, $\left(\mathrm{S}_{\text {water }} / \mathrm{S}_{\mathrm{alr}_{\mathrm{r}}}\right)$ is the ratio of the mean mass stopping power of water to that of air, $\rho_{\mathrm{arr}}=1.197 \mathrm{~kg} / \mathrm{m}^{3}$ is the density of air at the reference temperature and pressure $\left(22^{\circ} \mathrm{C}\right.$ and 1 standard atmosphere), $A=$ $7.083 \times 10^{-4} \mathrm{~m}^{2}$ is the area of the collecting electrode, $\mathrm{di}_{\mathrm{corr}} / \mathrm{ds}$ is the rate-of-change of corrected current with air-gap spacing in amperes per meter.

The corrected current is given by:

$$
i_{\text {corr }}=i f_{\text {TP }} f_{\text {side }} f_{b a c k} f_{\text {recom }} f_{\text {atten }} f_{\text {phot }} f_{d i v} k_{d e c a y} k_{h u m i d} k_{m a s s}
$$

where $i$ is the measured current and the $f^{\prime} s$ are, respectively, corrections for air density variations inside the chamber, for scatter from and/or shielding by the side walls of the chamber, for excess backscatter from the collection electrode, for recombination and diffusion of ions inside the chamber, for attenuation by the chamber air, for the presence of photons accompanying the beta particles, and for beta-particle beam divergence; and the $\mathrm{k}^{\prime} \mathrm{s}$ are, respectively, correction factors for source decay to the listed calibration date, for humidity variations, and for variations in the mass of air between source and chamber.

For the source submitted, one calibration was made. The rate of change of corrected current with air-gap thickness was determined from measurements with air-gap thicknesses of $0.5,1.0,1.5,2.0$, and $2.5 \mathrm{~mm}$. The water absorbed-dose rate is given in the table in SI units (grays per second). The tabulated dose rate applies to the date of calibration, to the sourcephantom distance and phantom depth given in the table, and to the reference 
temperature and pressure of $22^{\circ} \mathrm{C}$ and $101.325 \mathrm{kPa}$ (1 standard atmosphere). If the air density differs significantly from the density at the reference temperature and pressure, it may be necessary to apply a correction as given in: J.S. Pruitt, "The effect of altitude on beta-ray source calibrations," Radiation Protection Dosimetry 11, 151-157 (1985).

The $f$ factors associated with the extrapolation chamber, and the $k$ factors associated with the ambient conditions, are given in the table in the same order that they are listed in the above equations; if a factor varied during the measurements, the maximum and minimum values are given.

The overall uncertainty in this calibration is estimated to be $\pm 3 \%$; it is considered to have the approximate significance of a 958 confidence limit. The overall uncertainty is two times the square root of the quadratic sum of the component uncertainties, which were estimated and treated as if they were standard deviations.

Information on the technical aspects of this report can be obtained from J. S. Pruitt, Radiation Physics C214, National Bureau of Standards, Gaithersburg, Maryland 20899, (301) 975-5587.

Calibration performed by J. S. Pruitt $45 F$

Report approved by $\mathrm{R}$. Loevinger

For the Director

by

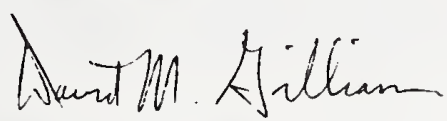

David M. Gilliam, Associate Chief Ionizing Radiation Division Center for Radiation Research National Measurement Laboratory

\begin{tabular}{|c|c|c|c|c|c|c|}
\hline Source & $S_{w a t e r} / S_{a i r}$ & $\begin{array}{c}\text { Correction } \\
\mathrm{k}\end{array}$ & $\begin{array}{c}\text { Factors } \\
\mathrm{f}\end{array}$ & $\begin{array}{c}\text { Phantom } \\
\text { Distance } \\
(\mathrm{cm})\end{array}$ & $\begin{array}{l}\text { Phantom } \\
\text { Depth } \\
\left(\mathrm{mg} / \mathrm{cm}^{2}\right)\end{array}$ & $\begin{array}{c}\text { Water } \\
\text { Absorbed-Dose } \\
\text { Rate } \\
(\mathrm{Gy} / \mathrm{s})\end{array}$ \\
\hline $\begin{array}{l}0.5 \mathrm{mCi} \\
204 \mathrm{Tl}\end{array}$ & 1.132 & $\begin{array}{l}1.00 \\
1.00 \\
1.00\end{array}$ & $\begin{array}{c}1.01-1.03 \\
1.00 \\
1.01 \\
1.00 \\
1.00 \\
1.00 \\
1.00-1.01\end{array}$ & 30 & 7 & $1.82 \mathrm{E}-7$ \\
\hline
\end{tabular}


The calibration at this laboratory of the Buchler ${ }^{147} \mathrm{Pm}$ source is considered important because its results provide a test of the validity of the recently developed high-altitude air-density correction factor. (See section 2.4 .3 .3 .)

1985 Jan 10

\author{
U.S. DEPARTMENT OF COMMERCE \\ NATIONAL BUREAU OF STANDARDS \\ GAITHERSBURG, MD 20899 \\ REPORT OF \\ TRIP TO IDAHO NATIONAL ENGINEERING LABORATORY \\ by \\ John S. Pruitt \\ Dosimetry Group \\ Center for Radiation Research
}

\title{
Introduction
}

In November, 1984, I traveled to the Idaho National Engineering Laboratory (INEL) with several objectives. The primary objective was to provide traceability to the National Bureau of Standards (NBS) for beta-particle dosimetry, and this objective was met by performing (1) a calibration of their electrometer used for ionization chamber current measurements. Secondary objectives were (2) to calibrate a 200-MBq (5-mCi) thallium-204 source, recently purchased from the University of Lowell, and (3) to calibrate a promethium-147 source purchased in 1980 from Buchler in West Germany. Calibration (2) was a service for INEL employees, and calibration (3) was an indirect comparison with the original PTB calibration, by way of my own measurements of the effect of altitude on beta-particle calibrations. The INEL is located on the Snake River plain at an altitude of about $1500 \mathrm{~m}$ (4900 ft.) above sea-level.

\section{(1) Electrometer Calibration}

The electrometer calibration was performed with the University of Lowell thallium204 source irradiating the INEL extrapolation chamber purchased from Nuclear Associates. For a fixed source distance of $300 \mathrm{~mm}$, a fixed air gap setting of 2.5 $\mathrm{mm}$, and a fixed chamber potential of \pm 25 volts, the chamber current was measured in two ways. Measurement A consisted of the digital readout of the Keithley 642 electrometer to be calibrated, used in the "Charge" mode, divided by the irradiation time. Measurement B used the Keithley 642 in the "External Feedback" mode, with a calibrated 100-pF General Radio capacitor as the feedback element, and the feedback voltage measured with a calibrated digital voltmeter (DVM). The results are:

(A) Indicated current $=\left(\frac{1.1640-(-1.2370)}{2}\right) \times \frac{10^{-11}}{100}=0.12005 \mathrm{pA}$

where 1.1640 and -1.2370 are averaged Keithley 642 readings for opposite chamber potential polarities, on the $10^{-11}$ coulomb scale, and 100 is the irradiation time in seconds. In addition:

(B) Measured current $=0.9987\left(\frac{0.05848-(-0.06168)}{2}\right) \times \frac{100.17 \times 10^{-12}}{50}=0.12021 \mathrm{pA}$ 
where 0.05848 and -0.06168 are averaged DVM readings for opposite chamber potential polarities, 0.9987 is the DVM calibration factor, $100.17 \times 10^{-12}$ is the capacitance of the 100-pF capacitor in farads, and 50 is the irradiation time in seconds.

These data show that the Keithley 642 readings in the "Charge" mode should be multiplied by the factor:

\section{$\frac{\text { Measured }}{\text { Indicated }}$ current $=1.001 \pm 0.002$}

where 0.002 is the standard deviation of the measurements.

(2) Thallium source calibration

The University of Lowell thallium-204 source was calibrated with the INEL extrapolation chamber, using 50-second runs, a fixed source distance of $300 \mathrm{~mm}$, and several different air-gap settings and chamber potentials. Current measurements were made using system B, described in section (1), with the calibrated capacitance and DVM. The currents were calculated with the formula:

$$
I=\frac{0.9987 \times 100.17 \times 10^{-12}}{50}\left(\frac{V^{+}-V^{-}}{2}\right)\left(f_{T} f_{S} f_{R}\right) A
$$

similar to equation (B) in section (1) except for the inclusion of three correction factors: $f_{T}$ corrects the chamber air to a reference temperature and pressure, chosen in this case to be $22^{\circ} \mathrm{C}$ and $635 \mathrm{mmHg}$; $\mathrm{fs}_{\mathrm{s}}$ is a perturbation correction to account for the presence of the chamber (taken from J. Bohm, Physics in Medicine and Biology 25, 65 (1980)); $f_{R}$ is a correction for ion recombination and diffusion inside the chamber (taken from J. Bohm, Physics in Medicine and Biology, 21, 754 (1976)). $V^{+}$and $V^{-}$are averaged DVM readings measured with positive and negative chamber potential respectively. The data used are:

d, $\mathrm{mm}$

\begin{tabular}{c|ccccc}
\cline { 2 - 6 } & 2.5 & 2.0 & 1.5 & 1.0 & 0.5 \\
\hline $\pm H V$ & 25 & 25 & 25 & 25 & 5 \\
$V^{+}$ & 0.05848 & 0.04690 & 0.03446 & 0.02242 & 0.01000 \\
$V^{-}$ & -0.06168 & -0.04976 & -0.03772 & -0.02574 & -0.01326 \\
$f_{T}$ & 1.0045 & 1.0041 & 1.0038 & 1.0036 & 0.9958 \\
$f_{S}$ & 1.0015 & 0.9994 & 0.9982 & 0.9984 & 0.9992 \\
$f_{R}$ & 1.0025 & 1.0024 & 1.0023 & 1.0022 & 1.0107 \\
\hline$I, p A$ & 0.12123 & 0.09727 & 0.07252 & 0.04838 & 0.02340
\end{tabular}


where $d$ is the air-gap setting in millimeters and \pm HV is the chamber potential in volts.

The listed values of I were fitted to a least-squares straight line as a function of air gap setting, $d$, and the slope of this line was used to determine the absorbed dose rate at the reference temperature and pressure, $22^{\circ} \mathrm{C}$ and $635 \mathrm{mmHg}$, on 84 Nov 28 at a depth of $7 \mathrm{mg} / \mathrm{cm}^{2}$ of polyethylene terepthalate:

Absorbed dose rate $=\frac{3.3 .7 \times 1.139 \times 0.978}{1.000 \times 707.3 \times 10^{-6} \times 0.04891 \times 10^{-9}}=2.60 \mu \mathrm{Gy} / \mathrm{s}$

where 33.7 is the mean energy expended per unit charge in air, in joules/coulomb; 1.139 is the ratio of the mean stopping power of water to that of air; 0.978 is a transmission factor correcting from the $2.61 \mathrm{mg} / \mathrm{cm}^{2}$ ion chamber depth to a depth of $7 \mathrm{mg} / \mathrm{cm}^{2} ; 1.000$ is the density of air at the reference temperature and pressure, in $\mathrm{kg} / \mathrm{m}^{3} ; 707.3 \times 10^{-6}$ is the collecting electrode area, in $\mathrm{m}^{2}$; and $0.04891 \times 10^{-9}$ is the least-squares straight line slope in $\mathrm{A} / \mathrm{m}$. The standard deviation of this measurement is about $0.3 \%$. It should be noted that correction of the above absorbed dose rate to sea level reference temperature and pressure, $22^{\circ} \mathrm{C}$ and $760 \mathrm{mmHg}$, would require multiplication by a factor of 0.987 (taken from J. Pruitt, The effect of altitude on beta-ray source calibrations, to be published in Radiation Protection Dosimetry).

(3) Promethium source calibration

The Buchler \#33 promethium-147 source was also calibrated with the INEL extrapolation chamber, using 50-second runs, a fixed source distance of 200 $\mathrm{mm}$, variable air gap settings and chamber potentials. Current measurements were made with system $A$ described in section (1), using the Keithley 642 calibrated readout. The currents come from:

$$
I=\frac{1.001}{50}\left(\frac{Q^{+}-Q^{-}}{2}\right) \times 10^{-11}\left(f_{T} f_{S} f_{R}\right) f_{A} A
$$

similar to equation (A) in section (1) except for the calibration factor 1.001 and the four corrections. These are the three ion chamber corrections already described, plus $f_{A}$, the altitude correction, which corrects the interactions in the air between source and chamber to the reference temperature and pressure, $22^{\circ} \mathrm{C}$ and $635 \mathrm{mmHg}$ (taken from J. Pruitt, op. cit.). $\mathrm{Q}^{+}$and $\mathrm{Q}^{-}$are averaged Keithley 642 digital readouts for positive and negative chamber potentials respectively. The data used are: 


\begin{tabular}{cccc} 
& 2.5 & 1.5 & 0.5 \\
\hline \cline { 2 - 4 } $\pm H V$ & 25 & 15 & 5 \\
$Q^{+}$ & 0.02477 & 0.01339 & 0.00524 \\
$Q^{-}$ & -0.02601 & -0.01603 & -0.00580 \\
$f_{T}$ & 0.9964 & 0.9963 & 0.9960 \\
$f_{S}$ & 1.0048 & 1.0029 & 1.0010 \\
$f_{R}$ & 1.0025 & 1.0038 & 1.0107 \\
$f_{A}$ & 1.0125 & 1.0131 & 1.0139 \\
\hline$I, f A$ & 5.166 & 2.992 & 1.129
\end{tabular}

where $d$ is the air gap setting and $H V$ is the ion chamber potential, as before.

The listed values of I were fitted to a least-squares straight line as a function of $d$, and the slope of this line was used to determine the absorbed dose rate at the reference temperature, pressure, and humidity, $22^{\circ} \mathrm{C}, 635 \mathrm{mmHg}$, and $20 \%$, respectively, on $84 \mathrm{Nov} 29$ at a depth of $0 \mathrm{mg} / \mathrm{cm}^{2}$ of polyethylene terepthal ate:

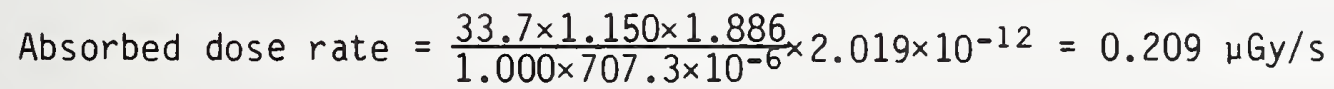

where 1.150 is the ratio of the mean stopping power of water to that of air, 1.886 is a transmission factor correcting from the $2.61 \mathrm{mg} / \mathrm{cm}^{2}$ ion chamber depth to a depth of $0 \mathrm{mg} / \mathrm{cm}^{2}$, and $2.019 \times 10^{-12}$ is the least-squares straight line slope in $\mathrm{A} / \mathrm{m}$. The standard deviation of the measurement is about $3 \%$.

This calibration may be compared with the original PTB calibration giving the absorbed dose rate at the reference temperature, pressure, and humidity of $20^{\circ} \mathrm{C}, 760$ $\mathrm{mmHg}$, and $45 \%$ respectively, on $80 \mathrm{Dec} 15$ at a depth of $0 \mathrm{mg} / \mathrm{cm}^{2}$. Corrected to $22^{\circ} \mathrm{C}$, $635 \mathrm{mmHg}$, and $20 \%$, the PTB calibration becomes:

Absorbed dose rate $=0.2729 \times 0.3517 \times 2.143 \times 1.011=0.208 \mu \mathrm{Gy} / \mathrm{s}$

where 0.2729 is the original PTB calibration, in $\mu$ Gy/s; 0.3517 is the decay factor (using $\lambda=7.234 \times 10^{-4} \mathrm{day}^{-1}$ ); 2.143 is the altitude factor ( $t$ aken from J. Pruitt, op. cit.); and 1.011 is the humidity factor (taken from the Buchler Handbook). The agreement with the absorbed dose rate measured at Idaho Falls is well within the statistical standard deviation of the Idaho Falls measurement. 
Appendix 3. Measurement Assurance Study by Means of PTW Transfer Ionization Chamber, Model $2047^{*}$ (See section 6.2)

DG $8555 / 86$

Page 1 of 2

DB $868 / 107$

TFN 236381

1986 JUN 19

\section{U.S. DEPARTMENT OF COMMERCE \\ NATIONAL BUREAU OF STANDARDS \\ GAITHERSBURG, MD 20899}

\section{REPORT OF INTERCOMPARISON}

PTW Ion Chamber \#2047

Measured at NBS in 1985 APR and 1986 MAY

Measured at - - - in 1985 NOV

This report concerns the intercomparison of beta-particle source calibrations, using sources of ${ }^{204} \mathrm{~T} l$ and ${ }^{90} \mathrm{Sr}+{ }^{90} \mathrm{Y}$. The two laboratories involved, the National Bureau of Standards (NBS) and - - possess similar sets of Amersham-Buchler sources, which have been calibrated in terms of tissue dose rate by the PTB in Braunschweig, Federal Republic of Germany. The intercomparison was performed with a thin-walled parallelplate ionization chamber as a transfer instrument. This chamber, PTW \#2047, was first calibrated in terms of tissue dose rate per unit current at NBS, then shipped to - - - for a similar calibration, then returned to NBS for a final calibration. The primary purpose of the comparison was to determine if the calibrations performed by the two laboratories were in adequate agreement.

It was agreed that the chamber calibrations would be made with the Buchler source alignment rods just touching the center of the outer surface of the chamber entrance window (on the side of the chamber labeled FOCUS), and with the plane of that surface perpendicular to the rods. Current measurements were to be made with the high-voltage electrodes at $100 \mathrm{~V}$, and the calibration results were to be averages of measurements with both polarities.

The measured chamber currents, after background subtraction, were normalized to $22^{\circ} \mathrm{C}$ and $101.3 \mathrm{kPa}$ to account for variations in air density inside the chamber. The tissue dose rates generating these currents were determined from the source-calibration dose rates, corrected by multiplicative factors for:

(1) Source decay.

(2) Variations in air density outside the chamber

*This report pre-dates a full uncertainty assessment. 
Each chamber calibration (in $\mathrm{Gy} / \mu \mathrm{C}$ ) is the ratio of a tissue dose rate (in $\mu \mathrm{Gy} / \mathrm{s}$ ) and a corrected current (in $\mathrm{pA}$ ). The reported results are listed below in $\mathrm{Gy} / \mu \mathrm{C}$ :

Calibration Factor

\begin{tabular}{l|ccc|c}
\hline Source & NBS(i) & $\begin{array}{c}\text { absolute } \\
--\end{array}$ & NBS(f) & $\begin{array}{c}\text { ratio } \\
--/ \mathrm{NBS}\end{array}$ \\
\hline $0.5 \mathrm{mCi} \mathrm{T \ell}$ & 0.3336 & 0.3580 & 0.3317 & 1.076 \\
$2 \mathrm{mCi} \mathrm{Sr}+\mathrm{Y}$ & 0.2917 & 0.2901 & 0.2907 & 0.996 \\
$50 \mathrm{mCi} \mathrm{Sr}+\mathrm{Y}$ & 0.3006 & 0.2978 & 0.3006 & 0.991
\end{tabular}

(1) The corrections for source decay from the source calibration date to the chamber calibration date made use of conventional half-lives.

(2) The two laboratories used different formulas for calculating correction (2). - - used the formulas supplied in their Buchler instruction manual, while NBS used formulas derived from an NBS study of the effect of altitude on beta-ray source calibrations. The corrections calculated by both methods are shown in the following table:

Correction for Variations in

Air Density Outside the Chamber

\begin{tabular}{l|cc}
\cline { 2 - 3 } Source & $-\cdots$ & NBS \\
\hline & & \\
$0.5 \mathrm{mCi} \mathrm{T \ell}$ & 1 & 0.998 \\
$2 \mathrm{mCi} \mathrm{Sr}+\mathrm{Y}$ & 1 & 1.002 \\
$50 \mathrm{mCi} \mathrm{Sr+Y}$ & 1 & 0.998
\end{tabular}

Information on the technical aspects of this report can be obtained from J.S. Pruitt, Radiation Physics C214, National Bureau of Standards, Gaithersburg, MD 20899 (301) 975-5587.

Calibration performed by J.S. Pruitt 0,59

Report approved by R. Loevinger

For the Director

by

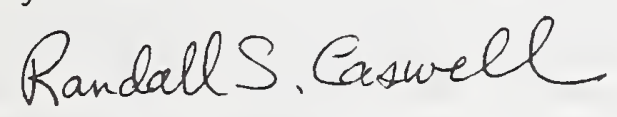

Randall S. Caswell

Chief, Ionizing Radiation Division

Center for Radiation Research 


\title{
PREDICTING BETA PARTICLE RESPONSE OF INSTRUMENTS FROM THEIR RESPONSE TO MONOENERGETIC ELECTRONS
}

\author{
C. G. Soares \\ Center for Radiation Research, National Bureau of Standards \\ Gaithersburg, MD, USA
}

\begin{abstract}
Accelerator-produced, nearly monoenergetic electron beams are being studied for use in obtaining the response of beta particle dosimetry instrumentation as a function of electron energy. Three detection systems were studied: a thin-window ionisation chamber, a thin thermoluminescence dosemeter, and an electron spectrometer. For each of the systems studied, broad spectrum response was measured with standardised sources of ${ }^{147} \mathrm{Pm},{ }^{204} \mathrm{Tl}$, and ${ }^{90} \mathrm{Sr}+{ }^{91} \mathrm{Y}$. The response of these instruments was also measured in the nearly monoenergetic electron beams. From the monoenergetic electron responses, a function was constructed of response versus electron energy. Broad spectrum response was then calculated using this function and pulse-height distributions of the three beta particle sources, measured with the electron spectrometer. This calculated response was then compared with the measured response. For ${ }^{204} \mathrm{~T} 1$ and ${ }^{90} \mathrm{Sr}+{ }^{90} \mathrm{Y}$, calculaled and measured responses agree to within experimental uncertainties.
\end{abstract}

\section{INTRODUCTION}

The National Bureau of Standards (NBS) is in the process of establishing a beta particle calibration facility using standardised sources of ${ }^{147} \mathrm{Pm},{ }^{204} \mathrm{Tl}$, and ${ }^{90} \mathrm{Sr}+{ }^{90} \mathrm{Y}$, making it possible to determine broad spectrum response of beta particle dosimetry instrumentation under standard conditions ${ }^{(1)}$. However, for a full characterisation of the response of beta particle dosimetry instrumentation, a determination of the energy dependence of instrument response is required. Because of the sroad spectra of beta particle sources, such sources are inadequate for this purpose. For this reason, NBS has developed a set of accelerator-produced nearly monoenergetic electron beams, the calibration and characterisation of which are described in an earlier publication ${ }^{(2)}$.

The object of this work is to determine the degree to which the broad spectrum response of beta particle detecting instrumentation can be predicted from response to monoenergetic electrons. For each of the detection systems studied, broad spectrum response was measured with the standard beta particle sources. The response of these instruments was also measured in the nearly monoenergetic electron beams. From the monoenergetic electron responses, a function is constructed of response relative to electron energy. Broad spectrum response is then calculated using this function and pulse-height distributions of the three beta particle sources measured with the $\mathrm{Si}(\mathrm{Li})$ detector. This calculated response is then compared with the measured response.

\section{DESCRIPTION OF THE DETECTION SYSTEMS}

Ion chamber survey meter (Eberllne Model RO-2A)*

This instrument incorporates a thin-window ionisation chamber for beta particle detection. It was calibrated in terms of exposure in a ${ }^{137} \mathrm{Cs}$ photon beam, and its electron and beta particle responses are expressed in terms of this calibration. For both irradiations, the point of reference was the front surface of the ion chamber.

\section{Thermolumlnescence personnel dosemeter (Panasonic Model 801AQ)*}

This dosemeter contains four sensitive elements 15 $\mathrm{mg} . \mathrm{cm}^{-2}$ thick under different filters. Only one of the elements is sensitive to beta particles. It is lithium tetraborate under $23 \mathrm{mg} \cdot \mathrm{cm}^{-2}$ of plastic. The dosemeter was calibrated in a ${ }^{60} \mathrm{Co}$ photon beam, again in terms of exposure.

\section{Beta partlcle spectrometer (SI(LI) detector)}

This system was chosen to simulate the sensitive element of state-of-the-art survey meter/ spectrometers now becoming available. These detectors rely on pulse-height analysis and use

- In this report, certain commercially available products are referred to by name. These references are for information purposes only, and do not imply that these products are the best or only products available for the purpose, and do not imply endorsement by NBS. 


\section{('. (i. S()ARES}

internal algorithms for deriving absorbed dose from the measured pulse-height spectra.

\section{DISCUSSION OF EXPERIMENTS AND RESULTS}

Accelerator-produced, nearly monoenergetic electron beams were used to measure the response of the three detection systems as a function of electron energy. The responses measured are shown in Table 1. As in the beta particle measurements, response is defined as instrument reading per unit absorbed dose to water. The ion chamber and TLD responses are expressed relative to their exposure calibrations. The

Table 1. Measured monoenergetlc electron responses.

\begin{tabular}{cccc}
\hline & \multicolumn{2}{c}{ Response to monoenergetic electrons } \\
\cline { 2 - 4 } $\begin{array}{c}\text { Electron energy } \\
\text { (keV) }\end{array}$ & lon chamber* & TLD* Spectromerer *.. \\
\hline 130 & 0.21 & 0.01 & 0.24 \\
220 & 0.30 & 0.72 & 0.40 \\
250 & 0.35 & 1.03 & 0.59 \\
320 & 0.35 & 1.13 & 0.68 \\
350 & 0.38 & 1.34 & 0.83 \\
1310 & 0.89 & 1.51 & 1.69 \\
1390 & 0.90 & 1.67 & 1.54 \\
2280 & 1.03 & 1.32 & 3.12 \\
2360 & 0.90 & 1.17 & \\
\hline
\end{tabular}

Expressed relative to response to ${ }^{137} \mathrm{Cs}$ photons.

" Expressed relative to response to ${ }^{60} \mathrm{Co}$ photons.

*** Response here was calculated as a quantity proportional to the mean stopping power of water.

Table 2. Comparison of measured and calculated broadspectrum lnstrument response.

\begin{tabular}{|c|c|c|c|c|c|c|}
\hline \multirow{3}{*}{ Radionuclide } & \multicolumn{6}{|c|}{ Response to beta particles } \\
\hline & \multicolumn{2}{|c|}{ Ion chamber* } & \multicolumn{2}{|c|}{ TLD*" } & \multicolumn{2}{|c|}{ Spectrometer } \\
\hline & Meas. & Calc. & Meas. & Calc. & Meas. & Calc. \\
\hline${ }^{147} \mathrm{Pm}$ & 0.06 & 0.16 & 0.00 & 0.01 & 0.08 & 0.18 \\
\hline${ }^{2144} \mathrm{TT}$ & 0.31 & 0.33 & 0.82 & 0.87 & 0.40 & 0.52 \\
\hline${ }^{91} \mathrm{Sr}+{ }^{9 / \mathrm{Y}} \mathrm{Y}$ & 0.80 & 0.58 & 1.70 & 1.53 & 1.06 & 1.24 \\
\hline
\end{tabular}

"Expressed relative to response to ${ }^{137} \mathrm{Cs}$ pholons.

- Expressed relative to response to ${ }^{610}$ Co photons.

* "Response here was calculated as a quantity proportional to the mean stopping power of water. response of the spectrometer was calculated as a quantity proportional to the mean stopping power of water:

$$
\sum n_{i}\left(\bar{T}_{1}\right) s_{\text {walci }}\left(\bar{T}_{1}\right) / \sum n_{1}\left(\bar{T}_{1}\right)
$$

where $n_{i}\left(\bar{T}_{i}\right)$ is the number of pulses in the ith pulseheight interval corresponding to an alverage electron energy $\overline{\mathrm{T}}_{i}$, and $\mathrm{s}_{\text {water }}\left(\overline{\mathrm{T}}_{\mathrm{i}}\right)$ is the stopping power in wilter in this interval, restricted to electron energies greater than $10 \mathrm{keV}^{(3)}$. Both the radionuclides and the accelerator beam monitors were calibrated with an extrapolation chamber. The response, $R$, averaged over the broad spectrum is given by

$$
R=\Sigma n_{i}\left(\bar{T}_{i}\right) r_{i}\left(\bar{T}_{i}\right) / \Sigma n_{i}\left(\bar{T}_{i}\right)
$$

where $n_{1}\left(\bar{T}_{i}\right)$ is the number of pulses in the ith interval with average energy $\bar{T}_{1}$, and $r_{i}\left(\bar{T}_{i}\right)$ is the instrument response cvaluated at energy $\mathrm{T}_{i}$ from the fitted monoenergetic response functions. The comparison between this calculation and the directly measured broad spectrum response is shown in Table 2.

The principal sources of uncertainty in these measurements are: (1) calibration of the monoenergetic electron beams, which are subject to variations in intensity and direction; (2) use of pulseheight spectra instead of fully corrected beta-particle spectra; and (3) random uncertainties in instrument readings. The uncertainty for the points on the response function curves is estimated to be $\pm 10 \%$, while the uncertainty of the calculated broad spectrum responses is estimated to be \pm 15 to $20 \%$.

For the ${ }^{204} \mathrm{Tl}$ and ${ }^{90} \mathrm{Sr}+{ }^{90} \mathrm{Y}$ data, measured and calculated responses are in agreement to within the experimental uncertainties. However, for the ${ }^{147} \mathrm{Pm}$ data, the calculated response is much greater than the measured response, especially for the ion chamber and the spectrometer. A possible explanation for this is a lack of consideration of a low energy cut-off in response due to entrance windows in these detectors. The results of this study indicate that the method of predicting instrument response to beta particles from response to monoenergetic electrons is valid.

\section{ACKNOWLEDGEMENTS}

I wish to thank Margarete Ehrlich, who suggested this study, and whose comments and encouragement are greatly appreciated; also Eric L. Bright for able assistance in performing some of the measurements.

This work was supported in part by the Office of Nuclear Regulatory Research of the US Nuclear Regulatory Commission. 
Appendix 4, continued

IRIIIT TINC; BETA IARTICIER RISSTONSE

\section{REFERENCE:S}

1. Ehrlich, M., Pruitt, J. S. and Soares, C. G. Standard Beta-Particle and Monoenergetic Electron Sources for the Calibration of Beta-Radiation Protection Instrumentation. NUREG/CR-4266 and NBSIR 85-3169 (US Nucleatr Regulatory Commission and US Department of Commerce. National Bureau of Standards. Washington, DC)(1985).

2. Soires, C. G., Dick, C. E., Pruitt, J. S. and Sparrow, J. H. Development of Monoenergetic Electron Beam Sources for Radiation-Instrument Calibration. Nucl. Instrum. Methods Phys. Res. B10/11, 937-941 (1985).

3. Berger, M. J. and Seltzer, S. M. Stopping Powers und Ranges of Electrons and Positrons. 2nd ed. NBSIR $82-255($ )-A (US Department of Commerce, National Bureau of Standards, Washington, DC) (1983). 
Appendix 5. Role of Nearly Monoenergetic Electron Sources in the Development of a New Generation of Survey Meters: Excerpts from two Publications

NUREG/CP-0050

\section{Proceedings of the International Beta Dosimetry Symposium}

Held at Washington, D.C.

February 15-18, 1983

Manuscript Completed: December 1983

Date Published: January 1984

T. F. Gesell, Executive Chairman

USDOE Radiological and Environmental Sciences Laboratory

Sponsored by

The U.S. Department of Energy

U.S. Nuclear Regulatory Commission

Office of Nuclear Regulatory Research

Health Physics Society

Proceedings published by the

U.S. Nuclear Regulatory Commission

Washington, D.C. 20555 


\section{LOS ALAMOS PORTABLE BETA-RAY SPECTROMETER}

B. H. Erkkila, R. J. Brake, and D. A. Waechter Los Alamos National Laboratory, Lus Alamos, NM 87545

*This work was performed under the auspices of the U. S. Department of Energy

Abstract: The integration of a beta-ray detector to multichannel analyzer (MCA) and computer has resulted in a portable spectrometer for studying beta rays in the field The present detector is a $5 \mathrm{~cm}$ diameter by $2 \mathrm{~cm}$ thick plastic scintillator manufactured by Bicron. Inc. Other detectors can easily be integrated into the package. The integral instrument package is $15 \mathrm{~cm}$ wide by $15 \mathrm{~cm}$ high by $25 \mathrm{~cm}$ long and weighs less than 10 pounds. Internal rechargeable batteries for 8 hours of field operation are included. The instrument contains a detector, an amplifier, a multichannel analyzer, and a liquid crystal display (LCD). A microprocessor controls all the functions of the instrument and is programmed to display all necessary information and 128-channel spectra on the LCD.

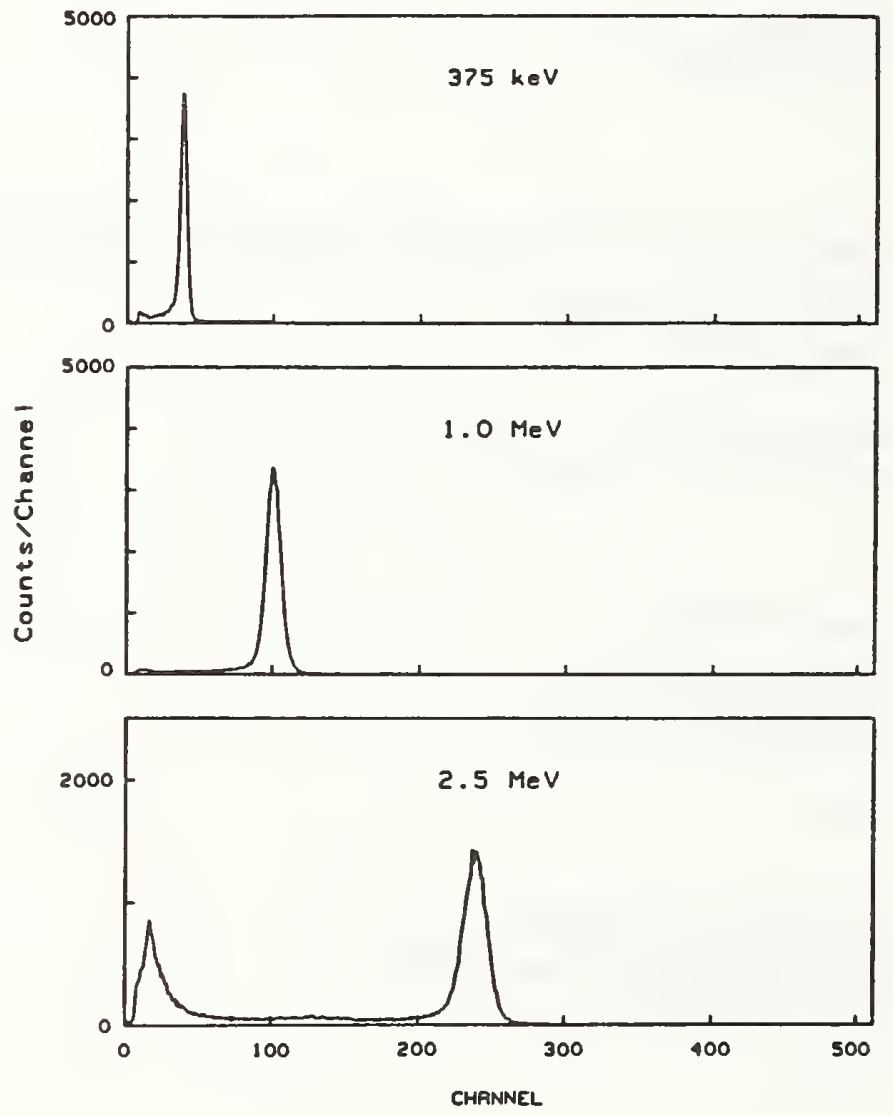

Fig. 3. Detector calibration measurements for three energies (375 keV, 1.0 MeV, and $2.5 \mathrm{MeV}$ electrons). 


\title{
FIELD TESTS OF A PORTABLE TISSUE EQUIVALENT SURVEY METER FOR MONITORING MIXED BETA/GAMMA RADIATION FIELDS
}

\author{
D. E. Martz \\ B. L. Rich \\ L. O. Johnson \\ S. H. Daniel, III
}

Published May 1986

EG\&G Idaho, Inc. Idaho Falls, Idaho 83415

Preparad for the Offlca of Nuclear Regulatory Rasarch Division of Radiatlon Programe and Earth Sciencas

U.S. Nuclear Ragulatory Commlssion

Washington, D.C. 20565

Fn No. A.6834

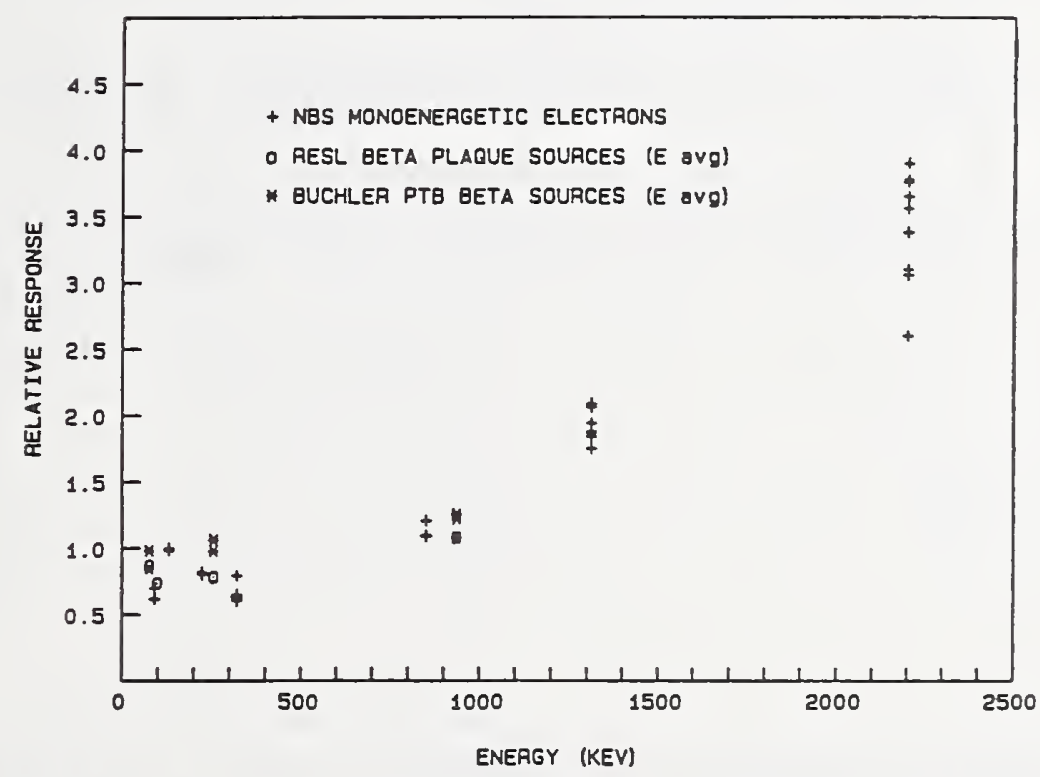

Figure 16. Measured energy dependence of the INEL TE survey meter to mono-energetic electrons and standard beta sources. 
11. List of Pertinent Tables and Reports on File in the Office of the Dosimetry Group

11.1 Pertaining to the Corrections Leading from Ionization Measurements with The Extrapolation Ionization Chamber to Absorbed Dose Rate to Water

Berger, M. J. and Seltzer, S. M., Stopping Powers and Ranges of Electrons and Positrons (2nd Ed.). NBSIR 82-2550-A; U.S. Department of Commerce, National Bureau of Standards, Gaithersburg, MD 20899; 1982.

Handbook of Chemistry and Physics, 67th Edition; Robert C. Weast, Editor; Chemical Rubber Publishing Co., Cleveland, OH; 1986-1987.

Hubbel1, J. H., Phot on Mass Attenuation and Energy Absorption Coefficients from $1 \mathrm{keV}$ to $20 \mathrm{MeV}$. Int. J. Appl. Radiat. Isot. 33, 1269-1290; 1982

ICRU Report 31; Average Energy Required to Produce an Ion Pair. International Commission on Radiation Units and Measurements; Bethesda, MD 20814; 1979.

\subsection{Pertaining to Radiation Protection}

American National Standard: Radiological Safety in the Design and Operation of Particle Accelerators. NBS Handbook 107; National Bureau of Standards, Gaithersburg, MD 20899; 1970.

ANL-7291, Revision 1; Moe, H. J., Lasuk, S. R., and Schumacher, M. C., The Health Physics and Radiological Health Handbook; Radiation Safety Technician Training Course; Argonne National Laboratory. U.S. Department of Commerce, National Technical Information Service, Springfield, VA $22161 ; 1972$.

ICRU Report 33; Radiation Quantities and Units. International Commission on Radiation Units and Measurements; Bethesda, MD 20814; 1980.

NCRP Report No. 39; Basic Radiation Protection Criteria. National Council on Radiation Protection and Measurements; Bethesda, MD 20814; 1971.

NCRP Report No. 51; Radiation Protection Design Guidelines for 0.1 - 100 MeV Particle Accelerator Facilities. National Council on Radiation Protection and Measurements; Bethesda, MD 20814; 1977.

NCRP Report No. 82; SI Units in Radiation Protection and Measurements. National Council on Radiation Protection and Measurements; Bethesda, MD 20814 ; 1985 . 
NBS-114A (REV. 2.80)

\begin{tabular}{c|l|l|l}
$\begin{array}{c}\text { U.S. DEP T. OF COMM. } \\
\text { BIBLIOGRAPHIC DATA } \\
\text { SHEET (See instructions) }\end{array}$ & $\begin{array}{l}\text { 1. PUBLICATION OR } \\
\text { REPORT NO. } \\
\text { NBS/SP-250/21 }\end{array}$ & 2. Performing Organ. Report Nof 3. Publication Date \\
\hline
\end{tabular}

4. TITLE AND SUBTITLE

NBS Measurement Services:

Calibration of Beta-Particle Radiation Instrumentation and Sources

5. $\operatorname{AUTHOR}(S)$

John S. Pruitt, Christopher Soares, and Margarete Ehrlich

6. PERFORMING ORGANIZATION (If joint or other than NBS, see instructions)

7. Contract Grant No.

NATIONAL BUREAU OF STANDARDS

U.S. DEPARTMENT OF COMMERCE

GAITHERSBURG, MD 20899

8. Type of Report \& Period Covered

Final

9. SPONSORING ORGANIZATION NAME AND COMPLETE ADDRESS (Street, City, State, ZIP)

Same as item 6.

10. SUPPLEMENTARY NOTES

Library of Congress Catalog Card Number 88-600514

Document describes a computer program; SF-185, FIPS Software Summary, is attached.

11. ABSTRACT (A 200-word or less factual summary of most significant information. If document includes a significant bibliogrophy or literoture survey, mention it here)

In a project funded jointly by the National Bureau of Standards (NBS) and the Nuclear Regulatory Commisston (NRC), NBS has developed a caltoration factlity for beta-particle instruments and sources used in radiationprotection dosimetry. Central to this factlity are beta-particle and nearly monoenergetic electron beams characterfied in terms of absorbed-dose rates to water and in terms of pulse-hefght distributions of beta-particle and electron spectra.

This documentation ut fl tzes materfal prevfously publ fshed or otherwise disseminated by members of the staff of the lontzing Radiation Diviston of the Center for Radfation Research (CRR) of the Nattonal Bureau of Standards (NBS). After a description of the factitty and the procedures, results are given of (1) studies that led to the determination of absorbed-dose rates to water for the NBS beta-particle and nearly monoenergetic electron beams, and to the uncertafnties entering into these determinations; (2) studies of the influence of source conftguration on beta-particle and nearly monoenergetic electron spectra; and (3) an estfmate of the overall uncertaintfes assoctated with the proposed callbration service. Included also are the results of some cal forations stmilar to those that will be performed under the calibration service employing the beta-partfcle sources, and of samples of studies demonstrating the beneftts of using the nearly monoenergetic electron beams in spectal instrument studies and in a future extenstion of the caltbration service.

12. KEY WORDS (Six to twelve entries: alphabetical order; capitalize only proper names; and separate key words by semicolons) accelerator-produced, nearly monoenergetic electrons; beam characterlzation; beta-particle sources; documentation; dosimetry; Instrument callbration; radiation protection; safety; source callbration; uncertalnties.

\section{AVAILABILITY}

区X Unlimited

$\square$ For Official Distribution. Do Not Release to NTIS

XX Order From Superintendent of Documents, U.S. Government Printing Office, Washington, D.C. 20402.

14. NO. OF PRINTED PAGES

75

15. Price

○ Order From National Technical Information Service (NTIS), Springfield, VA. 22I6I 

- 
U.S. Department of Commerce

National Bureau of Standards

Gaithersburg, MD 20899

Official Business

Penalty for Private Use $\$ 300$

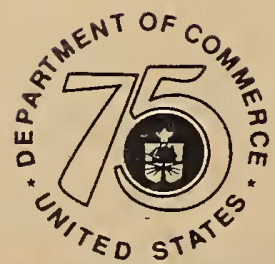

Stimulating America's Progress 1913-1988 